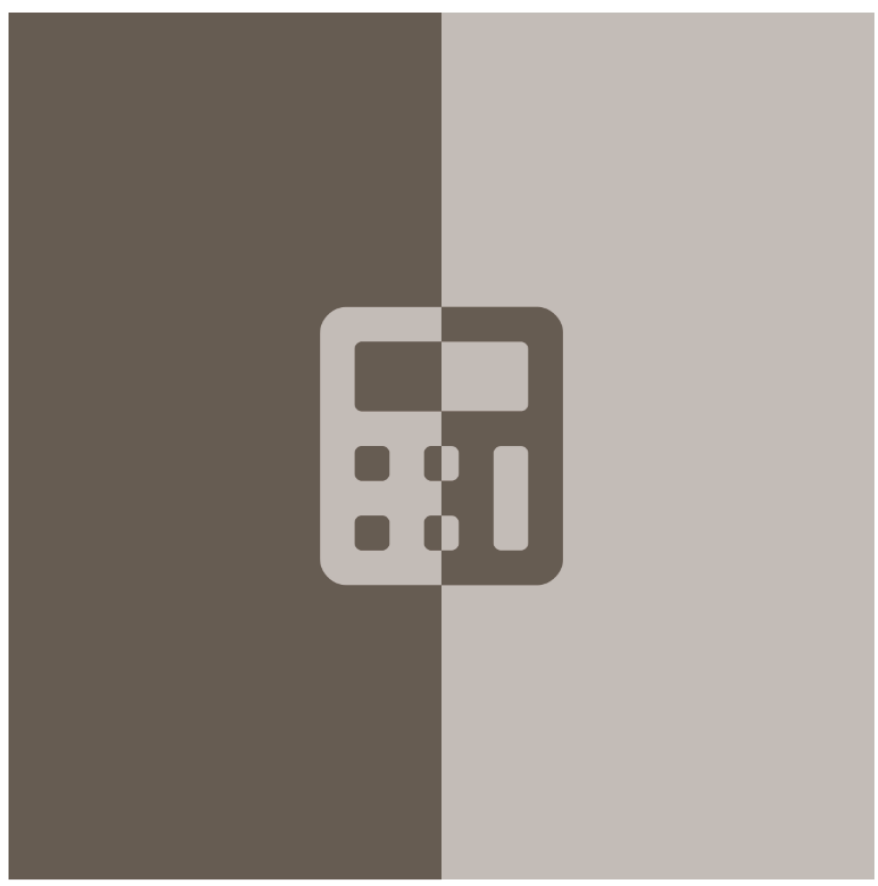

\title{
Carbon Accounting Modeling Project
}

A Report Developed for and Supported by the

\section{U-M President's Commission on Carbon Neutrality}

February 26, 2021

\section{Creators}

Gregory Keoleian - Director, Center for Sustainable Systems; Professor, SEAS \& CoE

Geoffrey Lewis - Research Specialist Lead, Center for Sustainable Systems

Nicholas Kemp - Research Associate, Center for Sustainable Systems

Nate Hua - Research Associate, Center for Sustainable Systems

Stephen Hilton - Research Associate, Center for Sustainable Systems 
Copyright (C 2021 by the Regents of the University of Michigan

Some rights reserved

(c) $(1)(9)$

This work is licensed under the Creative Commons Attribution-NonCommercial-NoDerivatives 4.0 International License. To view a copy of this license, visit http://creativecommons.org/licenses/by-nc-nd/4.0/ or send a letter to Creative Commons, PO Box 1866, Mountain View, California, 94042, USA.

Published in the United States of America by

Michigan Publishing

https://doi.org/10.3998/mpub.12245679

ISBN 978-1-60785-735-8 (open access)

This publication is a result of work sponsored by the University of Michigan (U-M) President's Commission on Carbon Neutrality (PCCN) to inform the PCCN's final recommendations to U-M President Mark Schlissel. This publication does not reflect Commission-level recommendations, and should not be interpreted as being recommendations of the PCCN nor carrying its endorsement. 


\section{Table of Contents}

Carbon Accounting Modeling Report - Executive Summary .................................................................

Carbon Accounting Subgroup Modeling Project Report ........................................................................ 8

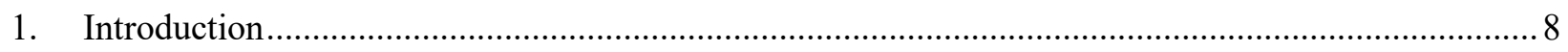

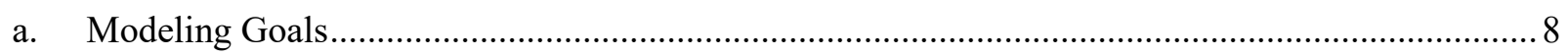

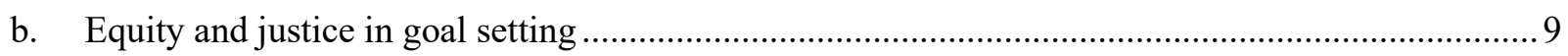

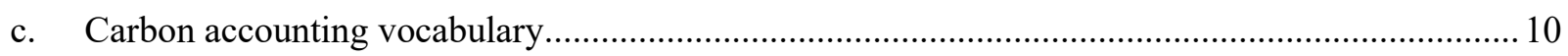

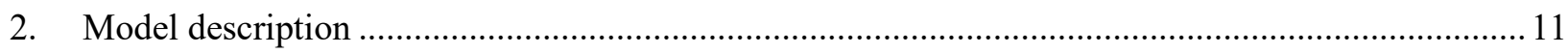

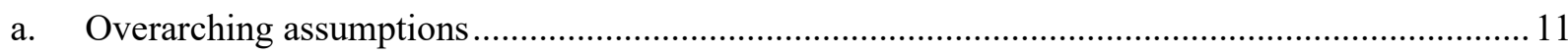

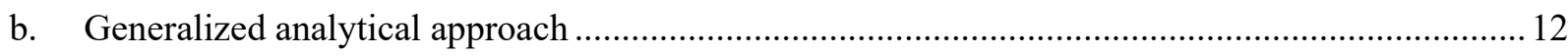

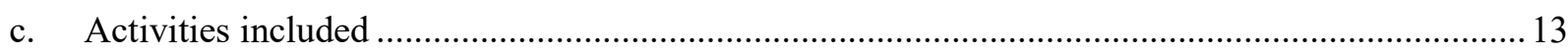

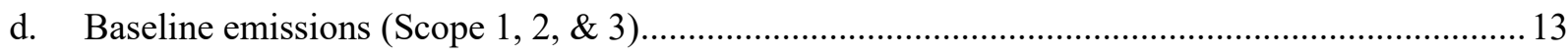

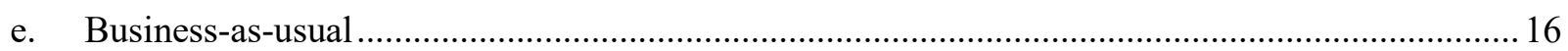

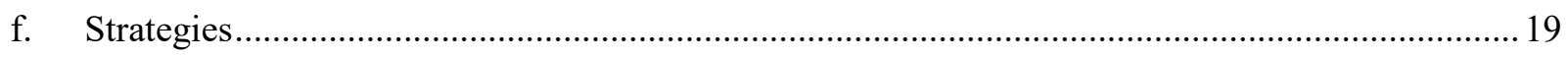

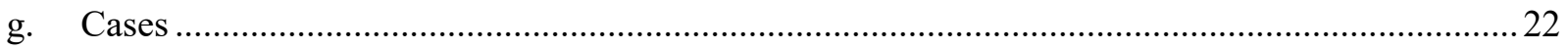

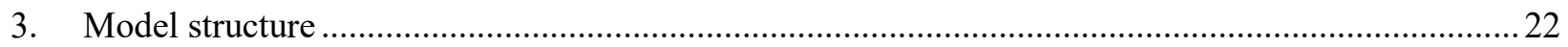

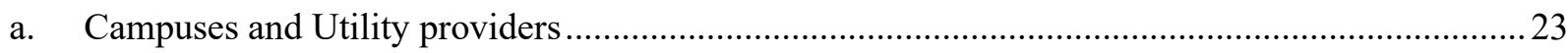

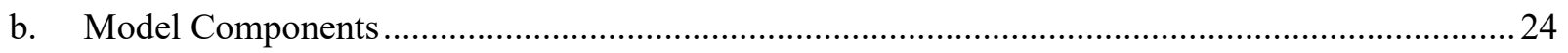

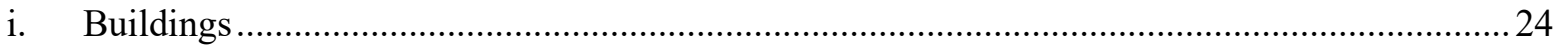

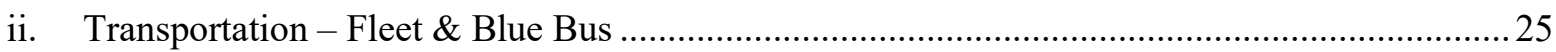

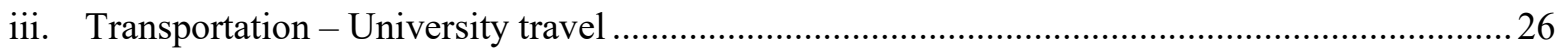

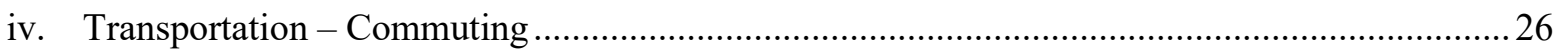

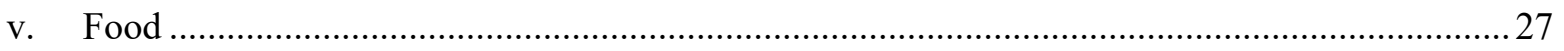

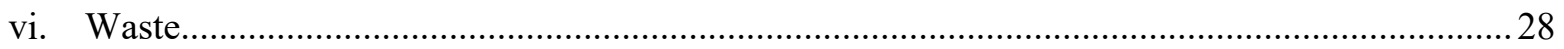

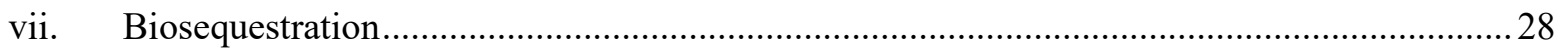

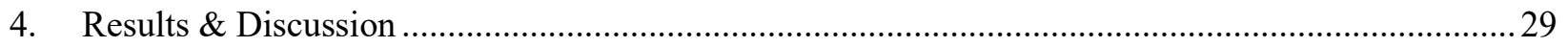

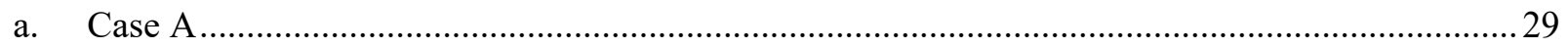

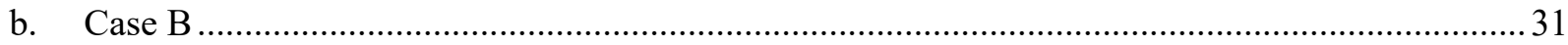

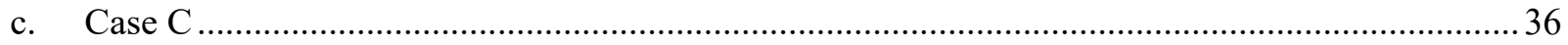

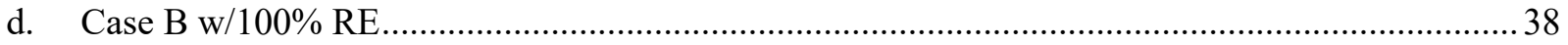

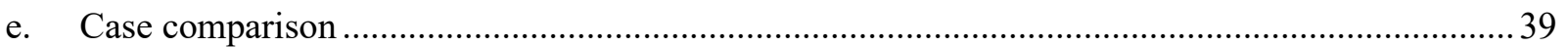

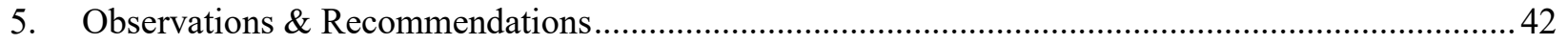

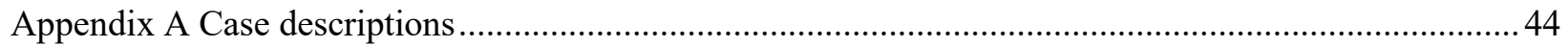

Appendix B Model assumptions \& calculation details ……………………………………………......5 50

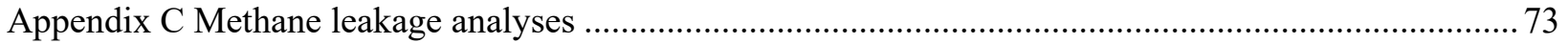




\section{Carbon Accounting Modeling Report - Executive Summary}

The Carbon Accounting Subgroup developed and implemented a comprehensive carbon accounting model for the University of Michigan (Ann Arbor, Dearborn, and Flint campuses). The model integrates existing work completed by Internal Analysis Teams (IATs), External Analysis Teams (EATs), the Electrification Subgroup, and Office of Campus Sustainability, supplemented with additional analysis by the Carbon Accounting Subgroup. The model provides guidance and informs the Commission on emissions reduction strategies (including both technical and policy strategies) and their reduction potential over time, the development of carbon neutrality pathways, and selection of neutrality goal years. The Carbon Accounting Subgroup also developed an iterative analysis and goal setting process for the PCCN incorporating the carbon accounting model (Figure ES1).

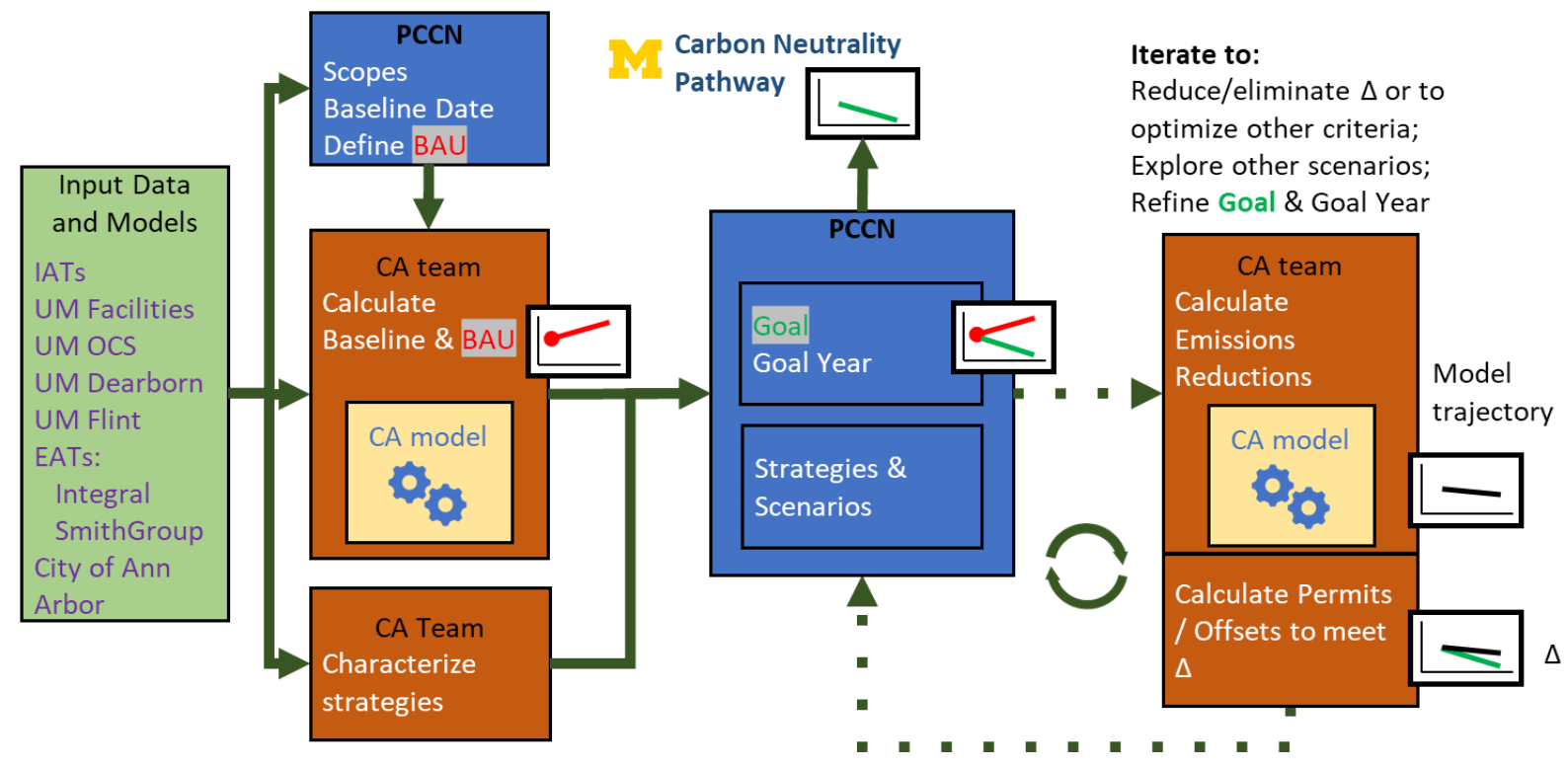

Figure ES1: PCCN goal setting process diagram.

\section{Model Description \& Methods}

The carbon accounting model evaluates the University's GHG emissions (in $\mathrm{CO}_{2} \mathrm{e}$ ) on an annual basis over the period 2018-2050 and tracks the GHGs emissions of carbon dioxide $\left(\mathrm{CO}_{2}\right)$, methane $\left(\mathrm{CH}_{4}\right)$ and nitrous oxide $\left(\mathrm{N}_{2} \mathrm{O}\right)$. The model calculates emissions separately for Scope 1 (direct on-campus), Scope 2 (purchased electricity), and Scope 3 (indirect, e.g., commuting, business travel, fuel and electricity upstream emissions) for all three UM campuses (AA, Dearborn, \& Flint) plus several field and research stations. Global Warming Potential (GWP 100$)$ values and emission factors are sourced from Argonne National Lab's GREET model. DTE and Consumers Energy provided projected fuel mixes and generation plans through 2050. We also sourced data from EPA and EIA on model parameters and technology forecasts. Upstream emissions include methane leakage and other emissions resulting from fuel processing, as characterized in GREET (using EDF estimates). Details on estimating methane leakage and other GHG emissions associated with natural gas production and transportation are contained in two 
documents in Appendix C. These documents contain information describing the approach taken by the Carbon Accounting Subgroup for modeling upstream GHG emissions.

The dynamic carbon accounting model characterizes and simulates GHG emissions for 29 carbon reduction strategies and includes over 100,000 data points and over 500 parameters for carbon reduction strategies. The high-level model structure is illustrated in Figure ES2. The strategies, some of which cause a change in emissions Scope, are illustrated in Figure ES3. The model characterizes the transition from existing heating and cooling systems to the proposed geoexchange system while also incorporating decarbonization of grid electricity. The model similarly captures the electrification of transportation (separately for fleet, commuting, and University travel). The model allows evaluation of the University's progress to both neutrality and to the Intergovernmental Panel on Climate Change (IPCC) $1.5^{\circ} \mathrm{C}$ target of $45 \%$ reduction globally by 2030 (the IPCC baseline year is 2010 but we use 2018 - OCS data indicates UM Scope $1 \& 2$ emissions decreased 6\% between 2018 and 2010). Since equity and justice are core principles of the PCCN, we also examined a per capita emissions reduction target $(76 \%$ reduction by 2030) that is more aggressive than the IPCC $1.5^{\circ} \mathrm{C}$ global emissions target. The per capita target ackowledges legacy emissions and the lack of resources in disadvantaged communities to reduce their emissions. The Carbon Accounting Subgroup report includes full details on model assumptions and calculations (in Appendix B), and descriptions of strategies modeled for each of the three Cases evaluated (in Appendix A). 


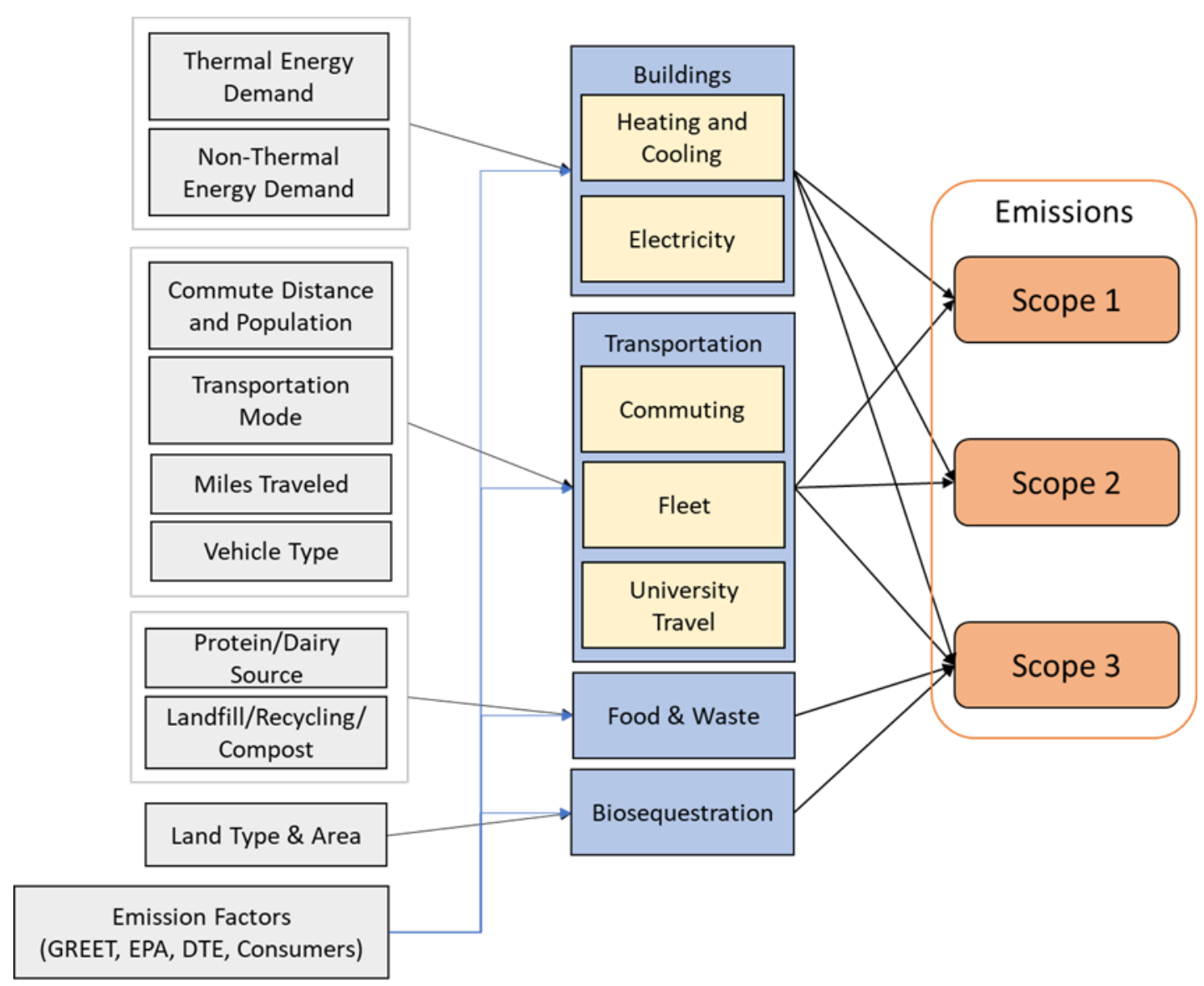

Figure ES2: Simplified carbon accounting model structure with data inputs on the left supplying modeling modules for activity categories that calculate annual GHG emission estimates 2018-2050.

\begin{tabular}{|c|c|c|c|c|c|c|}
\hline Buildings & University Travel & Non-Bus & Commuting & Food \& Waste & Bioseq. & $\begin{array}{l}\text { Other Mitigation/ } \\
\text { Offsets }\end{array}$ \\
\hline $\begin{array}{l}\text { Geothermal } \\
(\mathrm{GHX}) \\
1,2,3 \rightarrow 2,3\end{array}$ & $\begin{array}{l}\text { Replace air travel } \\
\text { with train travel } \\
3 \rightarrow 3\end{array}$ & $\begin{array}{l}\text { Electrify } \\
1,3 \rightarrow 2,3\end{array}$ & $\begin{array}{l}\text { Housing and land use } \\
\text { reform } \\
3 \rightarrow 3\end{array}$ & $\begin{array}{l}\text { Replace protein } \\
\text { sources } \\
3 \rightarrow 3\end{array}$ & $\begin{array}{l}\text { Convert ag. Land } \\
3 \rightarrow 3\end{array}$ & $\begin{array}{l}\text { DTE PPA } \\
2,3 \rightarrow 2,3\end{array}$ \\
\hline $\begin{array}{l}\text { PV } \\
2,3 \rightarrow 2,3\end{array}$ & \multicolumn{2}{|l|}{$\begin{array}{l}\text { Reduce air travel } \\
\text { (telework) } \\
3 \rightarrow 3\end{array}$} & $\begin{array}{l}\text { Parking policy reform } \\
3 \rightarrow 3\end{array}$ & $\begin{array}{l}\text { Replace dairy with } \\
\text { plant alternative } \\
3 \rightarrow 3\end{array}$ & $\begin{array}{l}\text { Enhance forest } \\
\text { and wetlands } \\
3 \rightarrow 3\end{array}$ & $\begin{array}{l}\text { REC purchases } \\
2,3 \rightarrow 2,3\end{array}$ \\
\hline $\begin{array}{l}\text { Reduce Energy } \\
\text { demand * } \\
1,2,3 \rightarrow 1,2,3\end{array}$ & \multirow[t]{2}{*}{$\begin{array}{l}\text { Reduce car travel } \\
\text { (telework) } \\
3 \rightarrow 3\end{array}$} & & $\begin{array}{l}\text { Cycling infra. } \\
3 \rightarrow 3\end{array}$ & $\begin{array}{l}\text { Reduce organic waste } \\
3 \rightarrow 3\end{array}$ & $\begin{array}{l}\text { Replace turfgrass } \\
3 \rightarrow 3\end{array}$ & $\begin{array}{l}\text { Off-site renewable } \\
\text { investments } \\
2,3 \rightarrow 2,3\end{array}$ \\
\hline $\begin{array}{l}\text { Reduce energy } \\
\text { demand - energy } \\
\text { efficiency * } \\
1,2,3 \rightarrow 1,2,3\end{array}$ & & & $\begin{array}{l}\text { Rideshare } \\
3 \rightarrow 3\end{array}$ & $\begin{array}{l}\text { Reduce recyclable } \\
\text { waste } \\
3 \rightarrow 3\end{array}$ & $\begin{array}{l}\text { Add green } \\
\text { infrastructure } \\
3 \rightarrow 3\end{array}$ & $\begin{array}{l}\text { Purchase and retire } \\
\text { RGGI permits } \\
2,3 \rightarrow 2,3\end{array}$ \\
\hline \multirow[t]{3}{*}{$\begin{array}{l}\text { New Building } \\
\text { Standards * } \\
1,2,3 \rightarrow 1,2,3\end{array}$} & \multicolumn{2}{|c|}{$\begin{array}{l}\text { *Both non-thermal electricity demand and } \\
\text { thermal energy demand } \\
{ }^{*} \text { Depends on if building growth is considered }\end{array}$} & $\begin{array}{l}\text { Universal } \\
\text { Access } \\
3 \rightarrow 3\end{array}$ & EAT Strat & & $\begin{array}{l}\text { Other voluntary } \\
\text { offsets } \\
2,3 \rightarrow 2,3\end{array}$ \\
\hline & \multicolumn{2}{|c|}{$\begin{array}{l}\text { Note(s): Other strategies not modeled } \\
\text { include building standards, carbon tax, } \\
\text { commuter-to-telework. }\end{array}$} & \multirow{2}{*}{$\begin{array}{l}\text { Electrify } \\
3 \rightarrow 3\end{array}$} & $\begin{array}{l}\text { IAT Strat } \\
\text { CAMP Strat }\end{array}$ & & \\
\hline & $\begin{array}{l}\text { Numbers below str } \\
\text { transition upon stra }\end{array}$ & $\begin{array}{l}\text { rategy denote scope } \\
\text { ategy implementation }\end{array}$ & & CAMP/IAT/EAT & Strat & \\
\hline
\end{tabular}

Figure ES3: Emissions reduction strategies, organized by activity. Scope $1 \& 2$ emissions are highlighted by red boxes, strategy text color indicates the group that analyzed the strategy, numbers below each strategy indicate Scopes before and after strategy implementation. 
The modeling process begins with calculation of 2018 baseline GHG emissions (by Scope) and then calculation and plotting the business-as-usual (BAU) emissions trajectory between 2018 and 2050. The BAU trajectory illustrates annual GHG emissions in the absence of any additional University action to reduce emissions. Three sets of emissions reduction strategies (called Cases) were implemented in the carbon accounting model and annual emissions reductions from BAU were calculated and plotted, resulting in three Case emission trajectories. These trajectories reveal the remaining emissions gaps to achieve neutrality in any year, and these gaps were monetized using recent RGGI permit prices to understand the potential cost of offsetting emissions.

\section{Results}

Baseline (2018) emissions results by activity are contained in Figure ES4 (Scope $1 \& 2$ ) and Figure ES5 (Scope 3 without purchased goods \& services). Negative Scope 3 emissions occur for activities such as biosequestration that pull GHGs out of the atmosphere. The range of Scope 3 emissions associated with purchased goods and services (estimated using economic inputoutput analysis and using high and low emissions activities to bound the estimate) was $290-$ $1360 \mathrm{kt} \mathrm{CO} 2$ e. Note that buildings (heating, cooling, and electricity) are responsible for $\approx 99 \%$ of Scope $1 \& 2$ baseline emissions. Note also that including purchased goods and services approximately doubles Scope 3 emissions, though uncertainty caused by data quality currently makes it difficult to accurately estimate emissions from this activity. Baseline emissions are discussed in Section $2 \mathrm{~d}$ of the report.

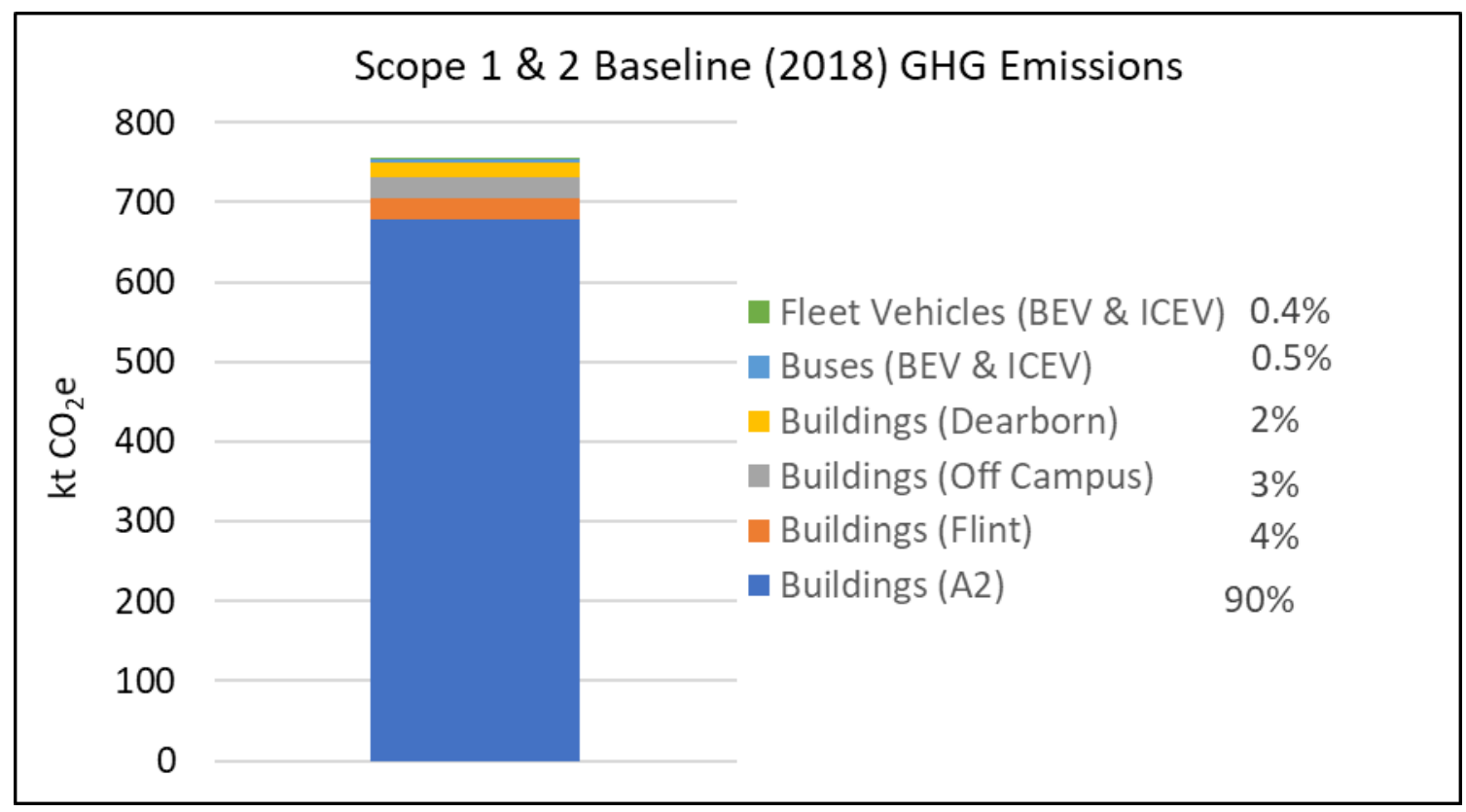

Figure ES4: Scope 1 \& 2 baseline GHG emissions, by activity (all campuses). 


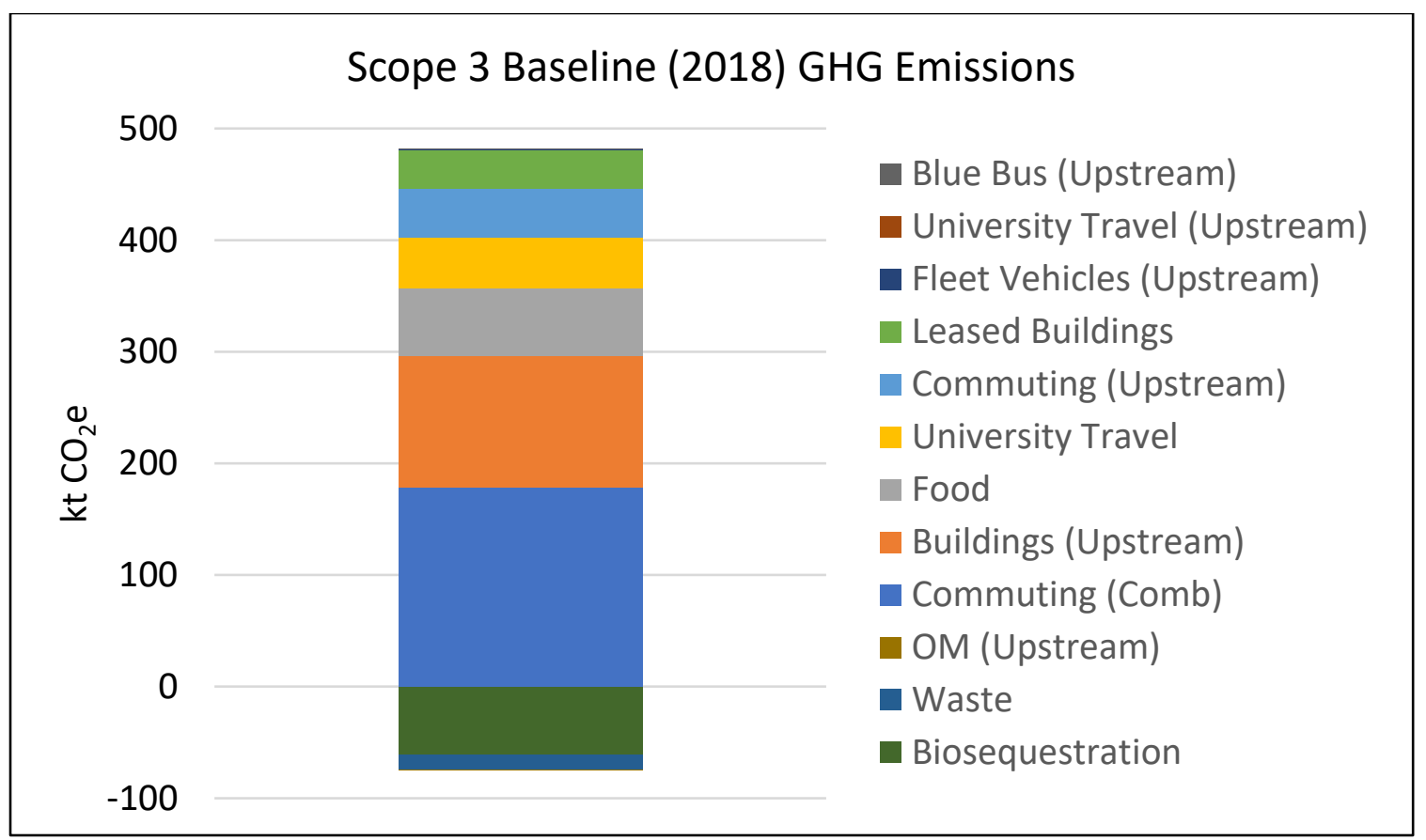

Figure ES5: Scope 3 baseline GHG emissions (not including purchased goods \& services), by activity (all campuses). $\mathrm{OM}=$ other mitigation, e.g., upstream associated with RECs. Comb = combustion.

GHG emissions trajectories are presented below for BAU and for Case B. Case B essentially follows the IAT, EAT, and Electrification Subgroup recommendations and also attempts to align with the City of Ann Arbor's A2Zero plan. Cumulative 2018-2050 GHG emissions for BAU (all Scopes) are $33 \mathrm{Mt} \mathrm{CO}_{2} \mathrm{e}$. Scope $1 \& 2$ trajectories (both separately and combined) are plotted in Figure ES6 and Scope 3 trajectories are plotted in Figure ES7. BAU is discussed in Section 2e and Case B is discussed in Section 4b. 


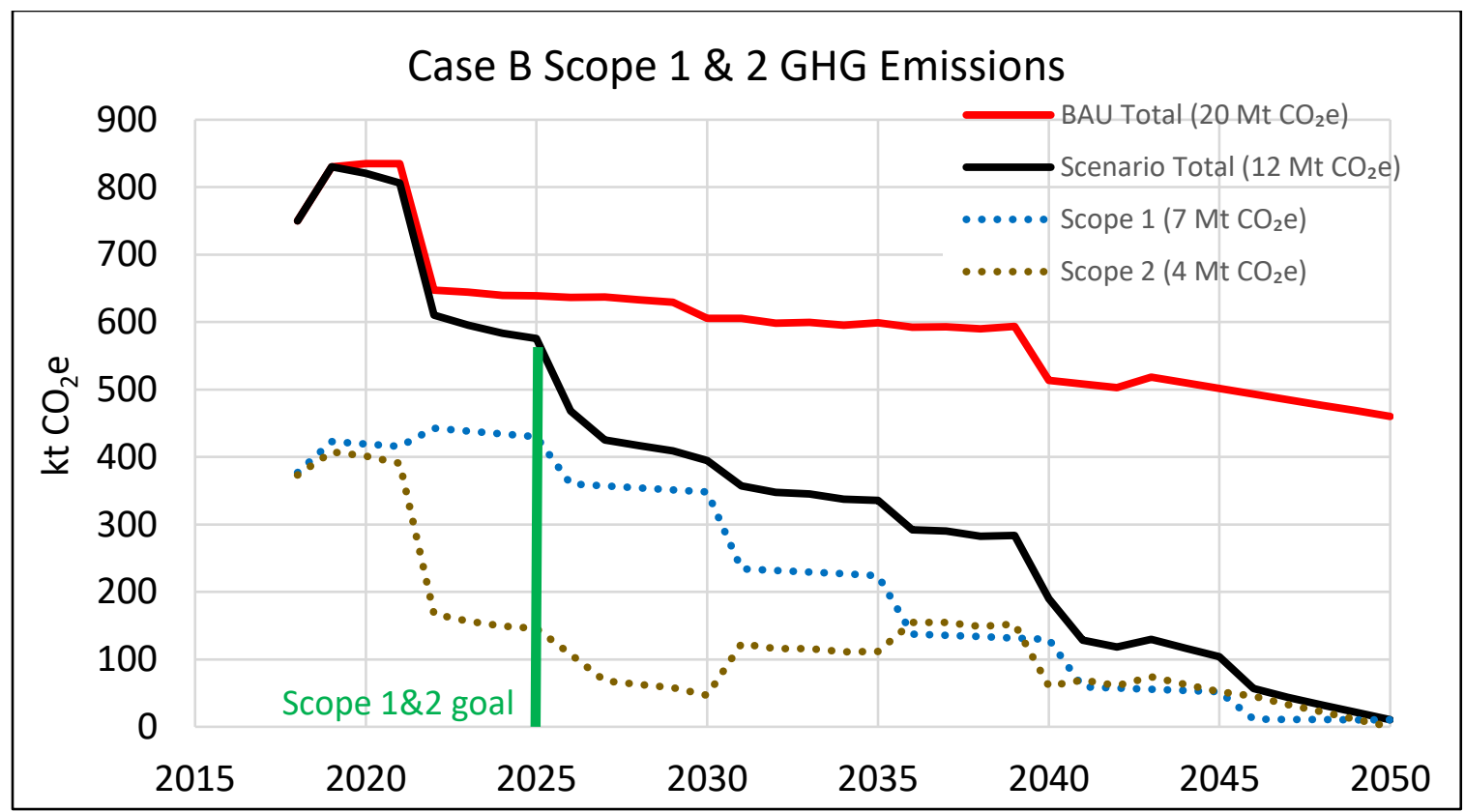

Figure ES6: Case B Scope 1 \& 2 GHG emissions trajectories (individual Scopes and combined 1 \& 2), values in the legend are cumulative 2018-2050 emissions in million metric tons (i.e., the area under each trajectory).

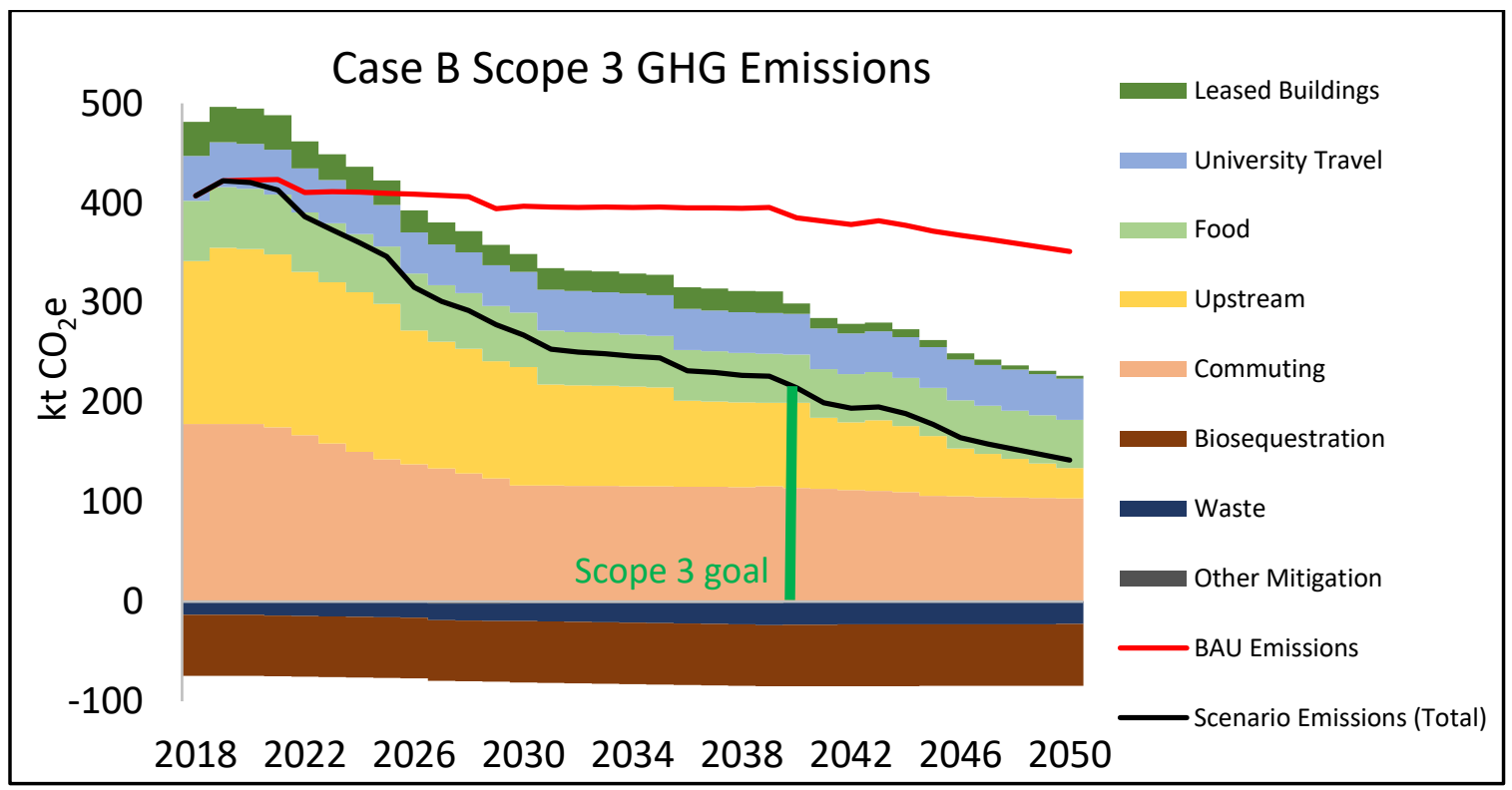

Figure ES7: Case B Scope 3 GHG emissions trajectories, total and by activity (not including purchased goods and services). Negative values indicate carbon removed from the atmosphere. See Figure 19 for a more detailed Scope 3 activity breakdown.

Scope $1 \& 2$ trajectories both with and without the implementation of the Geoexchange system recommended by the Heat and Power Infrastructure EAT (Figure 17 in the Carbon Accounting Subgroup report) illustrates the importance of this strategy recommendation in achieving any 
neutrality goals. Geoexchange transitions building heating and cooling from a combination of natural gas and electricity to all electricity.

Electrifying building heating and cooling (as well as fleet transportation) will result in an increase in electricity use, making it critical to reduce emissions associated with electricity generation. GHG emissions trajectories resulting from a switch to $100 \%$ renewable purchased electricity in 2020 are contained in Figure 22 in the Carbon Accounting Subgroup report. Note that there will still be some emissions associated with electricity on the Ann Arbor campus as long as natural gas is used to generate electricity in the Central Power Plant.

Purchased goods and services is the largest Scope 3 emissions category, but data quality needs to improve in order to accurately quantify the individual components of this category. Other activities responsible for significant Scope 3 emissions are commuting, upstream emissions associated with building energy use, food, and University travel. Note the decrease in building upstream emissions in Figure ES7, which is a result of the geoexchange system phasing in over time. We expect many of these trajectories to decrease more quickly than illustrated here as manufacturers and service providers decarbonize their own operations.

\section{Recommendations}

The Carbon Accounting Subgroup developed recommendations for improving carbon accounting systems for tracking progress and implementation of strategies for emissions reduction. The lack of data in several areas, mostly related to Scope 3 activities, highlight the need for improved accounting systems. This pertains especially to purchased goods and services, as is more fully detailed in the Carbon Accounting Subgroup report. The carbon accounting model will require annual updating and refinement as parameters change, data become more available, and carbon accounting methods evolve. Additional work will be required to transition the PCCN carbon accounting tool to an operational OCS tool for planning, tracking, reporting, and verification. In addition, it is recommended that emissions accounting be conducted the building-level to engage academic units more fully in achieving carbon neutrality. 


\section{Carbon Accounting Subgroup Modeling Project Report}

\section{Introduction}

This report describes the work completed by the carbon accounting modeling project (CAMP) in summer and fall 2020 to support the President's Commission on Carbon Neutrality (PCCN). It includes the goals for the modeling effort, a detailed description of the carbon accounting model and its many underlying assumptions, and a full set of results for the cases the CAMP team constructed. This document is not intended to be an operating manual for the model.

\section{a. Modeling Goals}

Develop a comprehensive carbon accounting framework for the University of Michigan (Ann Arbor, Dearborn, and Flint campuses) and implement it as an Excel model. The framework integrates existing work completed by Internal Analysis Teams (IATs), External Analysis Teams (EATs) and Analysis Subgroups. We filled gaps, extended existing work, and conducted new research as necessary to complete the model. This framework is intended to provide the PCCN with guidance on the strategies available and their carbon reduction potential over time as they prepare their recommendations for the President.

Principles for modeling goals:

- Seek a trajectory (set of strategies) to accelerate emissions reductions and minimize cumulative UM GHG emissions

- Evaluate scalable and transferable strategies

- Accommodate physical, logistical, administrative, and financial constraints

- Include activities and scopes that are measurable and can be tracked

- Promote equity and justice

The CAMP team also developed an iterative analysis and goal setting process for the PCCN that incorporates the carbon accounting model (Figure 1). 


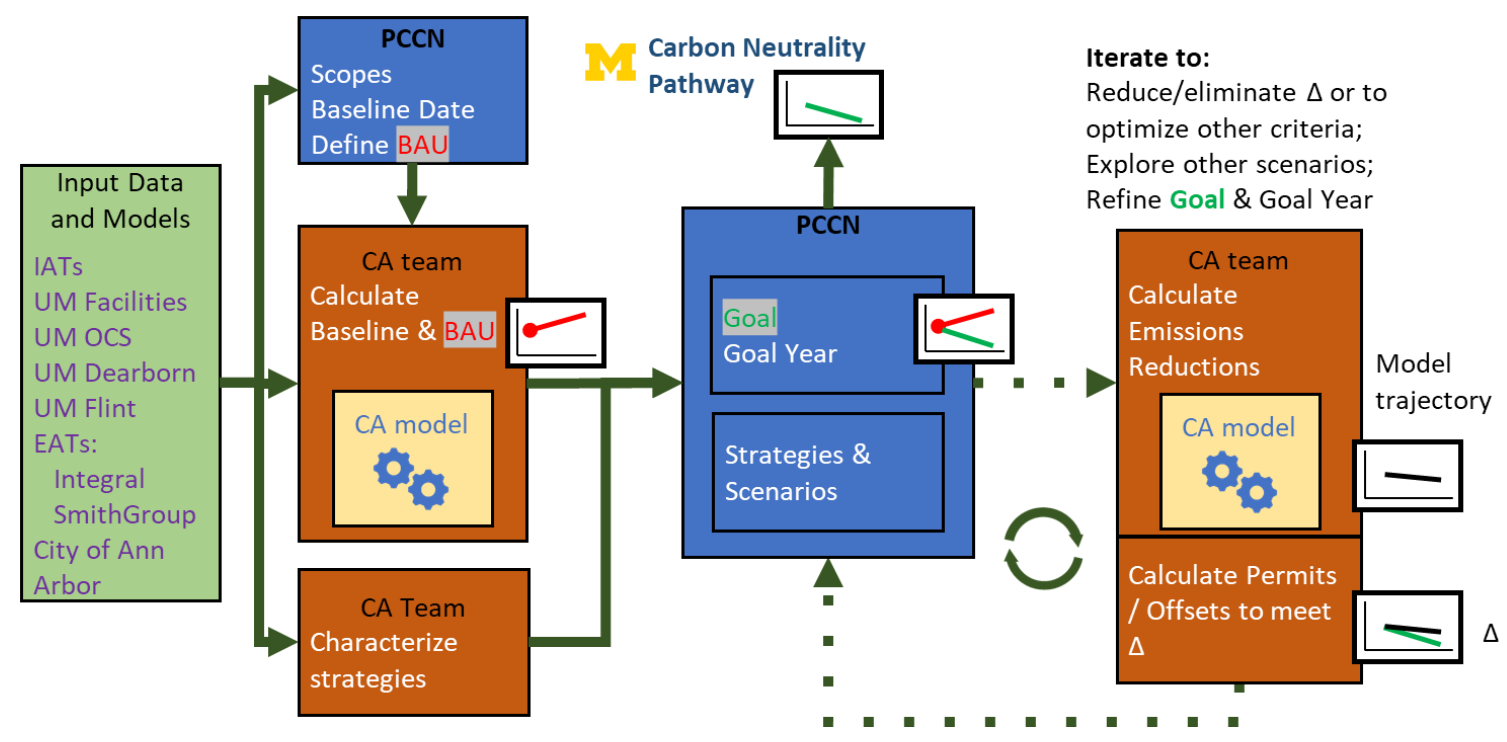

Figure 1: PCCN goal setting process diagram.

b. Equity and justice in goal setting

The United Nations Framework Convention on Climate Change (UNFCCC - Article 3.1) statement on equity and climate change reads: "The Parties should protect the climate system for the benefit of present and future generations of humankind, on the basis of equity and in accordance with their common but differentiated responsibilities and respective capabilities." Minority world regions continue to emit GHG emissions at rates disproportionate to their population while majority world regions are more severely impacted by climate change. Majority world region emissions will likely increase as they progress technologically, and minority world regions currently possess the financial resources necessary to combat climate change. Minority world regions also bear the greatest responsibility for GHGs released to the atmosphere to date.

The IPCC $1.5^{\circ} \mathrm{C}$ target is a $45 \%$ reduction from 2010 baseline emissions, globally. Acknowleding our historical emissions and the justice and economic argument above that we should exceed the IPCC reduction target, for goal setting we suggest that emissions should reduce from the 2010 North American per capita average $(13.4 \mathrm{t}$ $\left.\mathrm{CO}_{2} \mathrm{e}\right)$ to a global per capita average emissions $\left(2.8 \mathrm{t} \mathrm{CO}_{2} \mathrm{e}\right)$ consistent with the IPCC $1.5^{\circ} \mathrm{C}$ target by $2030^{1}$. Including US population growth ${ }^{2}$, this means that US emissions decrease from $4.14 \mathrm{Bt} \mathrm{CO}_{2} \mathrm{e}$ in 2010 to $0.99 \mathrm{Bt} \mathrm{CO}_{2} \mathrm{e}$ in 2030 , a $76 \%$ reduction.

\footnotetext{
${ }^{1}$ Ivanova, D., Barrett, J., Wiedenhofer, D., Macura, B., Callaghan, M., \& Creutzig, F. (2020). Quantifying the potential for climate change mitigation of consumption options. Environmental Research Letters, 15(9), 093001. doi:10.1088/1748-9326/ab8589

${ }^{2} 2010$ US population $=309.3$ million, 2030 US population $=355.1$ million
} 
c. Carbon accounting vocabulary

Scope - Category of emissions: 1-direct, 2-indirect energy, 3-indirect other (Figure 2)

Baseline - Measured emissions from agreed-upon scope within System Boundary

Baseline Year - Calendar or Fiscal year Baseline emissions are measured

BAU (Business as Usual) - emission trajectory without strategy implementation

Strategy - action focused on demand reduction or supply decarbonization

Technology - mechanical / electrical system improvements

Economic - permits, PPAs, RECs, \& other emission offsetting mechanisms

Policy - Institutional or governmental rule that influences emission amount or rate

Behavior - Human action that influences emission amount or rate

Case - set of Strategies, their deployment schedule, and Goal

Trajectory - path resulting from deployment of Strategies

Pathway - set of intermediate reductions between Baseline and Goal

Goal - Desired emissions target at Goal Year (final or interim)

Goal Year - Year Goal is planned to be achieved (final or interim)

\section{Units}

$\mathbf{t}$ - metric ton $(1000 \mathrm{~kg})$

$\mathbf{k}$ - kilo (thousand or $10^{3}$ )

$\mathbf{M}-$ mega (million or $10^{6}$ ) 


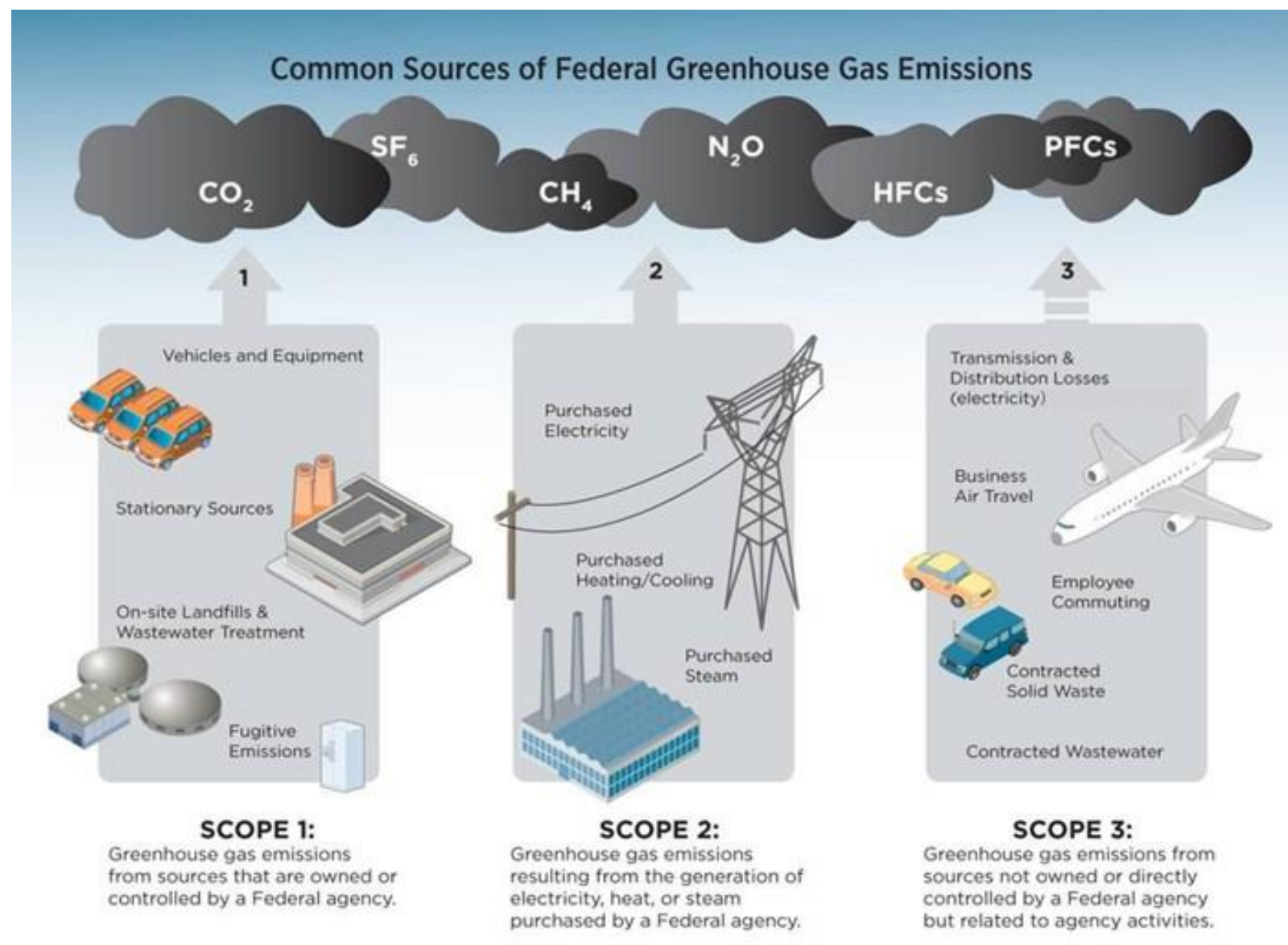

Figure 2: Greenhouse Gas Emissions Scopes (from ${ }^{3}$ ).

\section{Model description}

a. Overarching assumptions ${ }^{4}$

The model evaluates GHG emissions on an annual basis over the period 2018-2050 and employs $\mathrm{GWP}_{100}$ values throughout. The model includes the GHGs carbon dioxide $\left(\mathrm{CO}_{2}\right)$, methane $\left(\mathrm{CH}_{4}\right)$ and nitrous oxide $\left(\mathrm{N}_{2} \mathrm{O}\right)$. GWP 100 values and emission factors are sourced from Argonne National Lab's GREET model. DTE and Consumers Energy provided projected fuel mixes and generation through 2040 as well as guidance on how to treat the period 2040-2050. We also sourced data from EPA and EIA on model parameters and technology forecasts. Upstream emissions for electricity and fuel production were included in the model and include methane leakage and other emissions resulting from fuel processing, as characterized in GREET (using EDF estimates). More detail on estimating methane leakage and other GHG emissions associated with natural gas production and transportation are contained in two documents in Appendix C. These documents contain information

\footnotetext{
${ }^{3}$ https://19january2017snapshot.epa.gov/sites/production/files/styles/large/public/2015-08/scope123_large.png

${ }^{4}$ Detailed assumptions are in Appendix B
} 
describing the approach taken by the Carbon Accounting Subgroup for modeling upstream GHG emissions.

The carbon accounting model includes provision to calculate emissions separately for Scope 1 (direct), Scope 2 (energy indirect), and Scope 3 (indirect, including fuel and electricity upstream emissions) for all three UM campuses (AA, Dearborn, \& Flint) plus several field and research stations. Scope 1 emissions arise from combustion of natural gas in distributed boilers and the Central Power Plant (CPP) on the AA campus, as well as combustion of transportation fuels in fleet vehicles (buses and other UM operations vehicles). Scope 2 emissions are those associated with electricity purchased from DTE and Consumers Energy (and suppliers of smaller UM facilities such as Camp Davis). These emissions depend on the mix of fuels used by the electricity generators. Note that since the CPP generates both steam and electricity, electricity used on the AA campus is a mix of electricity purchased from DTE (Scope 2) and generated on-site (Scope 1). Scope 3 emissions result from upstream (pre-combustion) fuel extraction and processing, commuting, University travel, food (upstream and downstream), water treatment (upstream and downstream), land use, and upstream (production) embodied in purchased goods and services. There are two choices in GREET to estimate emissions associated with fuel upstream processes: EPA and EDF (also called "adjusted Alvarez et al. 5"). EPA data are updated annually, but are thought to be under-estimates, so we chose to use the EDF estimates in our calculations.

Recent historical trends show building square footage increasing and energy use intensity decreasing across the University, but both of these parameters are difficult to accurately quantify. Since these trends are moving in opposite directions we chose to assume that they are offsetting in this iteration of the model. Besides buildings that are currently under construction (Clinical Inpatient Tower, Ford Robotics), we assumed no growth in building square footage from 2023 through 2050.

\section{b. Generalized analytical approach}

The carbon accounting model implements the concepts represented in the following equations. Definitions of the nomenclature follow Equation 3. Equation 1 illustrates that total fuel cycle emissions for a given energy source are the sum of upstream and combustion emissions.

$$
T_{T F C, l}(t)=e_{u p}(t)+e_{c o m b}(t)
$$

Equation 1

\footnotetext{
${ }^{5}$ Alvarez, R. A., D. Zavala-Araiza, D. R. Lyon, D. T. Allen, Z. R. Barkley, A. R. Brandt, K. J. Davis, S. C. Herndon, D. J. Jacob, A. Karion, E. A. Kort, B. K. Lamb, T. Lauvaux, J. D. Maasakkers, A. J. Marchese, M. Omara, S. W. Pacala, J. Peischl, A. L. Robinson, P. B. Shepson, C. Sweeney, A. Townsend-Small, S. C. Wofsy, S. P. Hamburg, Assessment of methane emissions from the U.S. oil and gas supply chain. Science (2018), doi:10.1126/science.aar7204.
} 
Equation 2 describes calculation of GHG emissions for a given scope, activity, technology, and energy source as a product of total fuel cycle emissions for that energy source, the efficiency of energy conversion to meet a given demand, and the given demand.

$C_{i j k l}(t)=D_{i j}(t) \times S_{k l}(t) \times E_{T F C, l}(t)$

Equation 2

Equation 3 illustrates the calculation of total GHG emissions as a series of summations across scopes, activities, technology, and energy sources with a term included that subtracts emissions associated with any offsetting activities.

$$
C_{\text {Total }}(t)=\sum_{i=1}^{3} \sum_{j=1}^{n} \sum_{k=1}^{n^{\prime}} \sum_{l=1}^{n^{\prime \prime}} C_{i j k l}(t)-\sum_{m=1}^{n^{\prime \prime \prime}} o_{m}(t)
$$

Equation 3

Nomenclature for Equations 1-3:

$\mathrm{D}=$ demand for service (e.g., Btu heating, Btu cooling)

$\mathrm{S}=1 /$ efficiency of the process supplying energy to meet demand (e.g., boiler (Btu NG/Btu

heat delivered), heat pump ( $\mathrm{kWh} /$ Btu heat delivered))

$\mathrm{O}=$ offseting activity

$\mathrm{E}_{\mathrm{TFC}}=$ total fuel cycle emissions from fossil fuel combustion, including upstream and combustion

$\mathrm{t}=$ time

$\mathrm{i}=$ scope 1,2 , or 3

$\mathrm{j}=$ activity or end use (e.g., building heating, University vehicle, office supplies)

$\mathrm{k}=$ technology to meet the demand (e.g., boiler or heat pump)

$1=$ energy source (e.g., electricity, natural gas, gasoline)

$\mathrm{m}=$ offset mechanism (permits, PV, RECs)

\section{c. Activities included}

Activities accounted for in the model include Building operation (heating, cooling, electricity) (Scope $1 \&$ 2, fuels upstream is Scope 3), Fleet operation (Scope 1, fuels upstream is Scope 3), Commuting (Scope 3), University Travel (Scope 3), Food (Scope 3), Waste (Scope 3), Biosequestration (Scope 3), and a rough estimate of emissions associated with purchased goods \& services (Scope 3). Emissions associated with construction of infrastructure, buildings, and vehicles are not included in the carbon accounting model. Note that some strategies cause a shift in emission scope, which is one reason the model includes all three scopes. For example, fleet vehicle electrification moves emissions from Scope 1 (fuel combustion) to Scope 2 (purchased electricity), while the Scope 3 fuel upstream emissions switch to Scope 3 electricity upstream emissions.

d. Baseline emissions (Scope 1, 2, \& 3)

Baseline emissions are the current/recent emissions from which future reductions are measured. The IPCC $1.5^{\circ} \mathrm{C}$ global target (a $45 \%$ emissions reduction by 2030 ) uses a baseline year of 2010. We are using 2018 as the baseline year since that is the year IAT and EAT analyses begin. UM emissions (Scope $1 \& 2$, as reported by the Office 
of Campus Sustainability - OCS) were relatively flat between 2010 and 2018, decreasing $6 \%$ during the period (Figure 3 ).

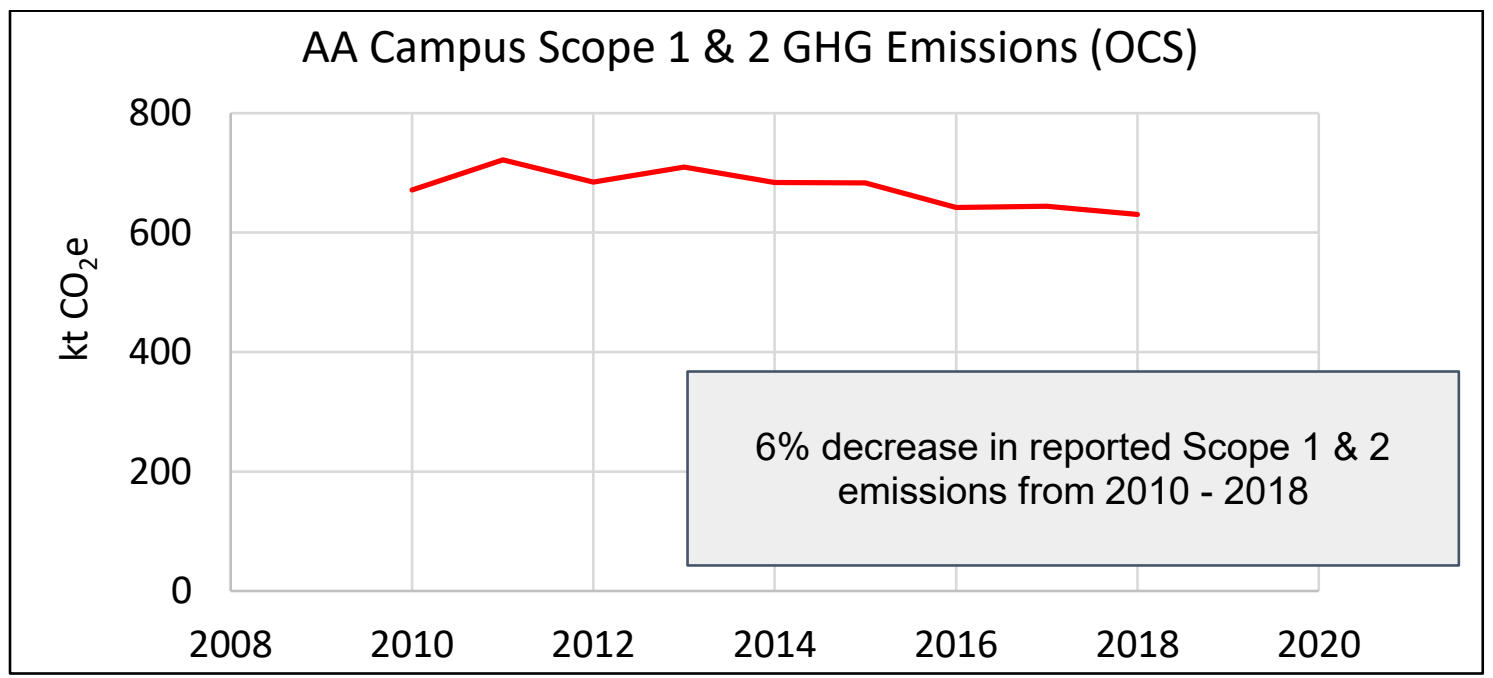

Figure 3: Ann Arbor campus Scope 1 \& 2 emissions, 2010-2018. Data from UM Office of Campus Sustainability.

Baseline emissions for UM are depicted in Figure 4 (Scope 1 \& 2) and Figure 5 (Scope 3, without purchased goods and services). Note that buildings are responsible for nearly all the University's Scope $1 \& 2$ emissions and that commuting (combustion and upstream emissions), buildings (upstream), food, and University travel are the largest Scope 3 emission categories.

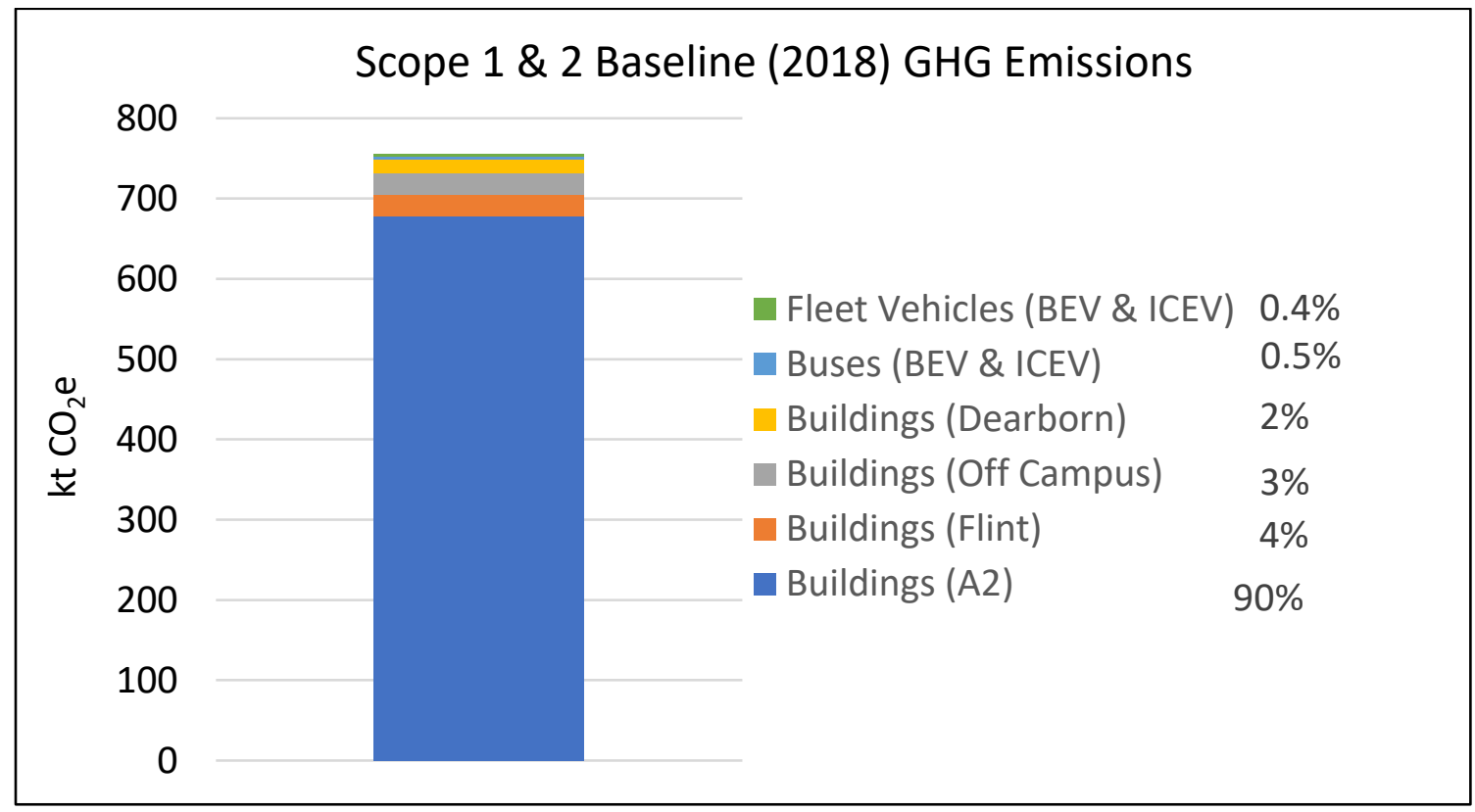

Figure 4: Scope 1 \& 2 baseline GHG emissions, by activity (all campuses). 


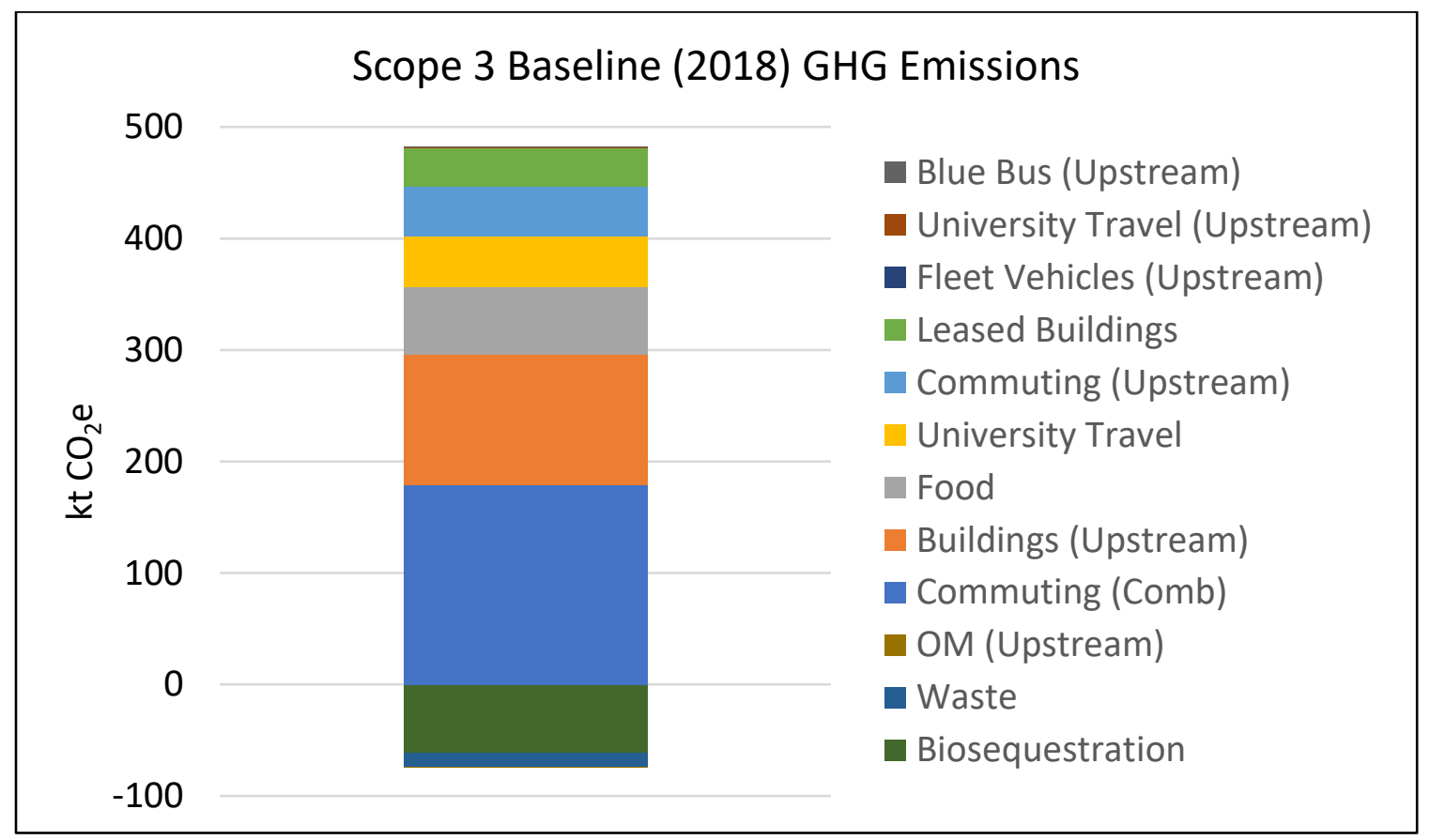

Figure 5: Scope 3 baseline GHG emissions (not including purchased goods \& services), by activity (all campuses).

We used Economic Input-Output (EIO) methods to estimate the range of emissions values based on UM expenditures for purchased goods and services (\$2.5B in FY19). Using data from Carnegie Mellon's EIOLCA.net on emissions per dollar $\left(\mathrm{t} \mathrm{CO}_{2} \mathrm{e} / \$\right)$ for a variety of activity categories, we assumed a low emission category (travel services $=147 \mathrm{t} \mathrm{CO}_{2} \mathrm{e} / \$ 1 \mathrm{M}$ ) to define the lower end of the range and a high emission category (paints and coatings $=680 \mathrm{t} \mathrm{CO}_{2} \mathrm{e} / \$ 1 \mathrm{M}$ ) to define the upper end of the range. The resulting range of emissions values for purchased goods and services was $290-$ $1360 \mathrm{kt} \mathrm{CO}_{2} \mathrm{e}$ (Figure 6). Note that 'purchased goods and services' contains some activities accounted for in other categories, so a disaggregation of this category will be necessary to correct this double counting and complete an accurate accounting for establishing a baseline and setting reduction goals. 


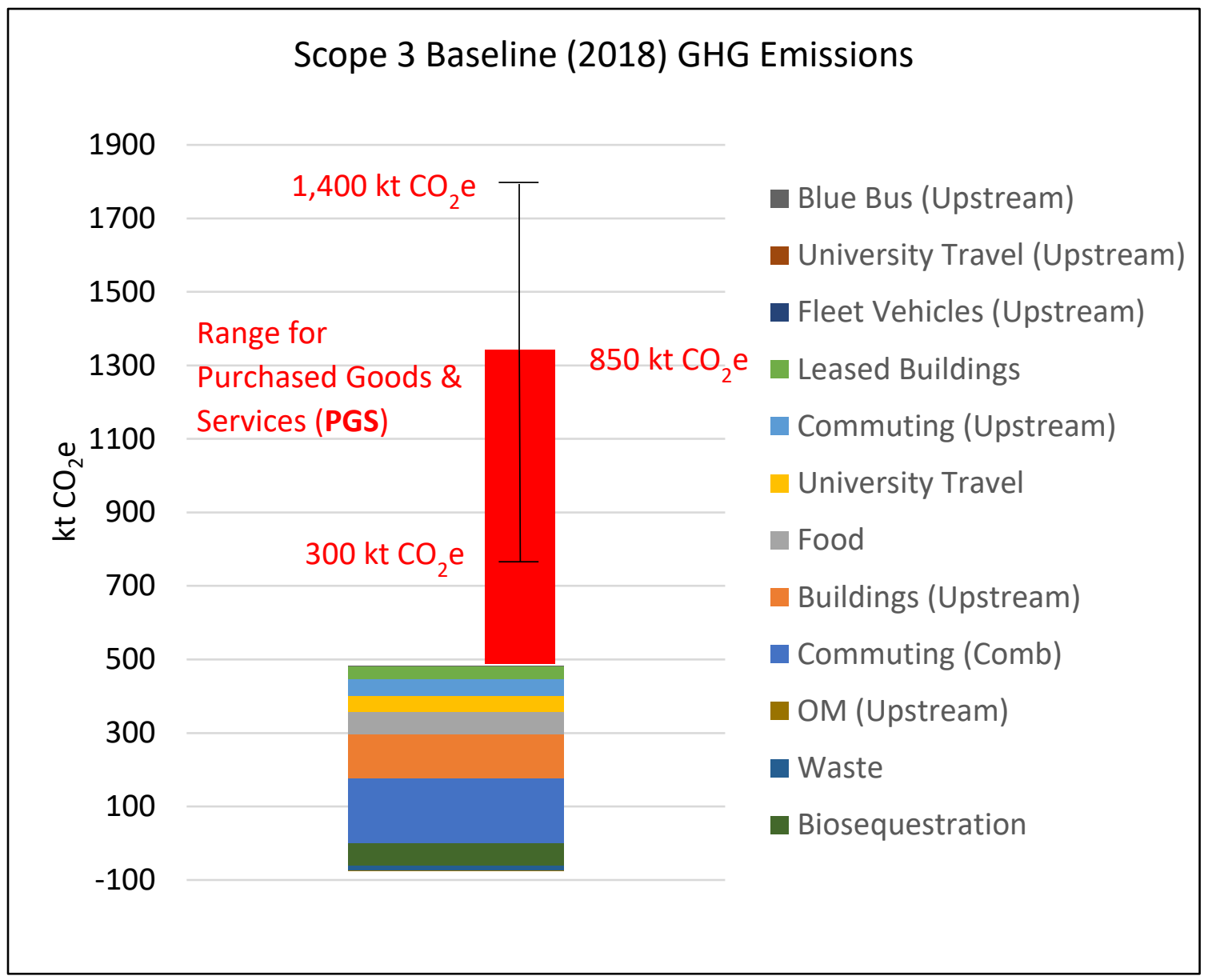

Figure 6: Scope 3 baseline GHG emissions, by activity, with a range of estimated values for purchased goods \& services.

\section{e. Business-as-usual}

The emissions trajectory from Baseline into the future in the absence of any emissionreduction strategy implementation is called business-as-usual (BAU). BAU includes, for example, utility decarbonization plans, a pending DTE power purchase agreement (PPA), the UM CPP expansion, expected improvements in vehicle fuel economy and vehicle electrification rates. When emissions reduction strategies are implemented, reductions in emissions in any year are measured from the BAU trajectory. We used the model to estimate BAU trajectories separately for Scope $1 \& 2$, and Scope 3.

Assumptions for BAU are:

\section{Buildings}

- Building sqft, energy conservation measures, \& EUI flat (CIT \& Ford Robotics are included in sqft)

- DTE and Consumers are carbon neutral in 2050 (linear decrease 2040-2050), Figure 7

- DTE PPA 2022-2042

- CPP Expansion comes on-line in 2022 
- Flint RECs same as historical

\section{Transportation}

- Commuting and University travel distances and modes are flat

- 7\% of the commuting SOV mode share will be electrified by 2030

- Bus fleet - new buses are diesel, FE improvement follows EIA

- Vehicle fleet - no electrification, FE improvement follows GREET time series data

\section{Food, Waste \& Biosequestration}

- Food \& Biosequestration remain flat

- Waste - 100 ton increase in compost for AA over next 2 years

\section{Upstream}

- includes upstream for fuels \& electricity, food upstream is included, purchased goods and services are not included

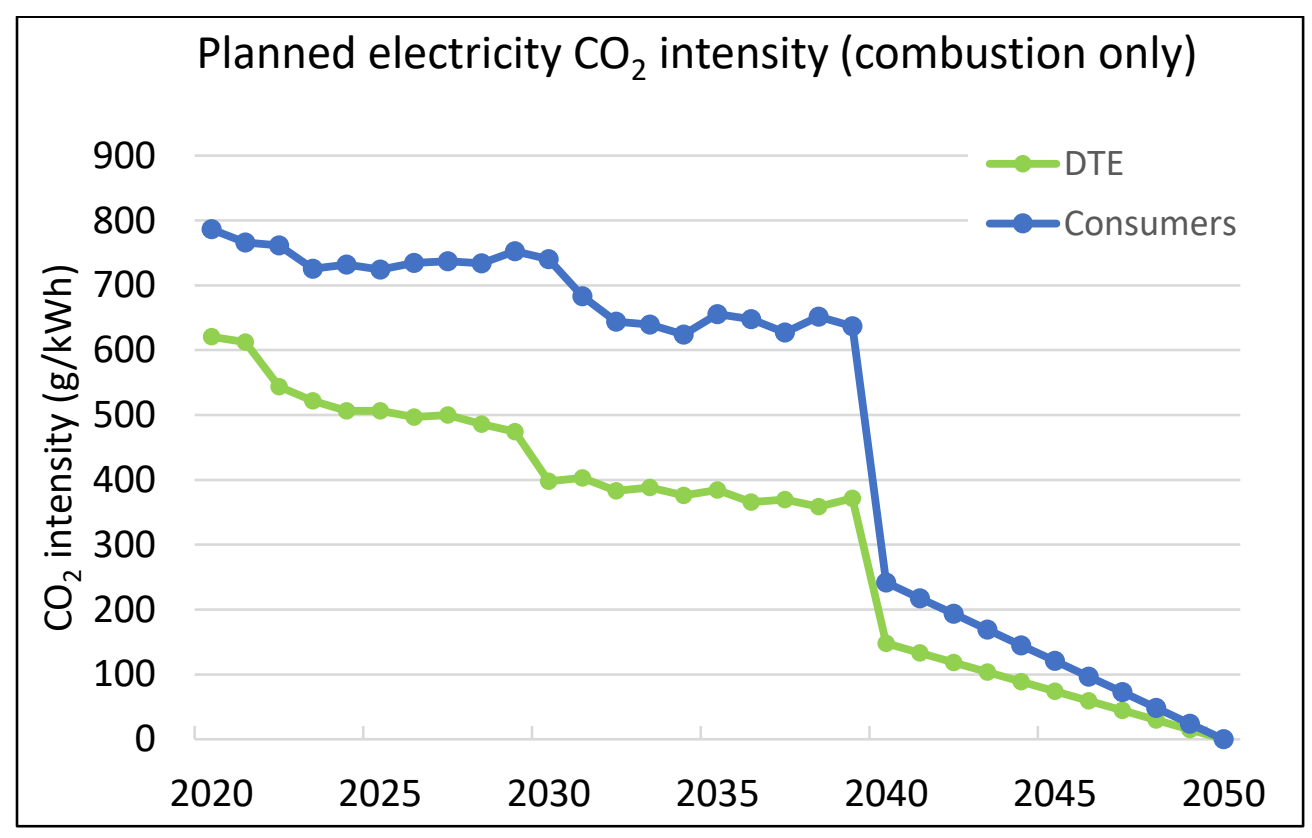

Figure 7: Planned $\mathrm{CO}_{2}$ combustions emissions intensity, 2020-2050, for DTE and Consumers Energy. Data supplied by DTE and Consumers.

The BAU trajectory for Scope $1 \& 2$ emissions is plotted in Figure 8. The growth in the first couple years is caused by addition of the CIT and Ford Robotics buildings. The decline in 2022 is due to the start of the DTE PPA and CPP expansion coming online. The drop in 2040 is a result of DTE closing the Monroe coal power plant and the small increase in 2043 is due to the expiration of the DTE PPA. Figure 9 illustrates the BAU trajectory for Scope 3 emissions and Figure 10 is a plot of total UM emissions (Scope 1, 2, \& 3). 


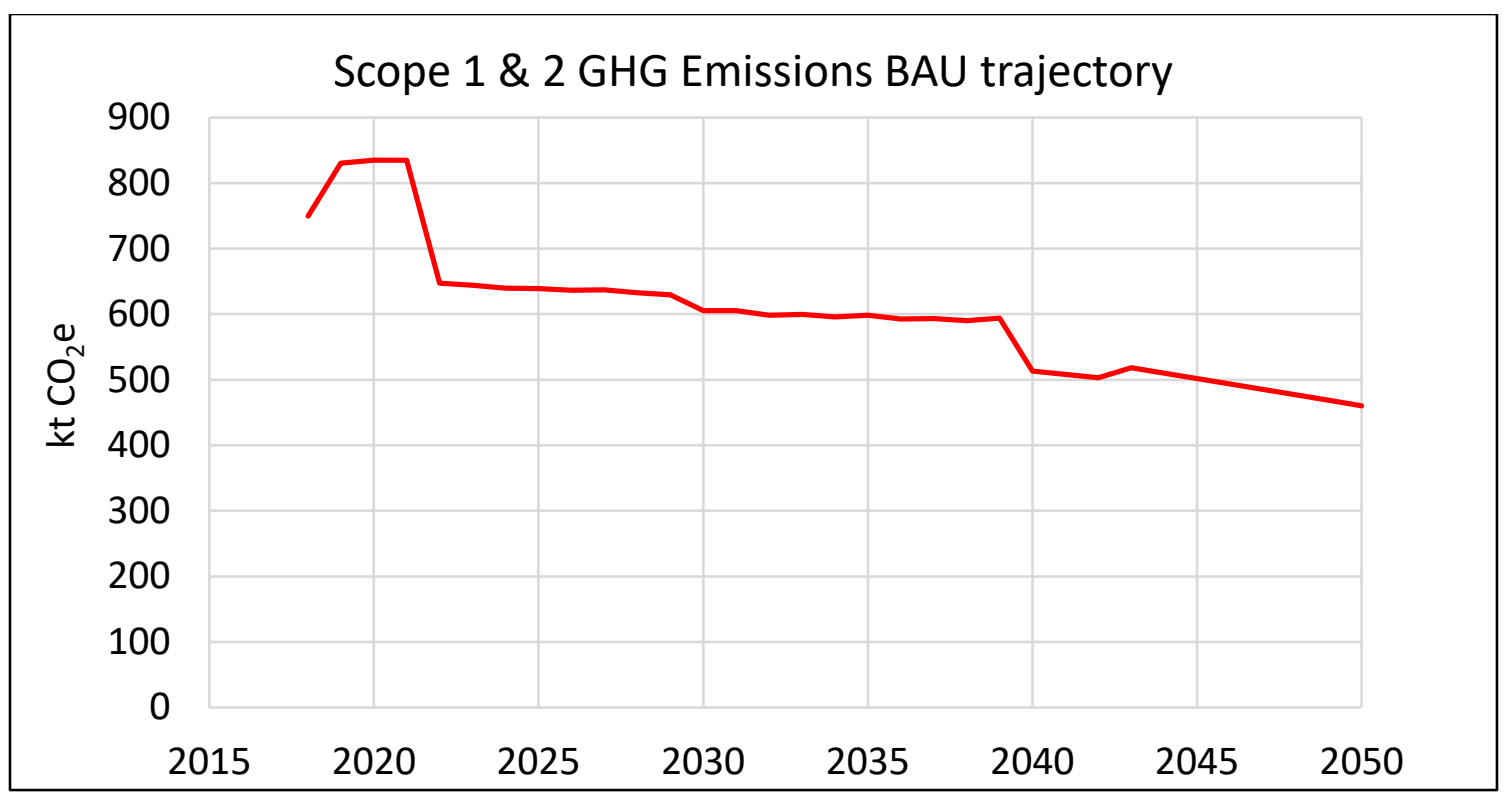

Figure 8: BAU Scope 1 \& 2 GHG emissions trajectory, 2018-2050.

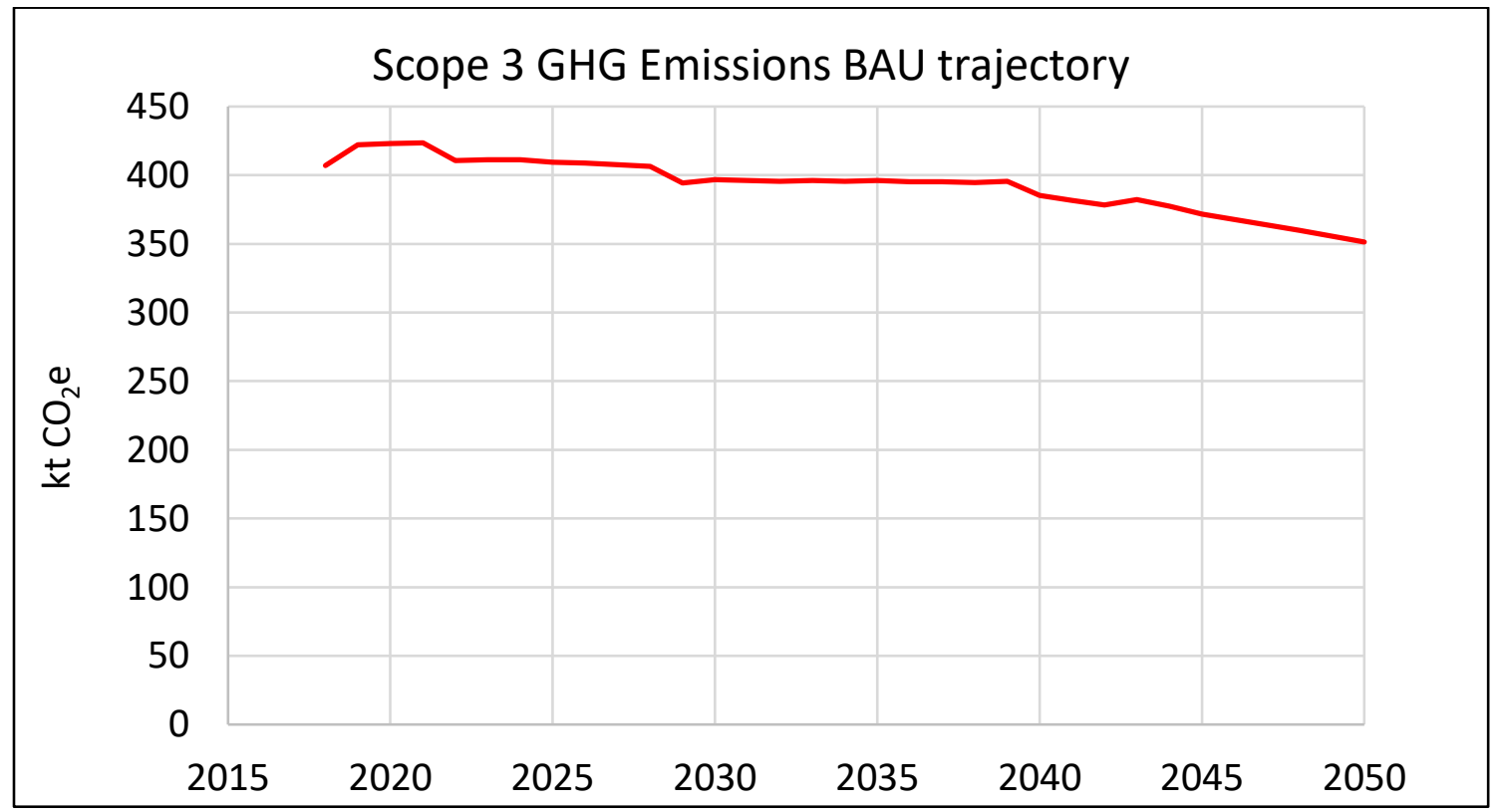

Figure 9: BAU Scope 3 GHG emissions trajectory (not including purchased goods and services), 20182050. 


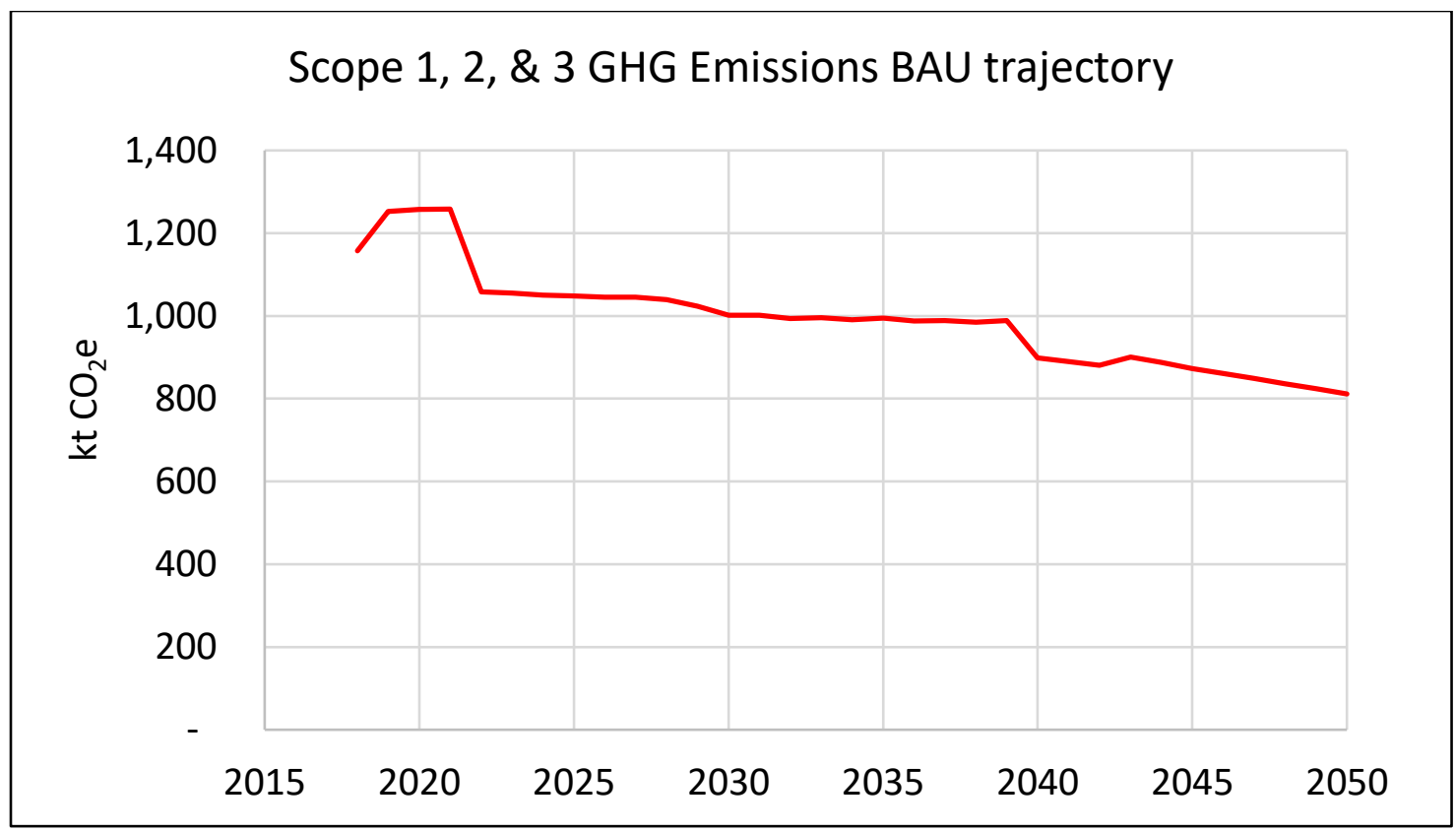

Figure 10: BAU Scope 1, 2 \& 3 GHG emissions trajectory (not including purchased goods and services), 2018-2050.

\section{f. Strategies}

The CAMP team implemented 29 emission reduction strategies that were either recommended by IATs or EATs, or that were developed by the team. These strategies are listed below with brief descriptions, sorted by activity (note that most energy strategies are included in the building operation activity). More details on many of these strategies can be found in the IAT and EAT reports, and their implementation in the carbon accounting model is described below in the Model Components section.

\section{Building operation}

\section{Install Geoexchange heating/cooling system (GHX)}

A transformational strategy to convert heating and cooling systems from NG combustion (steam) to electric heat pumps with ground-coupled heat exchange. Capital cost can be reduced by replacing a number of boreholes with supplemental heat from NG boilers. Requires building modifications simultaneous retrofits to reduce demand would also be beneficial but are not part of this strategy. This system is phased in with fractions of full system capacity added every 5 years to accommodate constraints in design and construction logistics.

\section{Install on-campus PV (on buildings \& parking lots)}

On-campus photovoltaics are proposed to be located on top of buildings and over parking lots or structures, but not on the ground. This is essentially 'behind-themeter' electricity generation that directly displaces purchased electricity.

\section{Install PV on off-campus buildings}

As above, but for the smaller number of UM-owned off-campus buildings. 


\section{Reduce non-thermal electricity demand}

Reductions in demand achieved through revised policy and behavior change. Applies to lighting and plug loads (computing equipment, electric kettles, etc.) in buildings.

\section{Reduce thermal energy demand}

Reductions in heating and cooling demand through revised policy and behavior change.

\section{Reduce NG use intensity}

Reductions in heating and cooling demand through building retrofits (increased insulation, window replacement, HVAC commissioning, etc.).

\section{Reduce electricity use intensity}

Reduction in electricity demand through building retrofits, primarily lighting and HVAC. Lighting reductions would result from replacement of fluorescents with LEDs, for example.

\section{Install PV on additional open land on campus}

Use open land without planned construction for on-campus solar array. Most applicable to AA north campus. This is essentially 'behind-the-meter' electricity generation that directly displaces purchased electricity.

\section{Fleet operation}

9. Blue Bus Electrification

Convert the Ann Arbor inter-campus buses from diesel to electric. The benefit of this strategy is increased if charging electricity is low- or no-carbon.

\section{Vehicle Fleet Electrification}

Convert on-campus vehicles from gasoline/diesel to electric. The benefit of this strategy is increased if charging electricity is low- or no-carbon.

\section{Commuting}

\section{Parking Policy Reform}

Remove mandated annual faculty and staff parking fees, eliminate monthly/annual passes and implement daily passes, link cost of parking passes to salary, and optimize use of existing peripheral parking locations.

\section{Rideshare Policy}

Create a carpool system and extend vanpool system to students, faculty, and staff.

\section{Cycling Policy, including infrastructure}

Provide easement to Ann Arbor for the Treeline Trail Route, create a NorthCentral Campus route, establish an on-campus bike-service facility and work with City of Dearborn on completing bikeways to campus.

\section{Universal Access Policy}

Dearborn and Flint develop agreement with SMART/MTA to extend universalaccess transit agreement to all students and increase routes serving campus. 


\section{Commuter Vehicle Electrification}

Incentivize commuters to purchase electric vehicles and build charging infrastructure to support increase in EVs on campus.

\section{University Housing Policy}

Build housing units for faculty, staff, and students on all three campuses.

\section{University travel}

17. University Travel Reduction

Reduced travel for university business, to be replaced by telepresence.

\section{Replace Air Travel with Train Travel}

Replace air travel by train travel where possible (trips less than 300 miles with direct train routes).

Food

\section{Switch to lower carbon protein source(s)}

Replace animal-based protein sources with plant-based protein sources.

20. Switch to lower carbon dairy alternatives

Replace animal-based dairy with plant-based dairy.

\section{Divert and prevent organic food waste}

Closes soil nutrient loops and prevents anaerobic decay and methane formation in landfills.

\section{Increase Recycling}

Closes material loops and prevents anaerobic decay and methane formation in landfills.

\section{New Waste Management System}

Add composting as a waste management option for the Dearborn and Flint campuses.

\section{Biosequestration}

\section{Convert/enhance existing landscape type}

Change land cover to a type with a higher carbon sequestration rate.

\section{Convert turfgrass to lower carbon alternative}

Change land cover to a type with a higher carbon sequestration rate and/or lower maintenance requirements.

\section{Purchase additional land} Increase the supply of land with the intent of changing land cover to a type with a higher carbon sequestration rate.

\section{Add Green Infrastructure}

Green roofs and walls - plants on the tops and façades of buildings. 


\section{Other mitigation}

\section{Purchase and retire RECs/RGGI permits, additional PPA}

Purchase emission permits or renewable energy certificates (RECs) to offset unavoided emissions. Enter into a power purchase agreement (in addition to the DTE PPA that's part of BAU) to buy electricity from renewable sources.

\section{Offsite solar}

Build and operate photovoltaic installation(s) off-campus.

Some strategies alter the Scope of emissions. The strategies that cause a switch in Scope are GHX (Scope 1, 2, \& 3 to Scope 2 \& 3) and vehicle (bus and fleet) electrification that cause a switch from Scope $1 \& 3$ to Scope $2 \& 3$. These strategies all move from providing a service via combustion of fuels (Scope 1) to providing a service via electricity (Scope 2). The upstream component (Scope 3) exists before and after implementation of these strategies but does change in magnitude.

\section{g. Cases}

Each case is made up of a set of emission reduction strategies and their associated implementation rates and degrees. Three cases were constructed: Case A (the most ambitious in degree and rate of strategy implementation); Case B (the moderate case); and Case $\mathrm{C}$ (the most conservative case in both degree and rate). Details on the cases are included in Appendix A. Case B largely followed the Integral and IAT recommendations. The results section is organized by these Cases.

\section{Model structure}

The carbon accounting model is realized in Excel, with groups of interlinked worksheets devoted to individual activities (input data, calculation of baseline and BAU, evaluation of strategies) and collection of results by scope for tabulation and graphing. The simplified model structure is illustrated in Figure 11. 


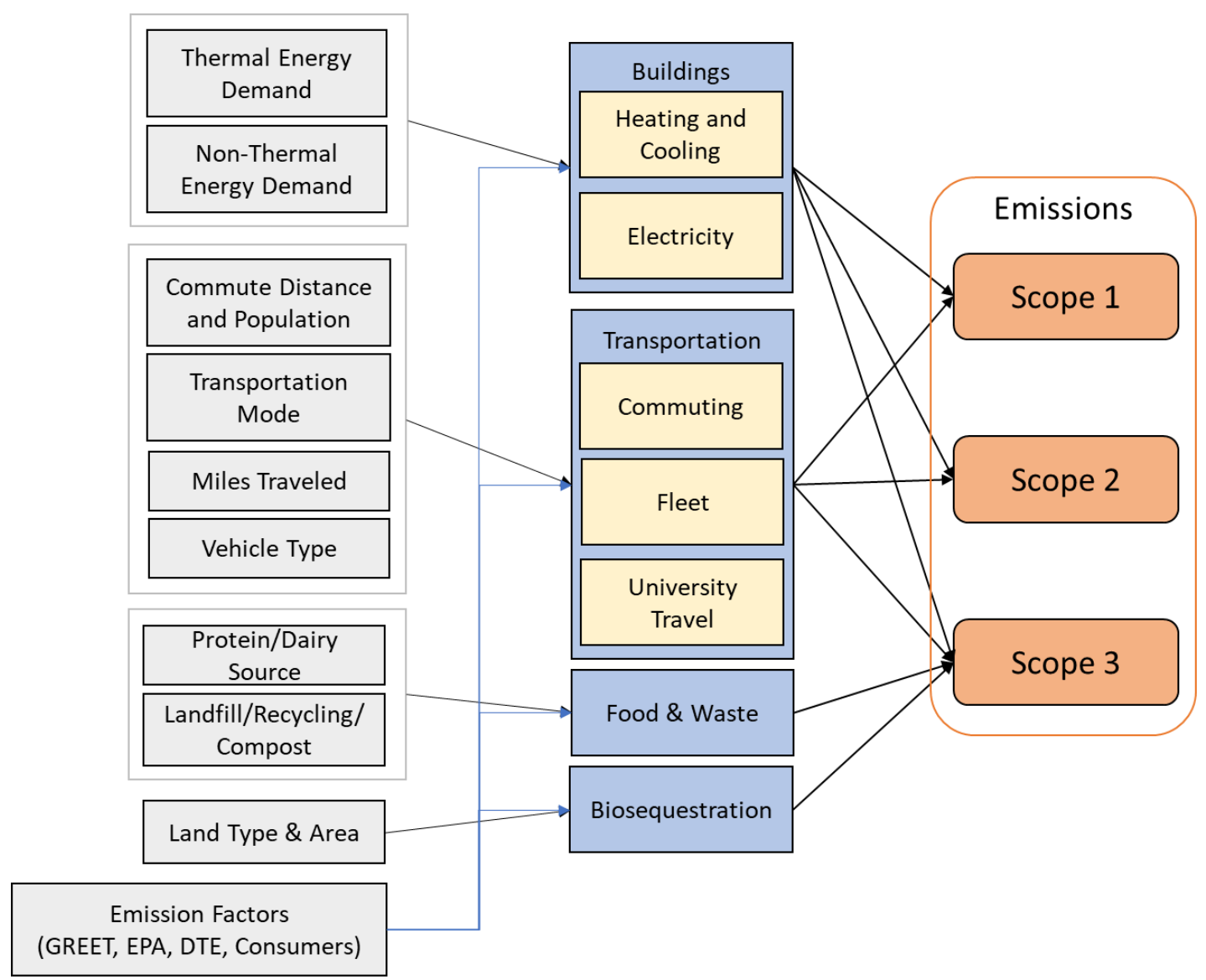

Figure 11: Simplified carbon accounting model structure with data inputs on the left supplying modeling modules for activity categories that calculate annual GHG emission estimates 2018-2050.

a. Campuses and Utility providers

Ann Arbor, Dearborn, and Flint campuses are included in the model as sections within each set of activity worksheets. Off-campus facilities are also included (the Biological Station in Pellston and the Osborn Preserve on Sugar Island, Camp Davis in Wyoming, as well as smaller facilities including Stinchfield Woods, Saginaw Forest, and the George Reserve). DTE is the utility provider for Ann Arbor and Dearborn (including smaller nearby facilities), Consumers Energy is the utility for Flint and the Biological Station, Lower Valley Energy is the utility for Camp Davis, and Cloverland Electric Cooperative supplies the Osborn Preserve.

Information on utility fuel mixes through 2040 were provided by DTE and Consumers and were collected from public sources and communications with LVE and Cloverland. These data were used to calculate annual emission factors (EF, in $\mathrm{t}$ $\mathrm{CO}_{2} \mathrm{e} / \mathrm{kWh}$ ) for each electricity provider. Once electricity consumption is known, the EF allows calculation of the resulting associated GHG emissions. DTE and Consumers have both made public commitments to net-zero emissions by 2050, so their EFs were taken linearly to zero between 2040 and 2050. 


\section{b. Model Components}

High-level descriptions of each of the main components of the carbon accounting model and of the emission reduction strategies are included below. Assumptions and calculation details are collected by component in Appendix B.

\section{i. Buildings}

Emissions result from meeting building energy demands for heating, cooling, lighting, and plug loads and are a function of how and where the energy is generated. Scope 1 emissions result from the combustion of natural gas, primarily for heating but also for cooling (via absorption chillers) and electricity generation in the Ann Arbor CPP. Scope 2 emissions are associated with purchased electricity and are based on the provider's annual EFs. Scope 3 emissions for buildings result from the upstream emissions associated with both natural gas and the fuels used by utilities to generate electricity.

The carbon accounting model relies heavily on the Integral Group's analysis and energy modeling conducted using data provided by UM Facilities, UM Utilities, and UM Office of Campus Sustainability for the Heat and Power Infrastructure Analysis EAT. Integral's analysis broke the University into six districts (AA Central/Medical, AA North, AA Ross Athletic, AA East Medical, Dearborn, Flint) and their proposed carbon reduction strategies follow this district organization. The model calculates emissions based on Integral's building energy demand analysis and our calculated utility EFs through 2050. Descriptions of the implementation of emissions reduction strategies associated with buildings are included below.

A geothermal heat exchange (GHX) system provides heating and cooling electrically and greatly reduces the need to burn natural gas on campus. Note this decreases Scope 1 emissions and increases demand for electricity, so it should be accompanied by procurement of decarbonized electricity to maximize the reduction in overall emissions. Integral proposed phasing in GHX by moving an increment of UM heating/cooling demand from the existing systems to GHX every five years. This was primarily a recognition of the scale of the effort and the design and logistical challenges involved in implementing a system of this scale. The phasing can be changed since the districts are individual projects, but the number of projects running concurrently should be minimized and the first projects begun should be the smaller, simpler ones. In the carbon accounting model, this strategy reduces the demand for steam and increases the demand for electricity, then calculates the reduced Scope 1 and natural gas upstream (Scope 3 ) emissions and increased demand for electricity. Scope 2 emissions are calculated based on the increase in electricity demand, and Scope 3 emissions are calculated for the upstream associated with the new electricity demand.

On-campus PV installations directly reduce demand for purchased electricity. Integral recommended this strategy only for the tops of buildings and parking 
areas. The model uses the amount of electricity generated (estimated by Integral) to reduce purchased electricity and calculates Scope $2 \& 3$ emissions for the remaining electricity demand from DTE and Consumers.

Off-campus PV installations are applicable to all facilities outside of the Ann Arbor, Dearborn, and Flint campuses and are included in the model identically to on-campus $\mathrm{PV}$, except the emissions are based on the appropriate local electricity provider's EF.

A strategy to include additional PV assumes ground mounting and uses NREL's PVWatts ${ }^{6}$ to estimate electricity production for a given area, which then reduces the demand for purchased electricity as with other PV. Reduced Scope $2 \& 3$ emissions are calculated based on the local electricity provider's EF.

The strategy to reduce non-thermal electricity demand is modeled as a percentage reduction resulting from behavior change. The same percentage reduction is applied to all six districts. The model calculates reduced emissions based on the electricity generation source.

The strategy to reduce thermal energy demand is also modeled as a percentage reduction resulting from behavior change. The same percentage reduction is applied to all six districts. The model calculates reduced emissions based on energy source.

Reducing natural gas use intensity is a strategy similar to reducing thermal energy demand above, with the exception that it results from technology rather than behavior change. It is modeled as a percentage reduction, applied to all six districts.

Reducing electricity use intensity is a strategy similar to reducing non-thermal energy demand above, with the exception that it results from technology rather than behavior change. It is modeled as a percentage reduction, applied to all six districts.

\section{ii. Transportation - Fleet \& Blue Bus}

Emissions result from operation of fleet vehicles and buses. Scope 1 emissions result from the combustion of gasoline and diesel fuel in University owned vehicles. Scope 3 emissions result from the upstream production of these fuels. The carbon accounting model relies primarily on data from UM's Fleet Department, specifying the number and type of vehicles as well as annual mileage data. EFs are sourced from GREET1 2019 and include projected fuel economy improvements. Emissions are categorized by campus and vehicle type (diesel bus, hybrid-electric bus, LLDT, HLDT, LHDDE, MHDDE, HHDDE).

${ }^{6}$ https://pvwatts.nrel.gov/ 
Vehicle electrification strategies are implemented separately by campus and vehicle type. The strategies replace existing ICEVs with EVs at a specified rate. Emissions from EVs are determined using GREET1 2019 fuel economy data, annual mileage, and EFs for the electricity source (e.g., DTE or Consumers). This strategy reduces emissions by switching from carbon intensive fossil fuels to a less carbon intensive electrical grid and should be accompanied by procurement of decarbonized electricity to maximize reduction in emissions. Vehicles are replaced on a first-in-first-out basis. EV charging emissions are Scope 2, and there are also upstream Scope 3 emissions associated with electricity used to charge EVs.

\section{iii. Transportation - University travel}

These Scope 3 emissions result from the combustion of fossil fuels to power all travel modes (air, train, car/truck, bus) for University travel. Emissions are calculated using transportation mode, appropriate EFs, and distance traveled. Mode and distance traveled are determined using data from sources including: A2ru; Athletics; Athletics Charter; Concur; Rackham Travel Grant; SEAS; Ross, Vice Provost Office; Shared Services. These data were compiled by the University Travel IAT.

The strategy to reduce emissions from University travel in the carbon accounting model is a percent reduction in miles that is applied to vehicle travel and air travel. Air travel reduction is split into three distance categories (short, medium, and long) because air travel emissions factors vary with distance. This strategy does not assume that the University will reduce its operations, but does assume that in-person engagement will be replaced by telepresence. No emissions are estimated for telepresence. Reductions are modeled separately for air travel and vehicle travel.

An additional strategy is included in the model that replaces short distance air travel with train travel. It is implemented as a percent change (mode switch) in miles traveled from more carbon intensive air travel to less carbon intensive train travel. This strategy is limited to trips that are less than 6 hours by train and have a direct route (no transfers required), which was 19\% of short distance air travel miles, based on an evaluation of all short air travel trips taken in 2018 .

\section{iv. Transportation - Commuting}

Commuting emissions are Scope 3 and result from travel to and from University property by faculty, staff, and students. Emissions are calculated using transportation mode, EFs, distance traveled, commuter population in a distance band, and number of annual commuting days. Modeled carbon reduction strategies come from the Commuting IAT report with some additional modeling work.

Adopting UM parking policy changes is one strategy to reduce commuting emissions (Commuting IAT report - Priority \# 2, Parking Policy 
Recommendations). Implementing these changes results in a mode switch from single occupancy vehicles (SOV) to less carbon intensive modes (i.e., rideshare, bus, bike), which is modeled as a change in the population using SOVs to commute. More details can be found in the Commuting IAT Report, Appendix D. Increasing ride sharing (Commuting IAT report - Priority \# 3, Motorized Transportation Improvements) is implemented as a mode switch from SOVs to ride sharing (in the same vehicle type). This increases vehicle occupancy, thereby decreasing an individual commuter's carbon emissions.

Increasing cycling for commuting reduces emissions by mode switching from SOVs (Commuting IAT report - Priority \# 4, Cycling Improvements). This strategy includes on-campus infrastructure improvements, co-ordination with local municipalities to improve biking infrastructure, and bike-sharing programs.

The Universal Access strategy estimates the impact of increasing bus access (negotiating with SMART and MTA to provide bus access through MCards) and improving bus routes servicing the Flint and Dearborn campuses. Universal Access is already in place for the Ann Arbor campus (through AAATA). This strategy reduces emissions by mode switching from SOVs to buses (Commuting IAT report - Priority \# 3, Motorized Transportation Improvements).

Another strategy to reduce commuting emissions is to build more university housing on campus for students, faculty, and staff. This strategy shifts population locations closer to campus to reduce commuting distance (Commuting IAT report - Priority \# 1, Housing Development and Land-Use Policy). There are 3 different strategy options for the Ann Arbor campus, each with a different number of new housing units. There is one strategy option for new housing units on both the Dearborn and Flint campuses. The strategy options are based on a spatial analysis completed by the Commuting IAT.

Vehicle electrification reduces emissions by shifting from fossil fuels to a less carbon intensive electric grid and should be accompanied by procurement of decarbonized electricity (on campus) to maximize reduction in emissions. (EVs charged by electricity from DTE or Consumers currently have lower emissions than ICEVs.) The strategy is modeled by modifying the SOV EF to reflect EVs making up an increased percentage of the SOV commuter fleet. There are three options for the percentage of EVs in the fleet, based on projections for EV market penetration. Constructing EV charging stations on campus and offering monetary incentives would accelerate $\mathrm{EV}$ adoption, though these activities are not included in the carbon accounting model.

\section{v. Food}

GHG emissions related to food production are categorized as Scope 3 and are calculated based on mass of food purchased $(\mathrm{kg})$ and EFs ( $\mathrm{kg} \mathrm{CO}_{2} \mathrm{e} / \mathrm{kg}$ food) for different food types. EFs include transportation of food to UM. The carbon accounting model includes 25 categories of food. 
The first emission reduction strategy included in the carbon accounting model related to food is replacing high-carbon protein sources such as red meat, fish and eggs with less carbon-intensive sources of protein such as legumes and soy (see the Food IAT Report for details). This strategy is implemented in the model as a percent reduction in the selected carbon-intensive protein sources, and a percent increase in the lower carbon protein sources. Behavior change is necessary for this strategy to be realized.

The second reduction strategy for food-related emissions is implemented as a percent replacement of dairy products with soy-based products (see the Food IAT Report for details). This strategy also requires behavior change to be successful.

\section{vi. Waste}

GHG emissions related to waste are categorized as Scope 3. They are calculated based on mass of waste, type of waste (e.g., landfill, recyclable waste, food waste), and relevant EFs. In addition to landfill, other methods of waste handling, such as recycling and composting are also included in the carbon accounting model. Waste reduction strategies are focused on food waste since they were compiled by the Food IAT (see the Food IAT Report for details on all of these strategies). Waste strategies can be changed by campus in the model.

The first waste GHG emissions reduction strategy is diversion/prevention of organic food waste. This strategy is implemented as a percent reduction in food waste (organic material) that is landfilled.

The second waste GHG emission reduction strategy is a percent decrease in the amount of recyclable waste that is landfilled. Not all recyclable materials are associated with landfill GHG emissions but many are and recovering a higher fraction of recyclable materials is necessary to close material life cycle loops and promote circularity.

The third strategy included in the carbon accounting model is implementation of composing at the Flint and Dearborn campuses. This strategy is implemented as a percent reduction in food waste (organic material) that is landfilled.

\section{vii. Biosequestration}

Biosequestration refers to the extraction of carbon from the atmosphere by living things (e.g., plants and trees) and storage in their tissues. Different landscape types have different annual sequestration rates (tons $\mathrm{CO}_{2} \mathrm{e} / \mathrm{ha}$ ), and these rates change over time as the landscape evolves. Biosequestration is implemented in the carbon accounting model as negative Scope 3 emissions.

There are multiple biosequestration strategies, which all model landscape conversion from low carbon sequestration landscapes to higher carbon sequestration landscapes. High carbon sequestration landscape types include 
constructed wetlands, reforested areas, bioswales, grasslands, and enhanced wetlands(see the Biosequestration IAT Report).

\section{Results \& Discussion}

This section contains a series of plots of GHG emissions trajectories produced with the carbon accounting model, organized by Case. Full details on the strategies and their implementation (depth and timing) in each Case are contained in Appendix A to keep this section more readable. Also included are results of several secondary analyses on upstream emissions, 100\% renewable purchased electricity, and GHX.

a. Case A

This is the most ambitious Case modeled, with emission reduction strategies starting earlier, being implemented more quickly, and reducing emissions more than in Case B or C. Note that the steps taken to make this Case ambitious, especially in the GHX phasing schedule, have resulted in set of strategies that would be extremely difficult to implement in reality even though it is still instructive in bounding emission trajectories.

The Case A GHG emissions trajectories for Scope $1 \& 2$ are plotted in Figure 12, both individually and as a combined total. The separate trajectories for Scope 1 and Scope 2 clearly show the phased increments of GHX implementation moving emissions from Scope 1 to Scope 2 every five years. Also apparent is the 2040 Monroe coal plant retirement. The legend contains the cumulative 2018-2050 GHG emissions for each trajectory. 


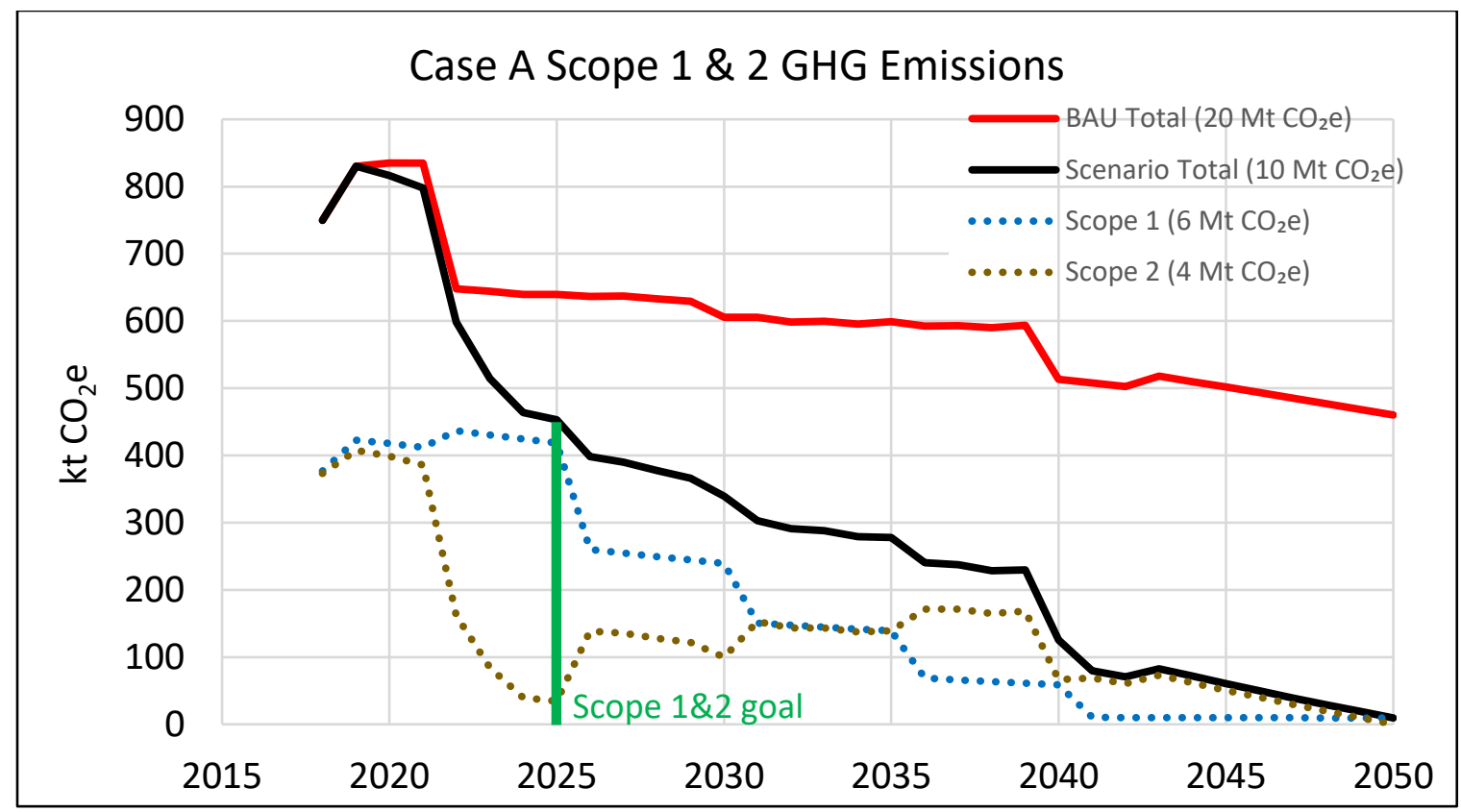

Figure 12: Case A Scope $1 \& 2$ GHG emissions trajectories (individual Scopes and combined $1 \& 2$ ), values in the legend are cumulative 2018-2050 emissions in million metric tons (i.e., the area under each trajectory).

The Case A GHG trajectories for Scope 3 activities are plotted both individually and in total in Figure 13. Some activities have negative emissions values, indicating activities that sequester carbon. Commuting and buildings (upstream) are the only activities that change appreciably over the 2018-2050 period modeled and are primarily responsible for the shape of the total Scope 3 emissions trajectory.

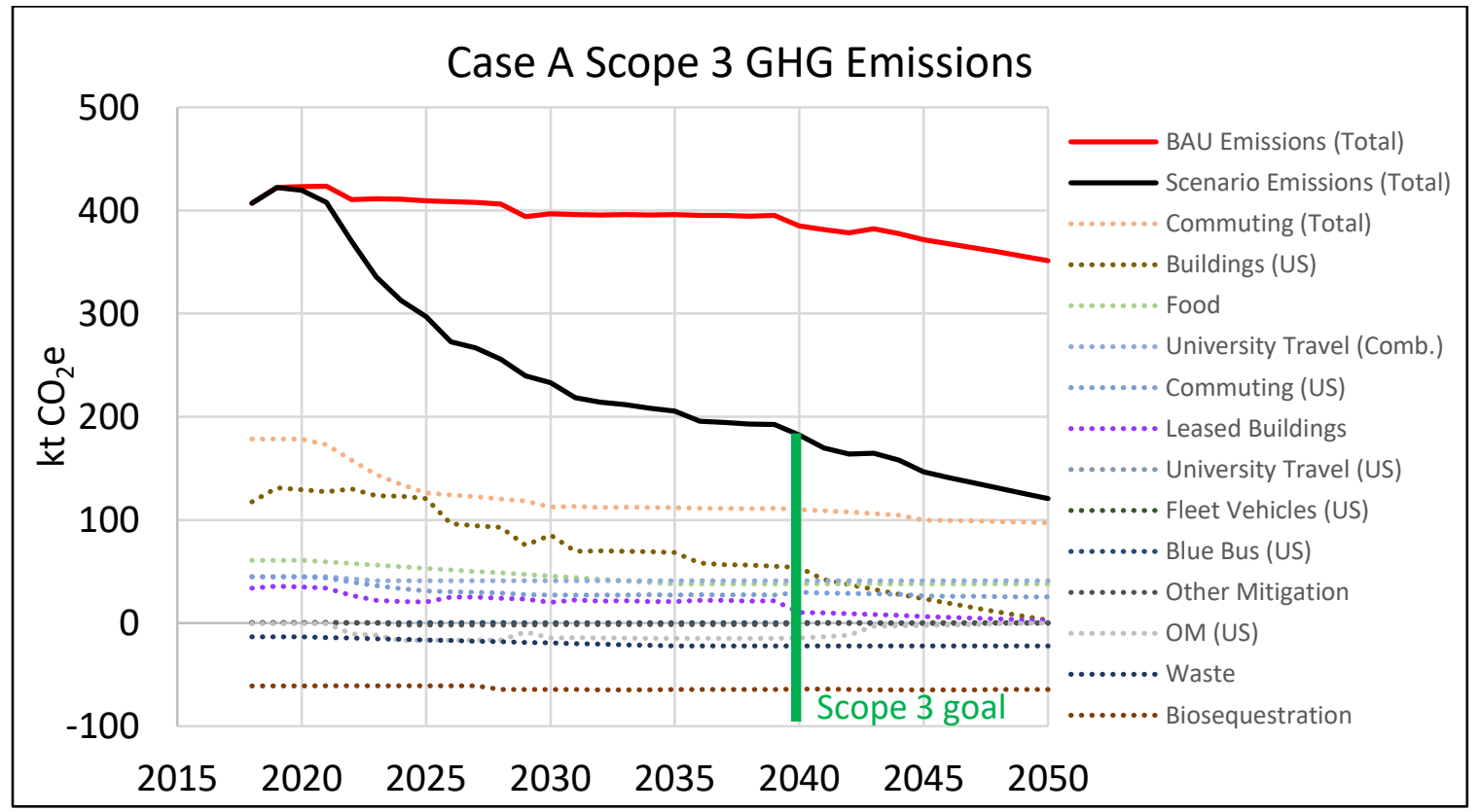

Figure 13: Case A Scope 3 GHG emissions trajectories, 2018-2050 (US = upstream, Comb = combustion) 
An analysis of the magnitude of upstream emissions from fuel and electricity production resulted in Figure 14, which illustrates this component of Scope 3 emissions using both EPA and EDF (or "adjusted Alvarez") EFs. The difference between these trajectories decreases over time as the amount of natural gas used on campus and in electricity production decreases. EDF EFs are the default in the carbon accounting model and are used in all results discussed here.

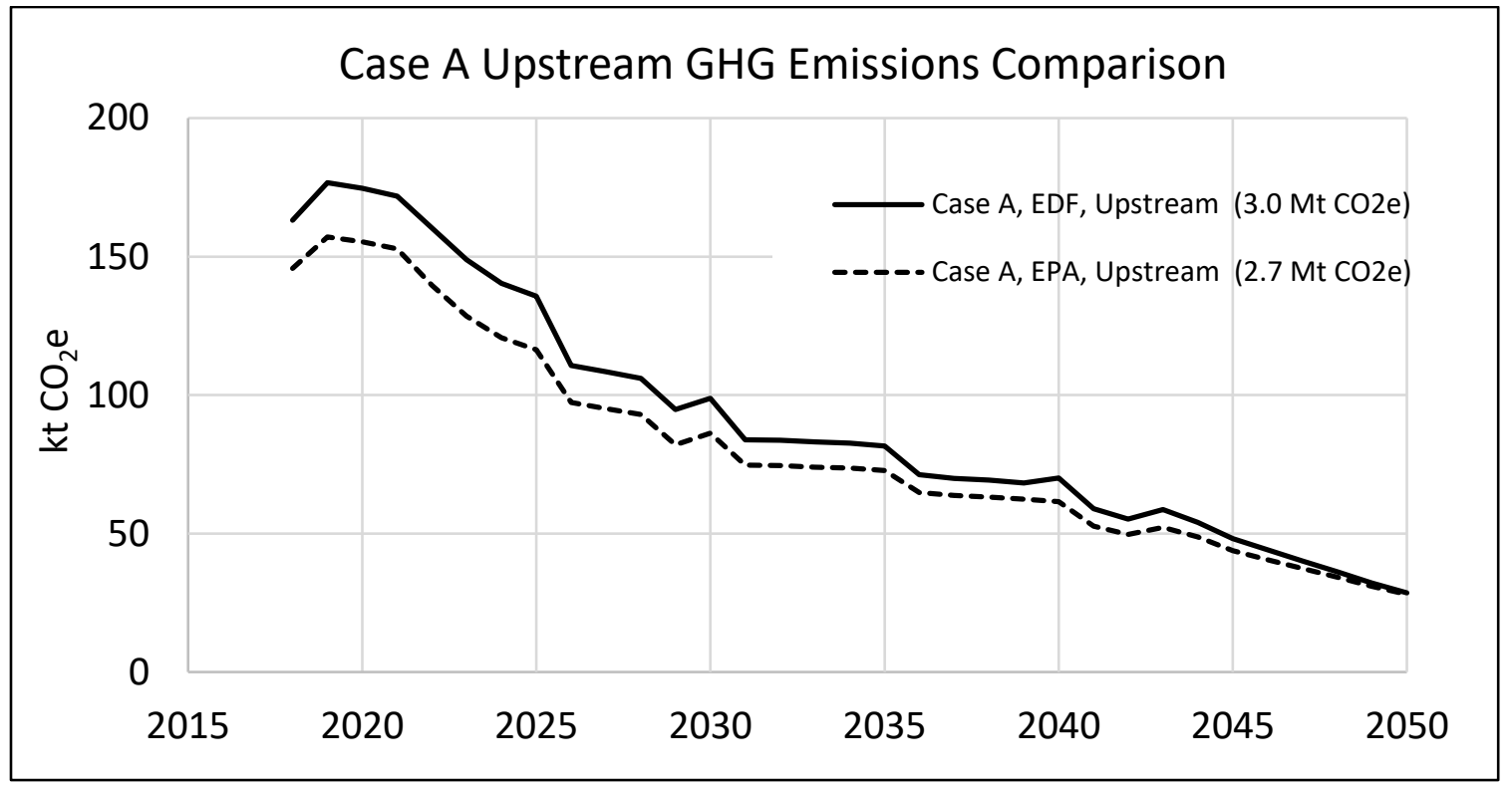

Figure 14: Case A upstream GHG emissions trajectories comparing EF values in GREET from EPA and EDF ("adjusted Alvarez et al."). EDF values are the default in the carbon accounting model.

b. Case B

Case B is the moderate Case and largely follows the recommendations of the IATs and Integral in timing and depth of emission reduction strategies. Case B Scope $1 \& 2$ GHG trajectories are plotted in Figure 15, both individually and as a combined total. 


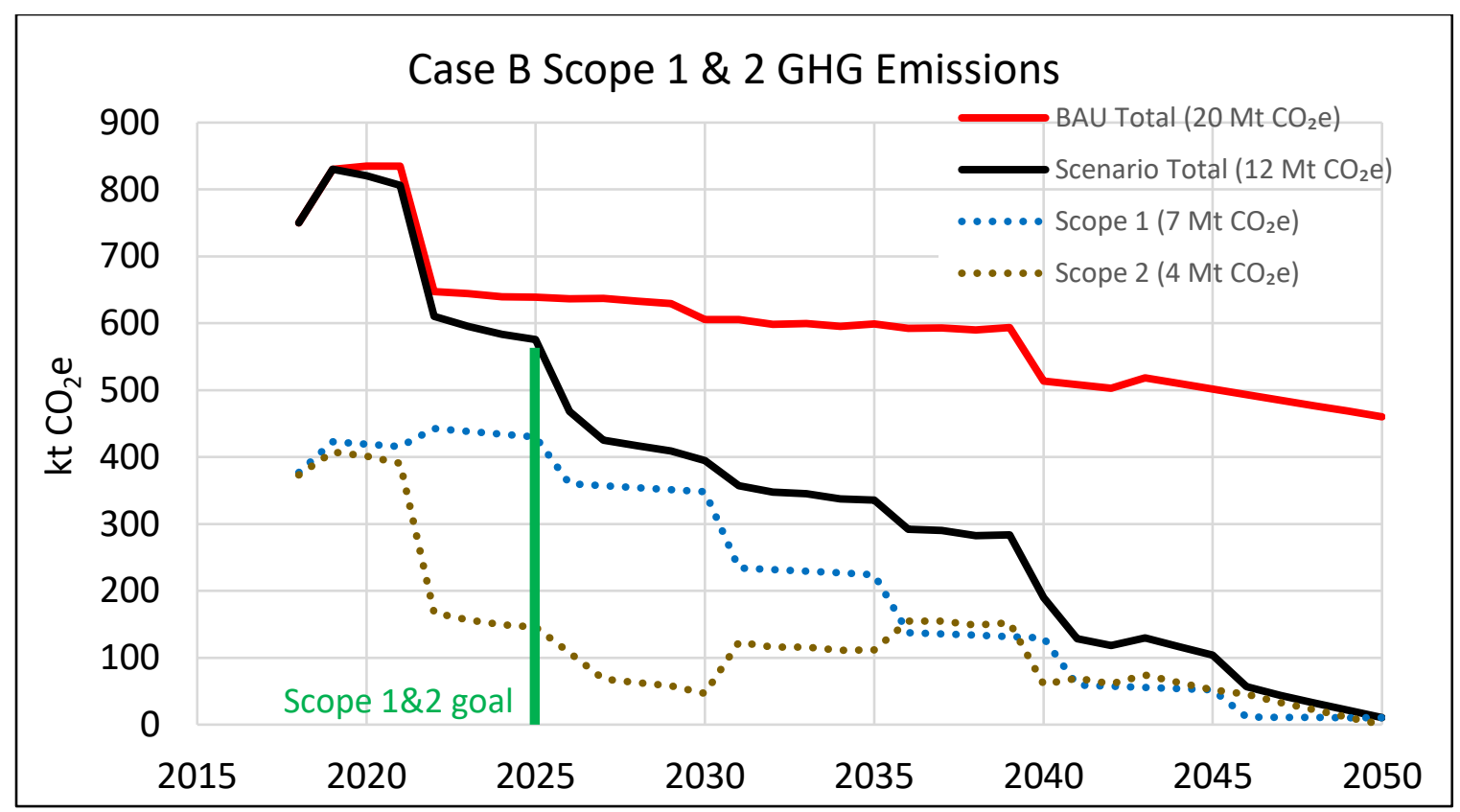

Figure 15: Case B Scope $1 \& 2$ GHG emissions trajectories (individual Scopes and combined $1 \& 2$ ), values in the legend are cumulative 2018-2050 emissions in million metric tons (i.e., the area under each trajectory).

A depiction of the cumulative remaining Case B Scope $1 \& 2$ emissions for a 2025 goal year is shown as the orange shaded area in Figure 16 (the area under the trajectory). Also in this figure are markers showing two versions of the IPCC $1.5^{\circ} \mathrm{C}$ 2030 targets, one a $45 \%$ reduction from 2010 that considers only our baseline and the other a $76 \%$ reduction from 2010 that indicates our per capita share of global 2030 emissions. The IPCC $1.5^{\circ} \mathrm{C}$ global target for 2050 is zero. 
Case B Scope 1 \& 2 GHG Emissions

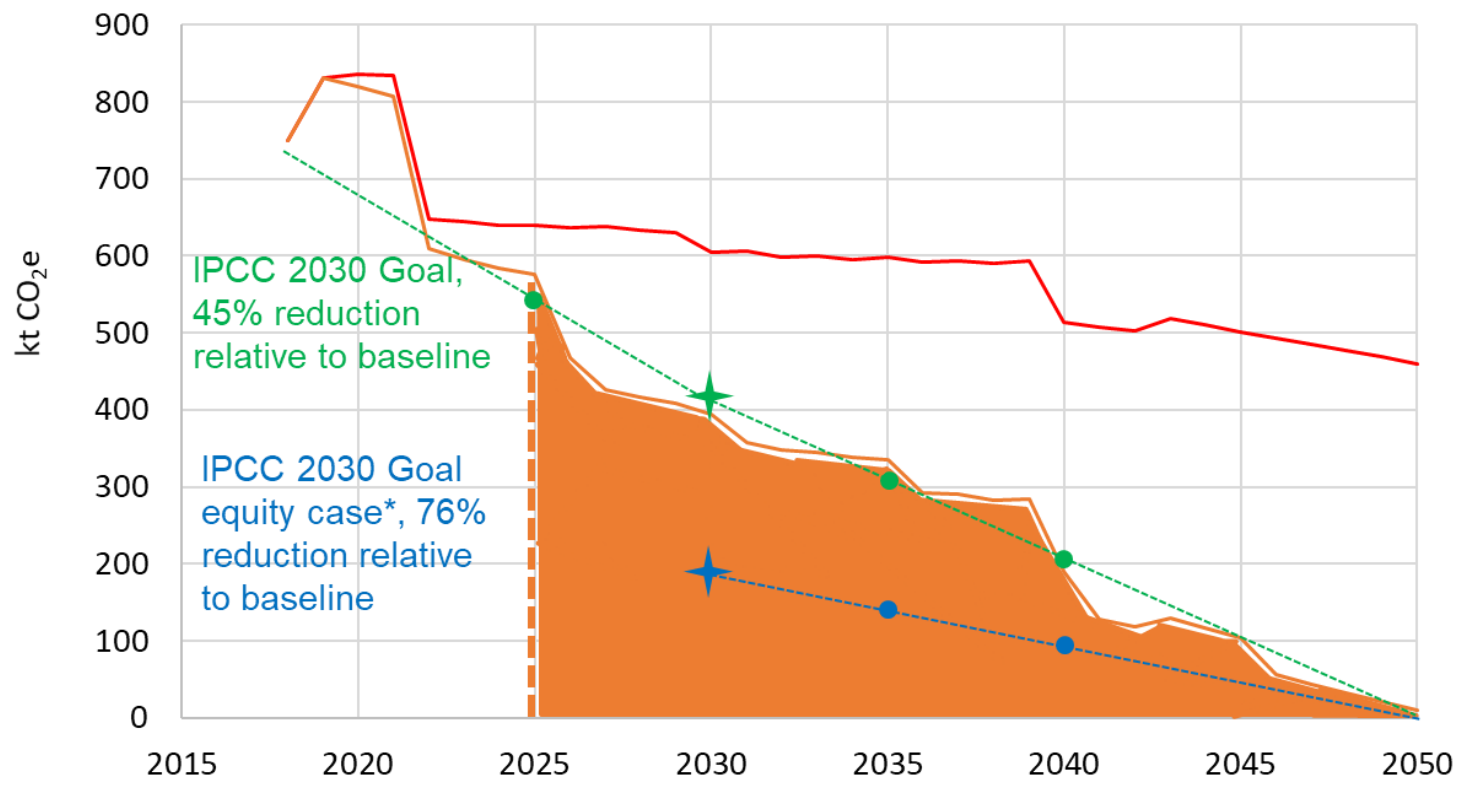

Figure 16: Depiction of cumulative remaining Case B Scope 1\&2 emissions for 2025 goal year. IPCC $1.5^{\circ} \mathrm{C} 2030$ targets also indicated $(45 \%$ starts from UM baseline, $76 \%$ is our per capita share of global emissions) IPCC $1.5^{\circ} \mathrm{C} 2050$ target is zero.

Results from a secondary analysis are plotted in Figure 17, which illustrates the scale of Scope 3 upstream emissions compared with Scope $1 \& 2$. If the PCCN were interested in including upstream Scope 3 emissions from electricity and fuels as part of an emissions reduction commitment, this Figure illustrates the magnitude of that component of Scope 3 emissions. 


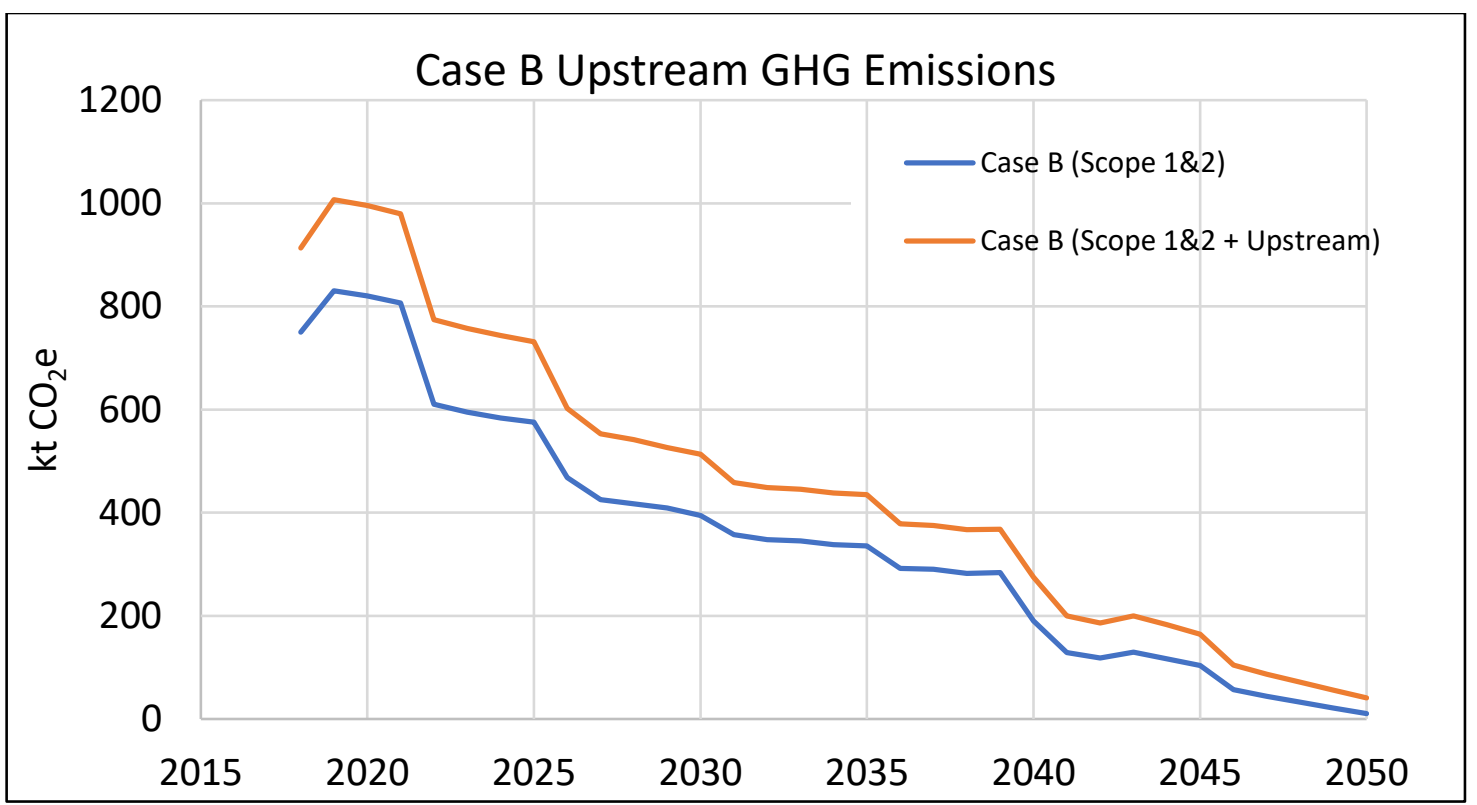

Figure 17: Case B Scope 1 \& 2 GHG emissions trajectories, with and without upstream emissions included (note that upstream emissions are accounted for in Scope 3).

Another secondary analysis examined the Scope $1 \& 2$ trajectory both with and without GHX (Figure 18). Recall that the majority of Scope $1 \& 2$ emissions are related to providing heating, cooling, and electricity for buildings. The trajectory with GHX approaches neutrality in 2050 and the trajectory without GHX remains nearly flat after 2025, illustrating the value of GHX in UM reaching neutrality. 


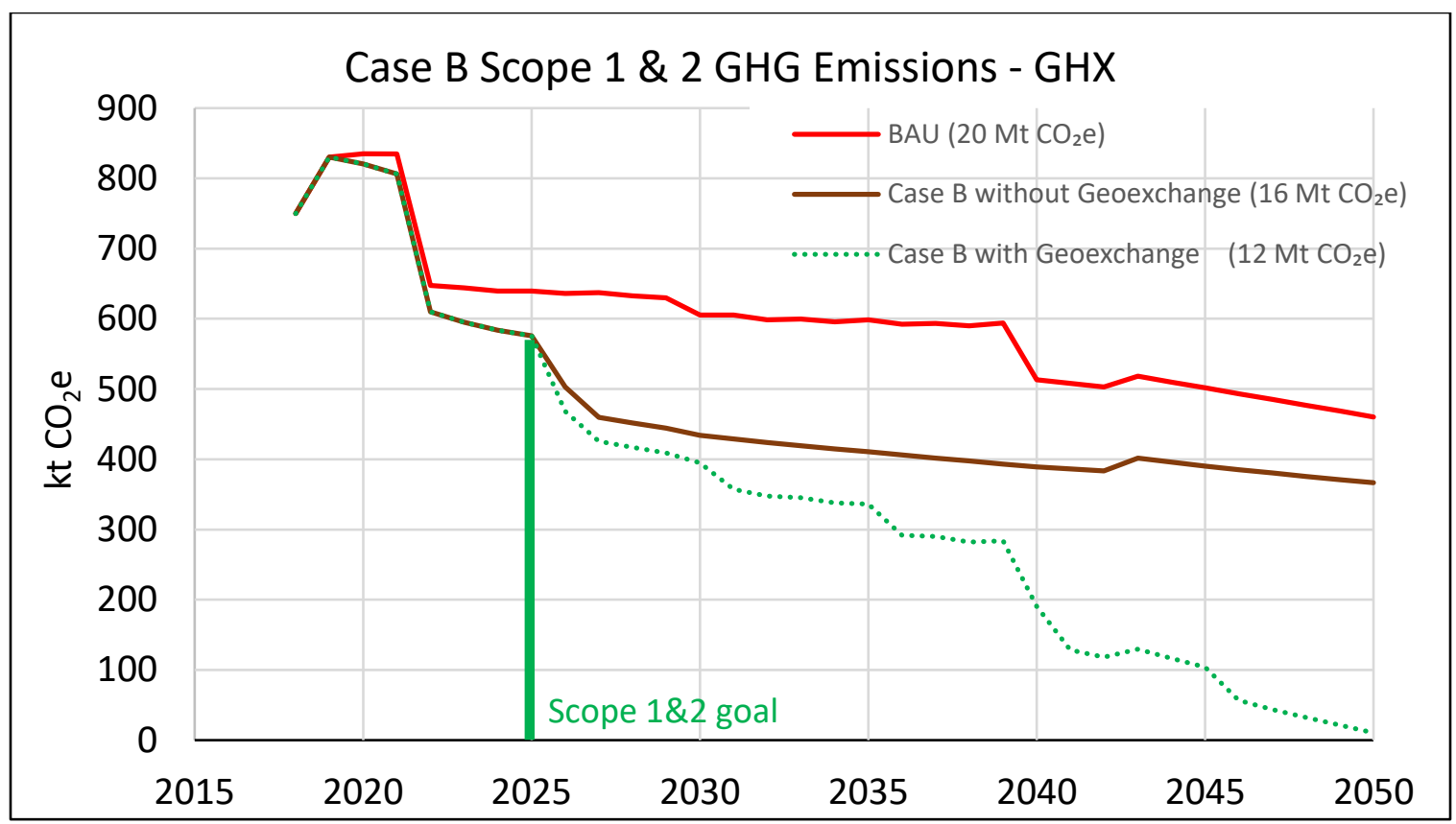

Figure 18: Case B Scope $1 \& 2$ GHG emissions, with and without selection of the Geoexchange system strategy. Values in the legend are cumulative 2018-2050 emissions in million metric tons (i.e., the area under each trajectory).

Case B Scope 3 GHG emissions are plotted in Figure 19, both individually and as a combined total. Some activities have negative emissions values, indicating activities that sequester carbon. As with Case A, commuting and buildings (upstream) are the only activities that change appreciably over the 2018 -2050 period modeled and are primarily responsible for the shape of the total Scope 3 emissions trajectory. 


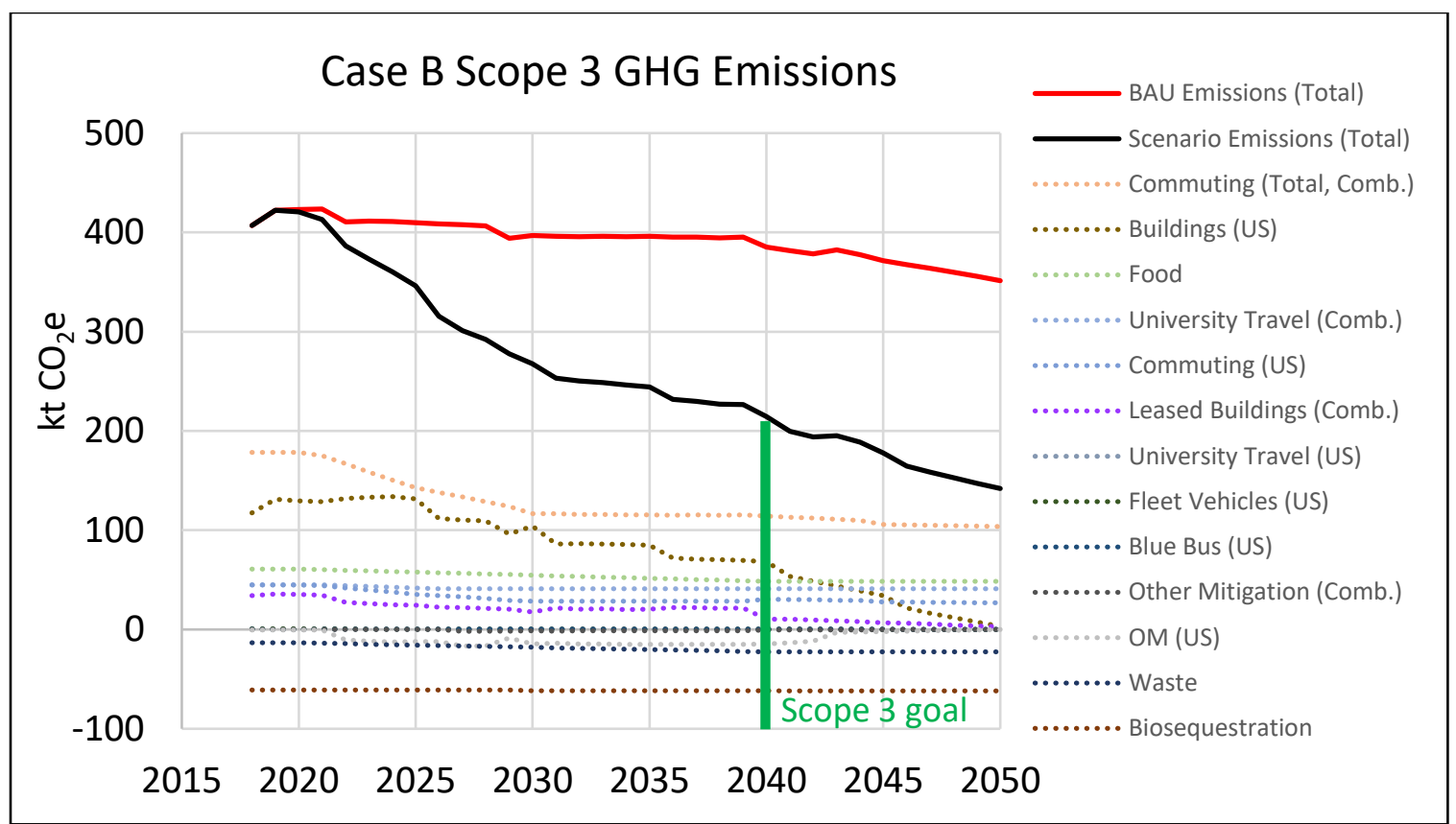

Figure 19: Case B Scope 3 GHG emissions trajectories, total and by activity. Negative values indicate carbon removed from the atmosphere. (US = upstream, Comb = combustion)

\section{c. Case C}

Case $\mathrm{C}$ is the most conservative Case in both degree and timing. Strategies were implemented here more slowly and/or less deeply than recommended by IATs and Integral. Case C Scope $1 \& 2$ GHG trajectories are plotted in Figure 20, both individually and as a combined total. 


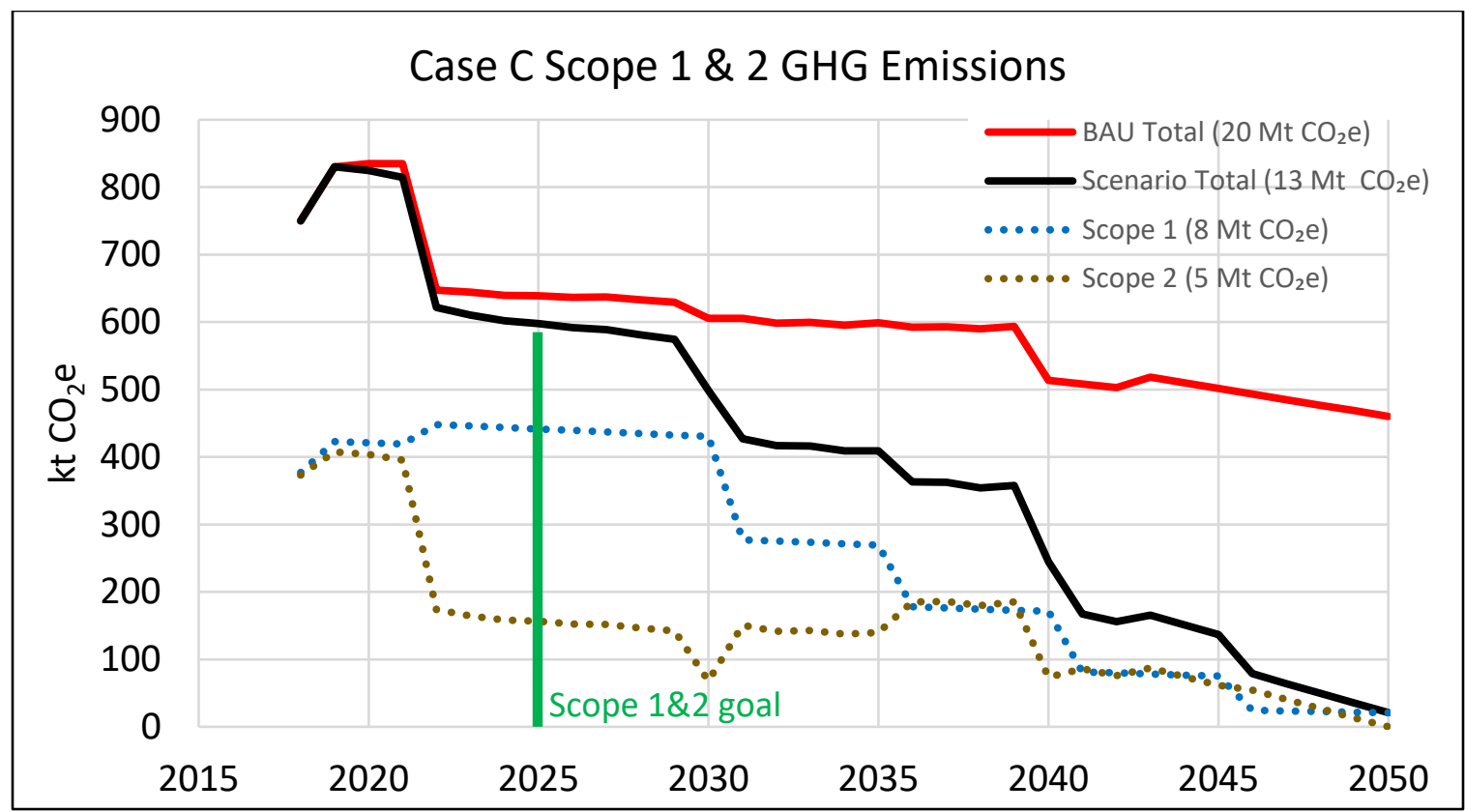

Figure 20: Case C Scope $1 \& 2$ GHG emissions trajectories (individual Scopes and combined 1 \& 2), values in the legend are cumulative 2018-2050 emissions in million metric tons (i.e., the area under each trajectory).

Results from a secondary analysis are plotted in Figure 21, which illustrates the scale of Scope 3 upstream emissions compared with Scope $1 \& 2$ for Case C. This figure is comparable to the Case B plot in Figure 17.

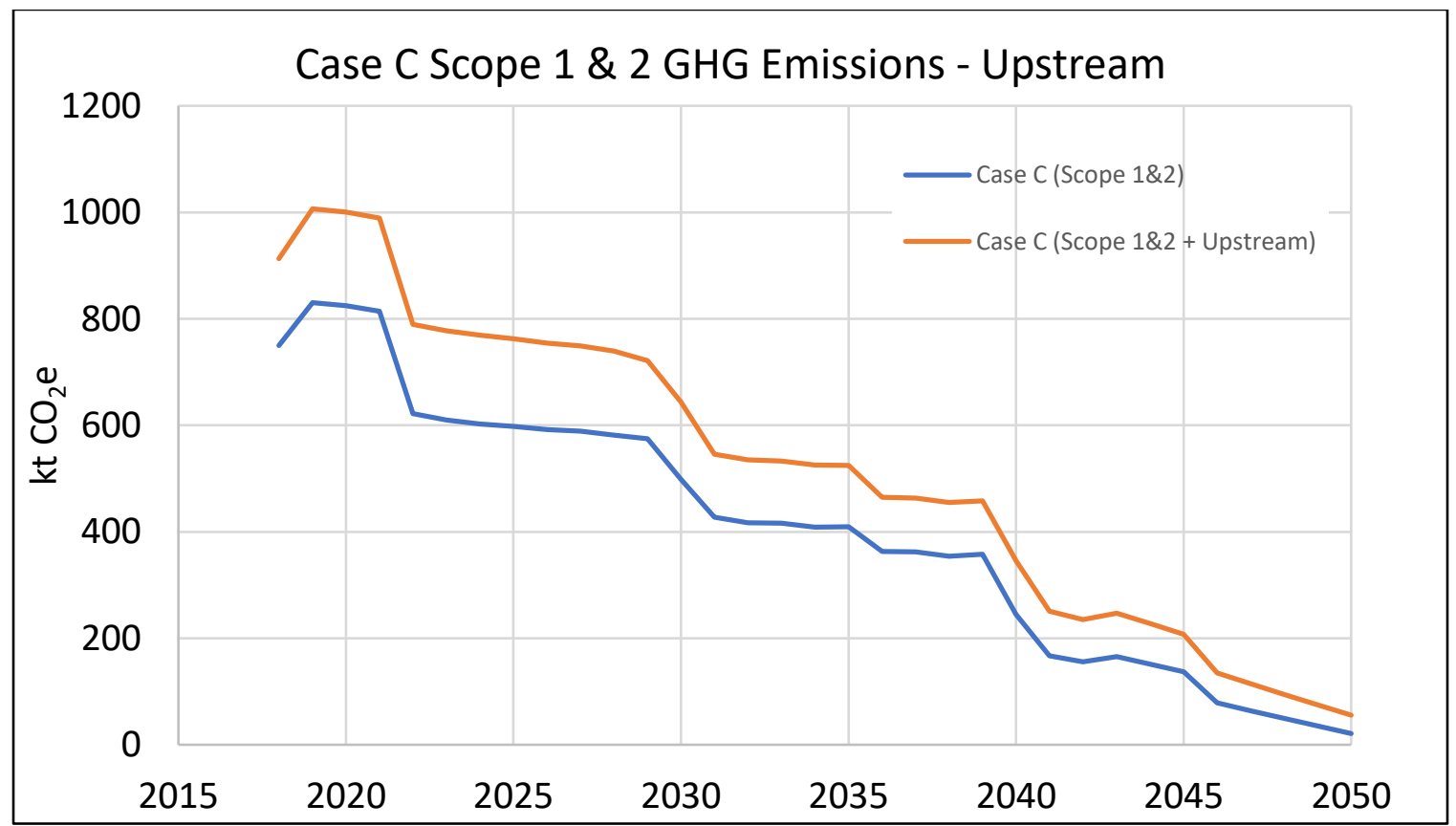

Figure 21: Case C Scope $1 \& 2$ GHG emissions trajectories, with and without upstream emissions included (note that upstream emissions are accounted for in Scope 3). 
Case C Scope 3 GHG emissions are plotted in Figure 22, both individually and as a combined total. Some activities have negative emissions values, indicating activities that sequester carbon. As with Case A and Case B, commuting and buildings (upstream) are the only activities that change appreciably over the 2018-2050 period modeled and are primarily responsible for the shape of the total Scope 3 emissions trajectory.

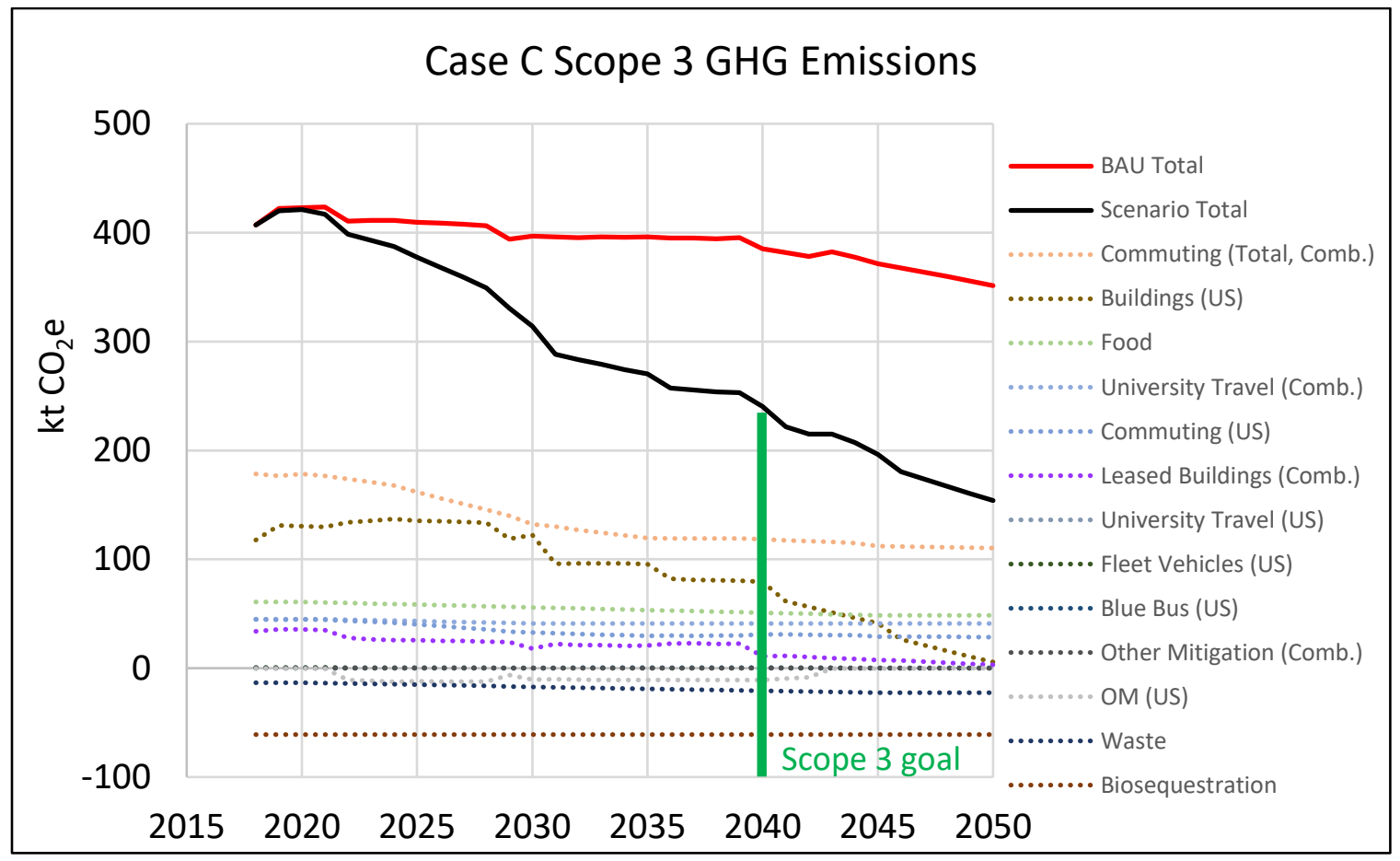

Figure 22: Case C Scope 3 GHG emissions trajectories, total and by activity. Negative values indicate carbon removed from the atmosphere. (US $=$ upstream, Comb $=$ combustion)

d. Case B w/100\% RE

The Scope $1 \& 2$ GHG emissions trajectory for a variant of Case B is shown in Figure 23. This variant has all purchased electricity sourced from zero emissions sources, and the trajectory for this variant markedly different from the standard Case B also shown in Figure 23. The steps in GHX implementation every five years are clearly visible as decreases in GHG emissions. Even though the shift to GHX increases electricity demand, the reduction in emissions from natural gas as GHX is implemented is much larger, especially if the electricity is from renewables (as is the case here). 


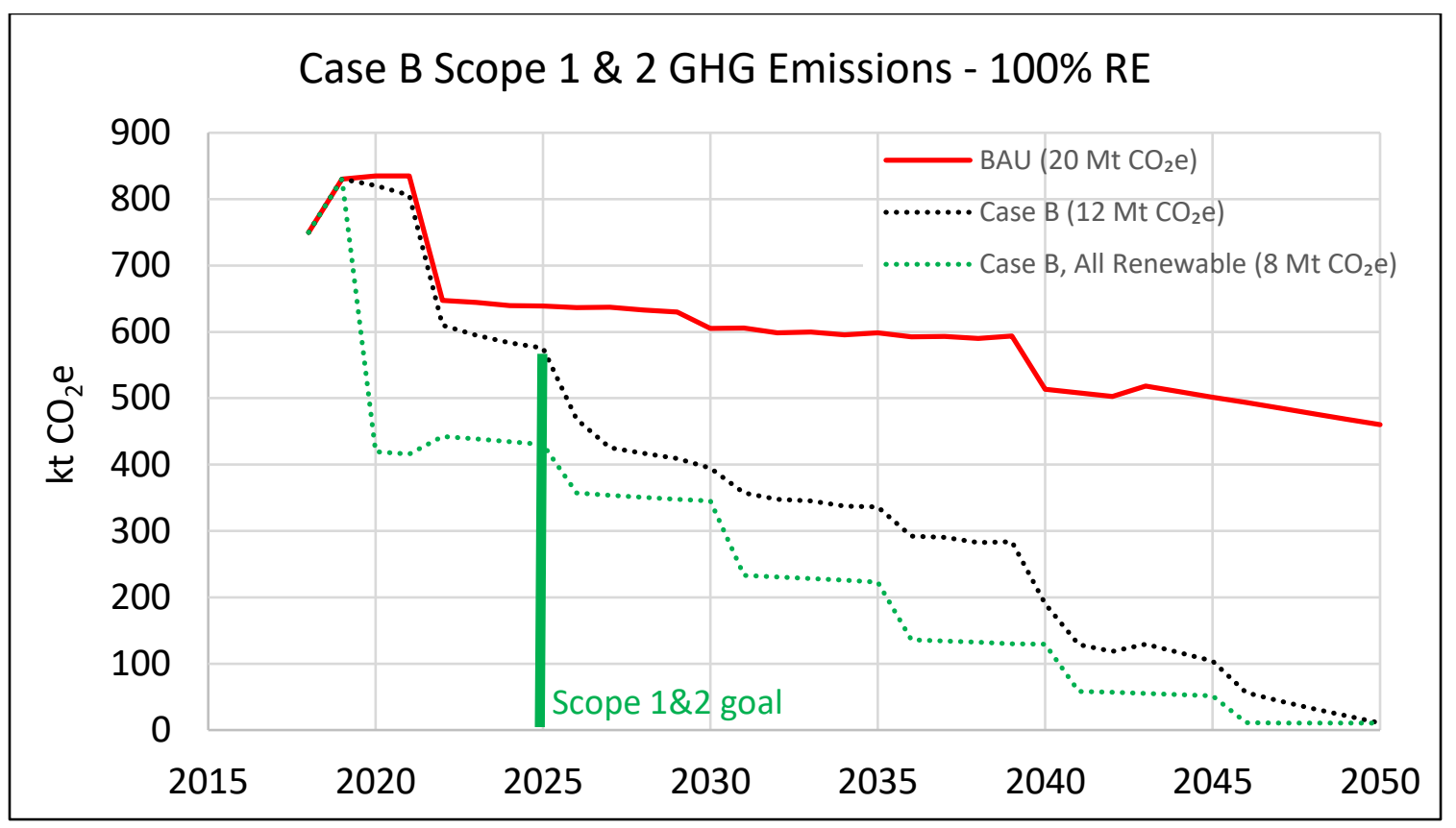

Figure 23: Case B Scope $1 \& 2$ GHG emissions trajectory, with a trajectory that includes $100 \%$ renewable (i.e., zero emissions) purchased electricity.

e. Case comparison

Since it can be difficult to see differences in the Case trajectories in multiple figures, they are collected here in a Scope $1 \& 2$ figure (Figure 24) and a Scope 3 figure (Figure 25), both of which also contain a BAU trajectory, just as all Case figures above have done. All three Case Scope $1 \& 2$ trajectories have generally similar shapes and reach neutrality in 2050, but with a different mass of cumulative emissions. Case A has the lowest cumulative emissions (roughly half of BAU) and Case $\mathrm{C}$ the highest.

A valuable use of figures like this is to estimate the emissions gap that needs to be closed in a carbon neutrality goal year. For example, if UM wished to achieve neutrality in 2030 and was able to implement the emissions reduction strategies to allow it to follow the Case B trajectory, in 2030 it would have approximately $400 \mathrm{kt}$ $\mathrm{CO}_{2} \mathrm{e}$ of emissions to offset via emissions permits or other mechanisms. Calculating the cost of this offsetting is straightforward if the cost per ton of GHG is known (or can be reasonably estimated).

As an illustration of this use of these trajectory plots, we use a carbon cost of $\$ 10 /$ ton $^{7}$ (based on recent RGGI permit cost) and a series of goal years with these plots to calculate cumulative (goal year through 2050) cost of closing the emissions gap. This essentially quantifies the area under an emissions trajectory between the goal year and 2050 (cumulative emissions 2018-2050 are contained in the Figure legends). These

\footnotetext{
${ }^{7}$ Moore, M., Stolper, S., Arvan, T., Rego, B. (2020). An Economic Perspective on Carbon Neutrality at the University of Michigan
} 
results are compiled Table 1 (Scope $1 \&$ 2) and Table 2 (Scope 3). For comparison with emission cost of $\$ 10 /$ ton for RGGI emissions permits, the carbon price of projects on the Clean Development Mechanism registry in 2018 varied from $\$ 0.45 /$ ton to $\$ 59.17 /$ ton $^{8}$.

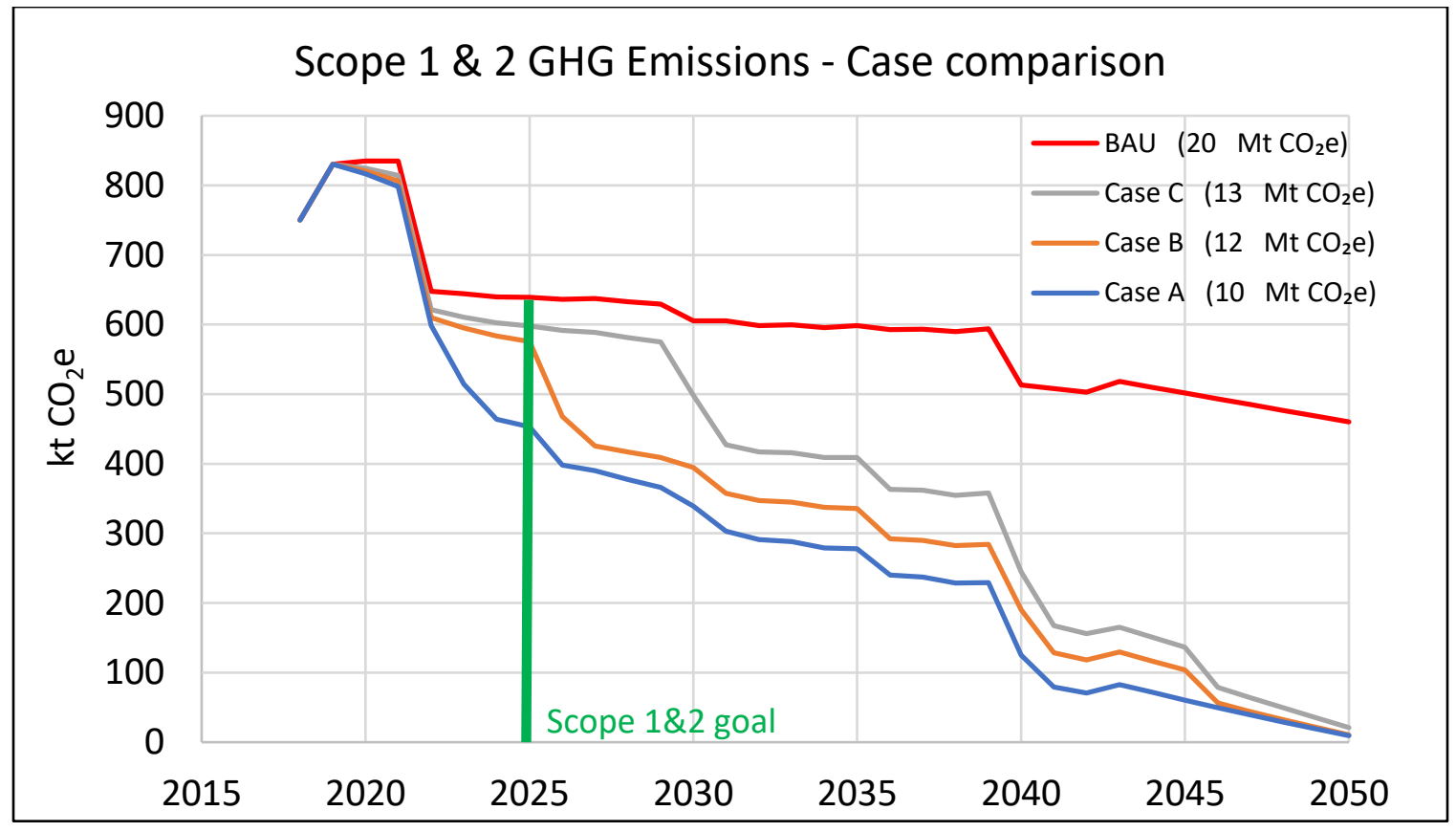

Figure 24: Scope 1 \& 2 GHG emissions trajectories for Case A, B, and C. Values in the legend are cumulative 2018-2050 emissions in million metric tons (i.e., the area under each trajectory).

Table 1: Cumulative (goal year through 2050) Scope $1 \& 2$ emissions gap estimates based on Figure 23 trajectories, in kt and \$ (assuming \$10/ton), for goal years 2025 and 2030.

\begin{tabular}{|l|l|l|}
\hline & \multicolumn{1}{|c|}{$\mathbf{2 0 2 5}$} & \multicolumn{1}{c|}{$\mathbf{2 0 3 0}$} \\
\hline Case A & $\begin{array}{l}5 \mathrm{Mt} \mathrm{CO}_{2} \mathrm{e} \\
\$ 50 \mathrm{M}\end{array}$ & $\begin{array}{l}3.4 \mathrm{Mt} \mathrm{CO} \mathrm{CO}_{2} \\
\$ 34 \mathrm{M}\end{array}$ \\
\hline Case B & $\begin{array}{l}6.5 \mathrm{Mt} \mathrm{CO} \mathrm{e} \\
\$ 65 \mathrm{M}\end{array}$ & $\begin{array}{l}4.2 \mathrm{Mt} \mathrm{CO} \mathrm{CO}_{2} \\
\$ 42 \mathrm{M}\end{array}$ \\
\hline Case C & $\begin{array}{l}8.2 \mathrm{Mt} \mathrm{CO} \mathrm{e} \\
\$ 82 \mathrm{M}\end{array}$ & $\begin{array}{l}5.3 \mathrm{Mt} \mathrm{CO} \mathrm{CO}_{2} \mathrm{e} \\
\$ 53 \mathrm{M}\end{array}$ \\
\hline
\end{tabular}

${ }^{8}$ Carbon offset market progresses during coronavirus, https://www.ft.com/content/e946e3bd-99ac-49a8-82c9e372a510e87c 
Trajectories for all three Cases' Scope 3 GHG emissions are displayed in Figure 25. Purchased goods and services are not included in these trajectories. These trajectories follow the same general pattern as for Scope $1 \& 2$ emissions above, but the main difference is that none of these trajectories comes close to neutrality by 2050 . Though many of the activities causing these emissions are not under the direct control of the University (hence their being labeled 'indirect' emissions), there are strategies many outlined by the IATs - that the University can implement to reduce these emissions. And as individuals and organizations start to pay more attention to reducing the emissions caused by their own activities, UM Scope 3 emissions will also decline.

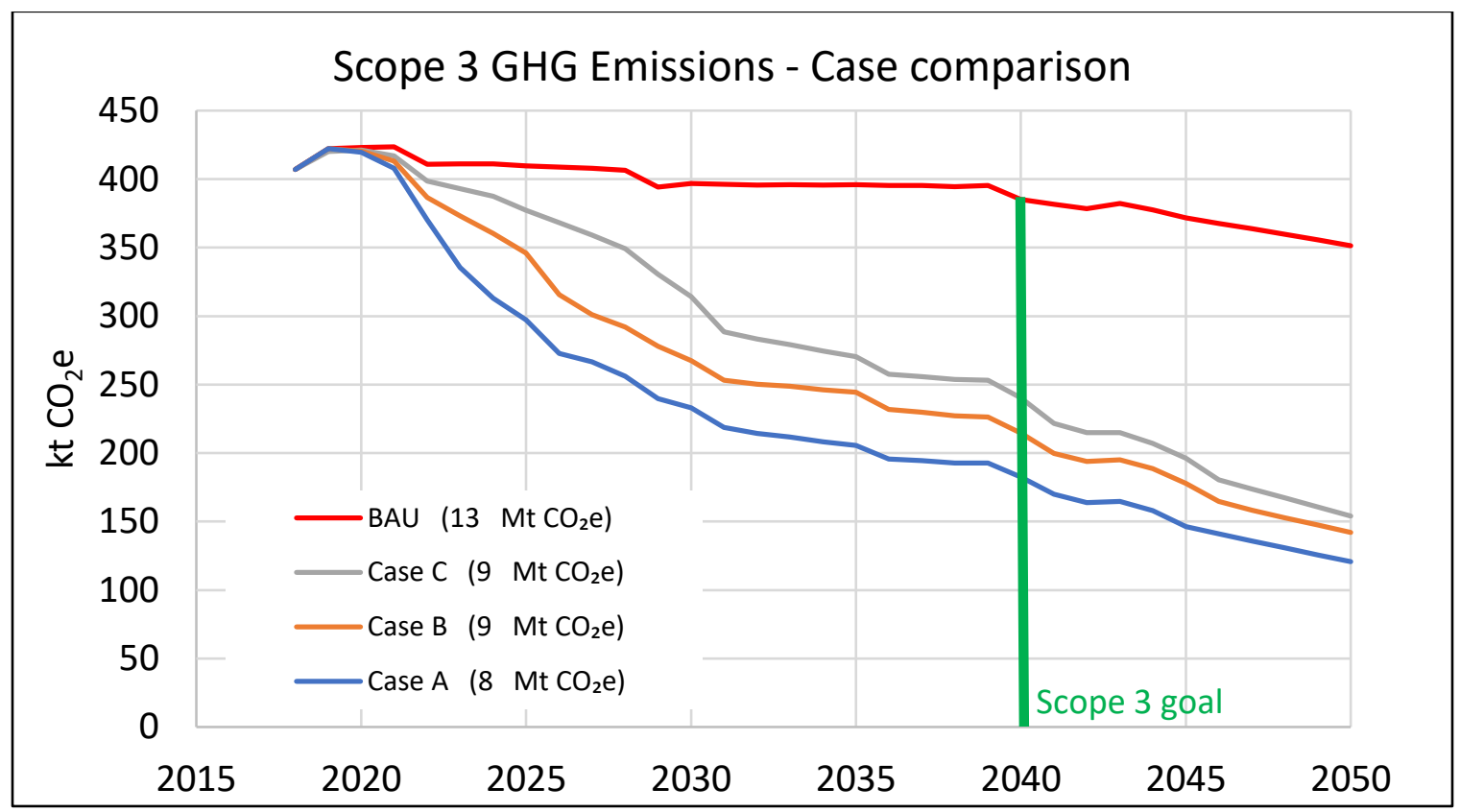

Figure 25: Scope 3 GHG emissions trajectories for Case A, B, and C (not including purchased goods and services). Values in the legend are cumulative 2018-2050 emissions in million metric tons (i.e., the area under each trajectory).

Table 2: Cumulative (goal year through 2050) Scope 3 emissions gap estimates based on Figure 24 trajectories, in kt and \$ (assuming \$10/ton), for goal years 2025, 2030, and 2035.

\begin{tabular}{|l|l|l|l|}
\hline & 2025 & 2030 & 2035 \\
\hline Case $\mathrm{A}$ & $5 \mathrm{Mt} \mathrm{CO}_{2} \mathrm{e}$ & $3.7 \mathrm{Mt} \mathrm{CO} 2 \mathrm{e}$ & $2.6 \mathrm{Mt} \mathrm{CO}_{2} \mathrm{e}$ \\
& $\$ 50 \mathrm{M}$ & $\$ 37 \mathrm{M}$ & $\$ 26 \mathrm{M}$ \\
\hline Case B & $6 \mathrm{Mt} \mathrm{CO}_{2} \mathrm{e}$ & $4.4 \mathrm{MtCO}_{2} \mathrm{e}$ & $3 \mathrm{Mt} \mathrm{CO}_{2} \mathrm{e}$ \\
& $\$ 6 \mathrm{M}$ & $\$ 44 \mathrm{M}$ & $\$ 30 \mathrm{M}$ \\
\hline Case $\mathrm{C}$ & $6.6 \mathrm{MtCO} \mathrm{CO}_{2} \mathrm{e}$ & $5 \mathrm{Mt} \mathrm{CO} \mathrm{CO}_{2} \mathrm{e}$ & $3.4 \mathrm{MtCO}_{2} \mathrm{e}$ \\
& $\$ 66 \mathrm{M}$ & $\$ 50 \mathrm{M}$ & $\$ 34 \mathrm{M}$ \\
\hline
\end{tabular}




\section{Observations \& Recommendations}

There are several observations that can be made based on building and exercising the carbon accounting model. These observations inform the UM neutrality goal setting and decarbonization planning processes.

The first observation is that the bulk of Scope $1 \& 2$ emissions result from supplying heating, cooling, and electricity to buildings, primarily using natural gas. Reducing and eliminating these emissions is a two-step process of first electrifying these activities and then of meeting the resulting electricity demand with zero emissions electricity.

Given that a substantial fraction of UM's electricity is currently generated from GHG emitting fuels, a second observation is that there are also large emissions reduction benefits to be had by decarbonizing electricity in advance of fully electrifying buildings, especially since the switch to GHX will take approximately 20 years.

A third observation is that implementing a similar "electrify and decarbonize" strategy applies to UM's vehicle fleet. This observation also applies to commuting and University travel, but this strategy may be more challenging to apply to those activities, though both of those activities are susceptible to other emissions reduction strategies (such as telepresence).

The effects of technological progress are not included in the carbon accounting model, so as effort is applied to reducing emissions across the planet all the trajectories illustrated here are likely to approach neutrality more quickly.

We also have a number of more specific recommendations arising from our carbon accounting modeling work, some of which reinforce IAT recommendations.

In relation to Scope $1 \& 2$, we recommend that UM prioritize building energy demand reductions based on OCS estimates and SmithGroup EAT work. An informal analysis conducted by OCS in support of our modeling work indicated the significant energy demand reduction potential of building energy conservation measures at UM. This work would logically be coordinated with building refitting in preparation for GHX implementation.

In relation to Scope 3 emissions, Our recommendations are focused on improving the quality and availability of data necessary to accurately estimate emissions. We recommend revising UM procurement systems to include GHG data in the purchasing process and working with vendors and suppliers to provide this information about their products and services. Accurate estimates of Scope 3 emissions depend on these data, which are necessary for goal setting, measurement, and tracking. We also recommend adding GHG reporting to University travel accounting systems for the same reason. 
The other two activities where data could be improved are waste and food, so we recommend also that UM accounting systems provide for the measurement and inclusion of waste generation and food purchasing data. 


\section{Appendix A Case descriptions}

\section{Case A}

\section{Buildings}

1. PV and GHX strategies are implemented, on all campuses

- starting in $2021 \mathrm{GHX}$, starting in 2022 all PV

- End dates range from 2026 to 2041, 2023 all PV

- GHX phasing by District:

\begin{tabular}{|l|l|l|l|l|l|}
\hline District & '21-'26 & '26-'31 & '31-'36 & '36-'41 & '41-'46 \\
\hline Central/Med & & & & & \\
\hline NC & & & & & \\
\hline Ross & & & & & \\
\hline EM & & & & & \\
\hline Dearborn & & & & & \\
\hline Flint & & & & & \\
\hline
\end{tabular}

2. Greater thermal and non-thermal building energy demand reduction

- $15 \%$ reduction over $2019-2030$

- $1 \%$ annual reduction from 2031 - 2050

3. Implement ground-mount PV on North Campus early

- $2022-2024,75$ acres

\section{Transportation}

1. Electrify buses and fleet vehicles as soon as possible (given available data)

- Bus Fleet 2021 - 2025

- A2 Vehicle Fleet

LLDT, 2022 - 2025

HLDT, 2022 - 2024

LHDDE, 2025 - 2027

MHDDE, 2025 - 2027

HHDDE, $2021-2033$

- Flint Vehicle Fleet

LLDT, 2022 - 2025

HLDT, 2022 - 2025

- Dearborn Vehicle Fleet

LLDT, 2022 - 2025

HLDT, 2022 - 2025 
2. Reduce university travel quickly

- $10 \%$ from $2021-2023$

3. Implement commuting policies and infrastructure improvements early

- Parking, 2021-2023

- Rideshare, 2021-2023

- Cycling, 2021-2023

- Universal Access, 2021-2021

- Electrification $<20$ miles, $20 \%$ from $2022-2030$

- Electrification $>=20$ miles, $20 \%$ from $2022-2030$

- New Student Housing, 2022 - 2025

- New F\&S Housing, 2022 - 2025

\section{Food, Waste \& Biosequestration}

1. Quick and significant reduction of all meat and dairy consumption

- $50 \%$ reduction of meat, $2021-2035$

- $50 \%$ replacement of all dairy with soy alternative, 2021 - 2035

2. High diversion of compostable and recyclable waste from landfill

- Halve food waste, triple food donations, no recyclable or compostable waste to landfills, 2021 - 2035

- Alter \& enhance moderate portion of university owned land to increase carbon sequestration capability

- Convert 89 acres from ag. land to wetland by 2028

- Enhance 127 acres of wetland (2028) and 1000 acres of forest (2031)

- Purchase an additional 341 acres of tree canopy land by 2038 and 433 acres of no mow fescue starting in 2021 by 2035

- Add 25 acres of green roofs (by 2038), bioswales and native grasslands (both by 2035, starting in 2021)

\section{Other Carbon Reduction Strategies}

1. DTE PPA, $2022-2042$

2. Purchase RECS, $540,000 \mathrm{kWh}$ from $2019-2050$ 


\section{$\underline{\text { Case B }}$}

\section{Buildings}

1. PV and GHX strategies are staggered, on all campuses

- Start dates ranging from 2021 to 2036 for GHX, 2025 for all PV

- End dates ranging from 2031 to 2046 for GHX, 2026 for all PV

- GHX phasing by District:

\begin{tabular}{|l|l|l|l|l|l|}
\hline District & '21-'26 & '26-'31 & '31-'36 & '36-'41 & '41-'46 \\
\hline Central/Med & & & & & \\
\hline NC & & & & & \\
\hline Ross & & & & & \\
\hline EM & & & & & \\
\hline Dearborn & & & & & \\
\hline Flint & & & & & \\
\hline
\end{tabular}

2. Moderate thermal and non-thermal building energy demand reduction, all campuses

- $10 \%$ reduction over $2019-2030$

- $0.75 \%$ annual reduction from $2031-2050$

3. Implement ground-mount PV on North Campus, delayed

- $2025-2027,75$ acres

\section{Transportation}

1. Electrify buses and fleet vehicles at a moderate pace (given available data)

- Bus Fleet $2021-2029$

- A2 Vehicle Fleet

LLDT, 2022 - 2026

HLDT, $2022-2026$

LHDDE, 2026 - 2030

MHDDE, 2026 - 2030

HHDDE, $2021-2036$

- Flint Vehicle Fleet

LLDT, 2022 - 2025

HLDT, 2022 - 2025

- Dearborn Vehicle Fleet

LLDT, 2022 - 2025

HLDT, 2022 - 2025

2. Reduce university travel at a moderate pace

- $10 \%$ from $2021-2030$ 
3. Implement commuting policies and infrastructure improvements gradually

- Parking, 2021-2025

- Rideshare, 2021-2025

- Cycling, 2021-2025

- Universal Access, 2021-2023

- Electrification $<20$ miles, $15 \%$ from $2022-2030$

- Electrification $>=20$ miles, $15 \%$ from $2022-2030$

- New Student Housing, 2022 - 2030

- New F\&S Housing, 2022 - 2030

\section{Food, Waste \& Biosequestration}

1. Significant reduction of red meat and milk consumption

- Red meat by $50 \%$ from $2021-2040$

- $50 \%$ of milk by soymilk, $2021-2040$

2. Diversion of compostable and recyclable waste from landfill

- $2021-2040$, double donations (food), no recyclable or compostable waste to landfill

3. Enhance some university owned land to increase carbon sequestration capability

- Forest (1000 acres) + Wetlands (127 acres) enhanced by 2030

\section{Other Carbon Reduction Strategies}

1. DTE PPA, $2022-2042$

2. Purchase RECS, $540,000 \mathrm{kWh}$ from $2019-2050$ 


\section{$\underline{\text { Case C }}$}

\section{Buildings}

1. PV and GHX strategies are implemented slowly, on all campuses

- Start dates ranging from 2026 to 2036 for GHX, 2029 for all PV

- End dates ranging from 2036 to 2046 for GHX, 2030 for all PV

- GHX phasing by District:

\begin{tabular}{|l|l|l|l|l|l|}
\hline District & '21-'26 & '26-'31 & '31-'36 & '36-'41 & '41-'46 \\
\hline Central/Med & & & & & \\
\hline NC & & & & & \\
\hline Ross & & & & & \\
\hline EM & & & & & \\
\hline Dearborn & & & & & \\
\hline Flint & & & & & \\
\hline
\end{tabular}

2. Low thermal and non-thermal building energy demand reduction, all campuses

- $5 \%$ reduction over $2019-2030$

- $0.5 \%$ annual reduction from $2031-2050$

3. No ground-mount $P V$ on North Campus

\section{Transportation}

1. Electrify buses and fleet vehicles slowly (given available data)

- Bus fleet, start in 2021 - end in 2034

- A2 Vehicle Fleet

LLDT, 2021 - 2030

HLDT, 2021 - 2030

LHDDE, 2027 - 2035

MHDDE, 2027 - 2035

HHDDE, 2021 - 2030

- Flint Vehicle Fleet

LLDT, 2027 - 2030

HLDT, 2027 - 2030

- Dearborn Vehicle Fleet

LLDT, 2027 - 2030

HLDT, 2027 - 2030

2. Reduce university travel slowly

- $10 \%$ from $2021-2030$ 
3. Implement commuting policies and infrastructure improvements slowly

- Parking, 2021-2030

- Rideshare, 2021-2030

- Cycling, 2021-2030

- Universal Access, 2021-2025

- Electrification $<20$ miles, $10 \%$ from 2022 - 2030

- Electrification $>=20$ miles, 10\% from $2022-2030$

- New Student Housing, 2025 - 2035

- New F\&S Housing, 2025 - 2035

\section{Food, Waste \& Biosequestration}

1. Reduce Beef and Milk consumption slowly

- Beef by $50 \%$ from $2021-2045$

- Milk by $50 \%$ from 2021 - 2045

2. High diversion of compostable and recyclable waste from landfill

- 2021 - 2045, double donations (food), no recyclable or compostable waste to landfill

3. Maintain lands, do not enhance for increased carbon sequestration

\section{Other Carbon Reduction Strategies}

1. DTE PPA, $2022-2042$

2. Purchase RECS, $540,000 \mathrm{kWh}$ from $2019-2050$ 


\section{Appendix B Model assumptions \& calculation details}

\section{Buildings (by Excel model sheet)}

1. Master EF

a. EF for heating and electricity sources

i. DTE, Consumers, CPP, Boilers, LPG, HFO, etc.

b. Upstream for CPPE used unit conversions and efficiency

c. Remaining EF calculated using GREET EF

d. Dearborn, Flint, and Hoover steam plants are all the same, assume large steam turbine, also NCRC (basis)

e. Orange means assumed value (back casted)

f. Switch for Consumers and DTE combustion emissions to go linearly to zero or stay flat from 2040 to 2050

2. Fuel upstream

a. Has EF for CPPe

b. Energy input and energy output data from OCS

c. Allocated based on energy output

d. Efficiency factor is built in

e. All green values taken from GREET

f. Upstream values using fuel mix from DTE and Consumers then with GREET for fuel EF

g. Orange shading means assumption

h. Switch for taking upstream to zero for DTE and CONS is in this sheet

i. This is where the GWP switch for buildings is

3. Building Strategies

a. Reduce thermal demand strategies

i. If these are yes and you input a reduction value then make sure thermal reduction for the GHX is zero, since the reduction is built in to the GHX already

ii. This allows you to evaluate savings for emissions reduction without GHX

b. Building standards strategies are non-functional

i. If that gets included that would go to the BAU tab

c. Install PV on off-campus buildings, if you say yes, you have to go to the buildings raw data tab and select the kWh that you want it to produce, rows $295-298$

4. Other Mitigation (OM) strategies

a. Has the input for all other mitigation strategies (e.g., building a solar farm in Arizona)

b. OM results are by campus

c. Other RECs and PPAs offset DTE and CONS

d. Offsite solar investment offsets grid local to site, currently the only choice we have is Tucson, this is built into the EF sheet (TEP - Tucson Electric Power) 
5. Building Results

a. Takes the input from all strategies and all the selections

b. IF statements show what data are being pulled from the calculation sheets

c. Darker line is always BAU

d. Lighter line is the Scenario line

e. There are some calculation tabs for individual strategies

f. The sheet where the strategy calculations exist are called out in the Building strategies sheet

g. Summary table is the top, all calculations happen below that (reduction values live here)

h. Base case includes no reduction in thermal currently

i. If you select a thermal reduction and GHX, the reduction values will be combined and exist in the Combined demand and supply side reductions

j. All linked emissions to our overall emissions sheets link to the Building results sheet

6. Buildings Raw Data

a. Some calculations exist here

b. Should have sources or comments for most values

i. PPA details are here

c. This would be input tab data (Advanced Building Input \& Raw Data)

7. EF sheet

a. Linked to master EF sheet

b. Exists because modeling was being done separately, nothing here gets changed

8. Buildings Baseline

a. Summary on top

b. We are accounting for steam, electricity, and natural gas

c. Within steam and within electricity there are different sources and end uses

i. Steam for heating, steam for cooling

ii. Electricity thermal, electricity non thermal, electricity from co-gen, electricity from PV, electricity from utility, RECs, Fuel oil, LPG

1. The only thing that doesn't come from Integral is co-gen, this comes from OCS

2. Electricity from utility is back calculated (subtract out co-gen from total)

d. Emissions calculations

i. Steam - unit conversions to go from kbtu to CCF, go from steam consumption to steam output ( $95 \%$ efficiency) to NG required to get that steam (use efficiency of plant) then multiply by EF, steam for CPP uses NG and fuel oil, so we assumed a consistent NG to FO ratio through 2050, $99 \% \mathrm{NG}$ - once you have energy required to generate steam, that ratio is used to determine how much energy comes from $\mathrm{NG}$ and how much comes from FO, then use energy intensity of fuel, then EF

ii. Integral $\mathrm{NG}$ values are at the consumption value 
iii. Co-gen uses co-gen emissions factor, utilities use utility EF

e. Leased properties are Scope 3

f. Primary fuel calculations are taking steam values back to fuel volume

i. This is used for BAU

g. Section 5. Is scope $3-T \& D$

i. $5 \%$ losses

ii. Emissions related to our consumption

9. Buildings BAU

a. Trajectory is based on extrapolation of historical data

i. We have data in terms of purchased electricity \& NG

ii. We calculate all the NG we consume for 2018

iii. Note: Fuel oil is same as HFO

b. We use HHV, this includes heat from condensation of exhaust, for stationary sources

i. LHV are used in transportation

c. Growth projections

i. Buildings in 2018 includes sq. $\mathrm{ft}$. for CIT and Ford Robotics, we have increased sq. $\mathrm{ft}$ data through 2023, we assume no growth past that

1. Adjustment for $\mathrm{NG}$ and electricity to baseline

a. Integral reported that we have $562 \mathrm{M} \mathrm{kWh}$

b. UM reported $599 \mathrm{M} \mathrm{kWh}$

c. Used historical purchase values to calculate the energy use intensity

d. For example, we have purchased electricity and sq. ft. for that year, you get energy use intensity for that year's purchased electricity from historic data

e. If we want to project we can forecast linearly or use power function

i. NG follows power curve to avoid going negative

ii. Linear fit for all electricity except Dearborn

1. Dearborn is power function

iii. There are switches here for fitting the data forecast

1. If you select combination option, you need to select the date, goes flat after selected date

2. Flat assumes an average of historical energy use intensities

d. New Ann Arbor CPP turbine is accounted for

i. As it comes online the electricity produced is subtracted from utility purchases

10. GHX strategy sheets

a. There are some functions that choose which values to select

i. Steam for heating 
ii. Steam for cooling

iii. If you don't select GHX it uses BAU value

b. Energy and emissions calculations are the same as BAU calcs

c. Growth projects do not do anything in this sheet

d. Section 6 - heating demand calculations

i. Heating demand is calculated not used

ii. 6.4 and 6.5 values are used in calculations

1. This is where sequencing is located, by construction timeline not specific year

2. End year meets demand that Integral says that the system can meet

3. Identical for heating and cooling

e. Section 7 -implementation calculations

i. Integral provided information by district

ii. The only values that are used here are for thermal energy demand

iii. Everything is scaled linearly here

iv. Steam is stepped down linearly as GHX goes online

1. This effects co-gen, for all energy produced by co-gen you have a ratio that is for steam and a ratio that is for electricity, for every portion you reduce steam, you equally reduce electricity for co-gen

a. What you lose in co-gen you increase in utility

b. Because you are decreasing co-gen output based on GHX, you also decrease electricity since it's the same plant.

f. Section 8 -implementation scenario (where demand changes are reflected)

i. Assumed flat between 5-year increments

ii. Assumed to be a switch that's flipped every five years until complete

iii. Between increment years, all values are assumed to be same

iv. Shows the demand in that year when GHX is implemented, assumed flat between years

g. Section 2 energy calcs takes into account if year matches year of GHX, subtract amount

11. PV

a. Switch to show which emissions you are offsetting

b. Default is utility

12. Non thermal energy reduction $-\mathrm{D}$ Strat 1

a. Linearly decreases demand based on user input

b. There is a check for demand reduction

c. Actual reduction value is reported as well

d. IF statements select strategy vs BAU values

e. Same utility vs. co-gen switch

i. Again co-gen doesn't really reduce emissions

f. Average annual reduction past 2030 is in Section 2. Energy calculations, currently at $0.75 \%$ 
13. D-Strat-2 Thermal demand reduction

a. sheet structure is different

b. BAU heating and cooling demand are calculated based on energy consumption

c. These values are adjusted to reflect demand values reported by Integral

i. Integral reported energy values being consumed, says it relates to this demand for heating and cooling

ii. Energy consumption and demand are both from Integral

d. We go from consumption data, set of assumptions on demand, to demand

i. Adjusted demand values to be close to Integral values

e. Starting with demand values you have to go back to energy consumption using efficiency values and heating values and conversion factors

i. After you have demand values, this is where the demand reduction strategy percent is included

ii. Then you go back to energy consumption values, using physical conversion factors and unit conversion factors

f. IF statements for BAU vs. Strategy value

g. All of these calculations occur only if GHX is not implemented

h. If you have GHX and thermal demand reduction then that's calculated in subsection 8

i. Same process - reduce demand from BAU and stepping up geoexchange, in any given year your demand is assumed to be the demand at the $20^{\text {th }}$ year, existing system meets demand that GHX doesn't meet 


\section{Transportation}

Assumptions

- All electric vehicles are assumed to have a charging efficiency of $85 \%$ (per ANL recommendations)

- No change in EFs between 5-year time series gaps given in GREET

\section{Transportation - Fleet \& Blue Bus}

Assumptions

- Lawn care equipment was not considered in modeling of the University's emissions. Lawn care equipment emissions are considered in the University's Environmental Metrics Report.

- Blue Bus annual distance traveled is constant and based on historical data

- Double counting occurs between Blue Bus emissions and commuting emissions in the 01 mile distance band. The double counting is less than the total Blue Bus emissions. Blue Bus emissions account for $\sim 0.4 \%$ of the University's total emissions.

- Electric buses are charged by the DTE grid

- Historical transit bus emissions factors based on GREET time series data

- Future transit bus emissions factors based on EIA projections for Freight Trucks (2020 Annual Energy Projections, Table 7) - per discussion with J. Kelly at Argonne National Laboratory

- Replacement frequency of Blue Bus is 4 buses every 4 years (UM Fleet Office)

- BAU replacement of BB is with diesel buses (UM Fleet Office)

- LLDT EPA vehicle classification is equivalent to GREET Passenger Car

- HLDT EPA vehicle classification is equivalent to GREET Pickup

- LHDDE EPA vehicle classification is equivalent to GREET CIDI Heavy Duty Pickup Trucks and vans

- MHDDE EPA vehicle classification is equivalent to GREET CIDI MHD vocational vehicle: Conventional and LS Diesel

- HHDDE EPA vehicle classification is equivalent to GREET CIDI HHD Vocational Vehicle: Conventional and LS Diesel

- GREET does not have HHDDE fuel economy or emissions data past 2020, it is assumed that the values remain constant through 2050

- Data were not available for the Flint vehicle fleet, so Flint was assumed to have a vehicle fleet identical to Dearborn

Blue Buses are currently replaced at a rate of 4 buses per year, on a 12-year replacement schedule. (UM Fleet Manager) The current UM Fleet replacement policy dictates that all new buses are to be diesel because they are less expensive than diesel-electric hybrid buses. (UM Fleet Department)

Buses with a model year within 4 years (+/-) of 2020 were assigned EF values sourced from GREET1 2019 on the HDV_WTW tab under the CIDI Transit Buses: Conventional and LS 
Diesel section for Diesel Blue Buses and Grid-Independent CIDI Hybrid Transit Buses: Conventional and LS Diesel for the Hybrid Blue Buses. EF's for buses with a model year that fell outside of the \pm 4 -year range were calculated based on historical or projected time series EF and fuel economy data provided in GREET1 2019. An example calculation is Equation 1, which shows how the EF for a diesel bus in 2020 is calculated.

$0.2273 \frac{\mathrm{gal}}{\mathrm{mi}} * 2.83 \frac{\mathrm{kg} \text { gasoline }}{\mathrm{gal}} * 0.828 \frac{\mathrm{kgC}}{\mathrm{kg} \text { gasoline }} * 44 \frac{\mathrm{kgCO}}{\mathrm{kgC}}=1.93 \frac{\mathrm{kg} \mathrm{CO}}{\mathrm{mi}} \quad$ Equation B13

The blue bus fleet emissions modeling and replacement schedule is based on the first in, first out principle. Diesel bus emissions decrease between 2018 and 2020 because new, more efficient diesel buses are replacing older, less efficient diesel buses. There is a slight spike in diesel bus emissions in 2021. This is a result of low annual mileage diesel buses being replaced in 2021 with modeled diesel buses that are assumed to have an average annual mileage (modeled annual mileage is average annual mileage of all diesel buses currently in fleet). Hybrid bus emissions remain constant until 2022 when they start to be replaced by diesel buses.

Vehicle electrification strategies are limited by several constraints. For example, most ICEV HLDTs do not currently have an available BEV equivalent. We assume that all LLDT vehicles in the UM fleet have an electric equivalent (e.g., Chevrolet Bolt EV, Honda Clarity Electric, Nissan Leaf Plus). Based on the current composition of the UM HLDT vehicle fleet, we estimate that 363 vehicles (55\% of current HLDT fleet) could be electrified in 2022 (source - Ford websites E-F150, E Transit). Details for which HLDT vehicles will have an electric equivalent in 2022 are shown in Table 3.

Information on current vehicles was provided by the UM Fleet Manager's Office. BEV equivalents were selected based on "equivalent function" to their ICEV counterpart; vehicle manufacturer was not taken into consideration. Our modeling assumes that all UM HLDT fleet vehicles will have an electric equivalent by 2025. A list of the University's 661 HLDT vehicles is provided in Table 4. There are currently no electric equivalents for the LHDDE and MHDDE vehicles that the university owns. 
Table 3 HLDT vehicles, their 2022 electric equivalents, and number of vehicles in the UM fleet.

\begin{tabular}{|c|c|c|c|}
\hline Vehicle Type & $\begin{array}{l}\text { Electric } \\
\text { Equivalent }\end{array}$ & $\begin{array}{l}\text { Number of } \\
\text { vehicles }\end{array}$ & $\begin{array}{l}\text { EPA } \\
\text { Classification }\end{array}$ \\
\hline MID SIZE CREW CAB PICKUP & EV Ford F-150 & 4 & HLDT \\
\hline MID SIZE EXTENDED CAB PICKUP & EV Ford F-150 & 23 & HLDT \\
\hline MID-SIZE PICKUP & EV Ford F-150 & 16 & HLDT \\
\hline PICKUP CREW CAB & EV Ford F-150 & 6 & HLDT \\
\hline PICKUP CREW CAB ETHANOL & EV Ford F-150 & 8 & HLDT \\
\hline PICKUP CREW CAB WITH SNOW PLOW & EV Ford F-150 & 4 & HLDT \\
\hline PICKUP REG CAB ETHANOL & EV Ford F-150 & 12 & HLDT \\
\hline PICKUP REG CAB SNOW PLOW ETHANOL & EV Ford F-150 & 33 & HLDT \\
\hline PICKUP REGULAR CAB & EV Ford F-150 & 8 & HLDT \\
\hline PICKUP REGULAR CAB WITH SNOW PLOW & EV Ford F-150 & 2 & HLDT \\
\hline SPORT UTILITY VEHICLE & Kia Niro EV & 13 & HLDT \\
\hline SPORT UTILITY VEHICLE ETHANOL & Kia Niro EV & 31 & HLDT \\
\hline TRUCKS & EV Ford F-150 & 3 & HLDT \\
\hline UTILITY CREW CAB SRW & EV Ford F-150 & 2 & HLDT \\
\hline UTILITY REG CAB ETHANOL & EV Ford F-150 & 5 & HLDT \\
\hline UTILITY REGULAR CAB & EV Ford F-150 & 3 & HLDT \\
\hline $\begin{array}{l}\text { WORK VAN AWD WITHOUT WINDOWS } \\
\text { ETHANOL }\end{array}$ & EV Ford Transit & 4 & HLDT \\
\hline WORK VAN W/O WINDOWS ETHANOL & EV Ford Transit & 6 & HLDT \\
\hline WORK VAN WITH WINDOWS & EV Ford Transit & 57 & HLDT \\
\hline WORK VAN WITHOUT WINDOWS & EV Ford Transit & 123 & HLDT \\
\hline Total & EV Ford Transit & 363 & \\
\hline
\end{tabular}


Table 4 All HLDT vehicles in the UM fleet, by type and number.

\begin{tabular}{|c|c|c|}
\hline Vehicle Type & $\begin{array}{l}\text { Number of } \\
\text { vehicles }\end{array}$ & $\begin{array}{l}\text { EPA } \\
\text { Classification }\end{array}$ \\
\hline 15 PASSENGER VAN LIFT EQUIPPED & 2 & HLDT \\
\hline CARGO VAN 10 FOOT & 7 & HLDT \\
\hline CARGO VAN 10 FT ETHANOL & 2 & HLDT \\
\hline CARGO VAN 12 FOOT & 12 & HLDT \\
\hline CARGO VAN 14 FOOT & 9 & HLDT \\
\hline CARGO VAN 15 FOOT & 1 & HLDT \\
\hline CARGO VAN 9 FOOT & 4 & HLDT \\
\hline MID SIZE CREW CAB PICKUP & 4 & HLDT \\
\hline MID SIZE EXTENDED CAB PICKUP & 23 & HLDT \\
\hline MID-SIZE PICKUP & 16 & HLDT \\
\hline MINIVAN 5 PASSENGER LIFT EQUIPPED & 1 & HLDT \\
\hline MINIVAN 7 PASSENGER ETHANOL & 221 & HLDT \\
\hline PICKUP CREW CAB & 6 & HLDT \\
\hline PICKUP CREW CAB ETHANOL & 8 & HLDT \\
\hline PICKUP CREW CAB WITH SNOW PLOW & 4 & HLDT \\
\hline PICKUP EXTENDED CAB & 2 & HLDT \\
\hline PICKUP EXTENDED CAB ETHANOL & 9 & HLDT \\
\hline PICKUP EXTENDED CAB WITH SNOW PLOW & 1 & HLDT \\
\hline PICKUP REG CAB ETHANOL & 12 & HLDT \\
\hline PICKUP REG CAB SNOW PLOW ETHANOL & 33 & HLDT \\
\hline PICKUP REGULAR CAB & 8 & HLDT \\
\hline PICKUP REGULAR CAB WITH SNOW PLOW & 2 & HLDT \\
\hline SPORT UTILITY VEHICLE & 13 & HLDT \\
\hline SPORT UTILITY VEHICLE ETHANOL & 31 & HLDT \\
\hline STAKE 10 FOOT WITH HOIST & 2 & HLDT \\
\hline STEP VAN 12 FOOT & 1 & HLDT \\
\hline TRUCKS & 3 & HLDT \\
\hline UTILITY CREW CAB SRW & 2 & HLDT \\
\hline UTILITY EXTENDED CAB & 9 & HLDT \\
\hline UTILITY EXTENDED CAB ETHANOL & 13 & HLDT \\
\hline UTILITY EXTENDED CAB WITH DUAL WHEELS & 1 & HLDT \\
\hline UTILITY REG CAB ETHANOL & 5 & HLDT \\
\hline UTILITY REGULAR CAB & 3 & HLDT \\
\hline VAN 8 PASSENGER LIFT EQUIPPED & 1 & HLDT \\
\hline WORK VAN AWD WITHOUT WINDOWS ETHANOL & 4 & HLDT \\
\hline WORK VAN W/O WINDOWS ETHANOL & 6 & HLDT \\
\hline WORK VAN WITH WINDOWS & 57 & HLDT \\
\hline WORK VAN WITHOUT WINDOWS & 123 & HLDT \\
\hline
\end{tabular}


The Ann Arbor fleet has five HHDDE vehicles, all of which are rubbish trucks. An electric rubbish truck is currently being produced by BYD ( $\underline{\text { Source }}$.

\begin{tabular}{|l|l|l|l|}
\hline Vehicle Type & Electric Equivalent & $\begin{array}{l}\text { Number of } \\
\text { vehicles }\end{array}$ & $\begin{array}{l}\text { EPA } \\
\text { Classification }\end{array}$ \\
\hline RUBBISH TRUCK & BYD 8R & 5 & HHDDE \\
\hline
\end{tabular}

Electrification rates (modeled as vehicles/year) are separate for each vehicle type (i.e., Bus, LLDT, HLDT, etc.) and each campus. If modeled electrification rates are smaller than the vehicle replacement frequency in a given year, the remaining vehicles are assumed to be replaced by a new ICEV. 


\section{Transportation - University Travel}

Assumptions

- GHG effects of contrails are not considered for air travel

- Travel will remain constant

- Travelers would not travel further than 6 hours by train

- Travel data are not available by Campus

Data for flight mileage were extracted from the following sources: 1. A2ru, 2. Athletics, 3. Athletics Charter, 4. Concur, 5. Rackham Travel Grant, 6. SEAS, 7. Ross, 8. Vice Provost. The team wrote Python scripts to determine great circle distances for all available trips. The GCD for all trips were split into three categories based on differing air travel EF by distance: 1. Short, $<300$ miles, 2. Medium, $>=300$ miles $\&<2,300$ miles 3. Long, $>=2,300$ miles. (Guidelines to Defra/DECC's GHG Conversion Factors for Company Reporting, 2017). Available Concur data only represented $\sim 30 \%$ of all unique trips, so all air travel data from Concur was scaled up by a factor of 3.33 (see University Travel IAT Report, Appendix B: Data Gathering, for details). EFs were then applied to all passenger-miles recorded for each category and GWP values were applied to calculate the total GHG emissions in $\mathrm{CO}_{2} \mathrm{e}$. Data extracted from Shared Services yielded 7,055 unique trips. An EF ( $\mathrm{t} \mathrm{CO}_{2} \mathrm{e}$ /unique trip) was calculated based on the emissions and number of trips from the other 8 data sources (see University Travel IAT Report, Appendix B: Data Gathering, for details). This factor was then applied to the 7,055 unique trips from Shared Services to estimate GHG emissions (including ground travel).

The same data sources were used to determine ground travel mileage (car, bus, and train). Emissions were calculated using mode specific EFs (GREET1 2019) and distances traveled. 


\section{Transportation - Commuting}

Assumptions

- New housing units are randomly distributed to all F\&S and students more than one mile away from campus

- Distances calculated from a single point on each campus/campus location and not to work building

- All people within a distance band travel the average distance within the band

- Students within one mile of campus have the same mode share as students within 2 miles (only data available from SCIP)

- Mode share determined from SCIP

- Per capita emissions for each new faculty/staff member are equal to the average for their campus location

- 250 work days per year, 180 class days per year

- Assume 50/50 split between sedans and SUVs for both ICEVs and EVs. This is modeled by averaging the EF of LLDT and HLDT vehicles.

- Walking and cycling produce negligible emissions

- Rideshare has two participants

- Park and ride commuters split travel equally between driving and transit

- New Housing units will be distributed randomly throughout the population living more than 1 mile from campus

- Mode share for each bucket will not change because of moving population

- IAT report Table 3.2.1 details mode share shift in response to universal access agreement

- Decreases in parking are equivalent to MIT's value of $13 \%$ on the AA campus and half of that on the Dearborn and Flint campuses due to less constrained parking environment

- Decrease in SOV mode share is distributed b/w walking biking, bus, and rideshare given by IAT table 3.3.1 (Parking Policy)

- Decrease in SOV mode share concentrated in the 1-4 mile bands due to availability of alternatives

Most of the commuting modeling was completed by the Commuting IAT. Minor modifications were made to the model based on input from CAMP team members, including adding projected annual emissions, strategy selection options, and changing to GREET EFs.

Projections of vehicle electrification estimate that electric vehicles may be up to $30 \%$, but likely not more than $20 \%$, of new vehicle sales by $2030^{9}$. The Fleet Electrification subgroup recommends supporting infrastructure for $20 \%$ adoption of EVs by commuters traveling $20+$ miles.

\footnotetext{
${ }^{9}$ Noori and Tatari, Development of an agent-based model for regional market penetration projections of electric vehicles in the United States, 2015. https://doi.org/10.1016/j.energy.2015.12.018
} 


\section{Food}

Assumptions

- This work mostly follows the work of the Food IAT and uses many of the same assumptions.

- All food purchases are based on MDining food purchases from fall of 2019

- \$1 from MDining resulted in the same amount of food as $\$ 1$ for any other food organization.

$\circ$ While Flint and Dearborn are more than $1 \%$ and $1.7 \%$ of the UM population respectively, because their food expenditures only make up this much, they are assumed to be responsible for that much of the food purchased.

- We also assume that all organizations use the same ratios of food types purchased.

- If red meat and dairy are similar then it should be a decent approximation.

- It was assumed that food purchases in spring/summer terms are negligible.

- The ratios of food purchased do not change over time.

- Current trends in food purchasing (in general, not specifically at UM) show slight increases in vegetarian and vegan options.

- The food purchases are based on MDining, which has Sustainable Mondays. It is believed that this practice is reducing red meat purchases across the University system.

- The carbon footprint of the foods per $\mathrm{kg}$ will not change over time.

- E.g. more environmentally friendly agricultural practices would not occur, or the carbon footprint will not decrease due to local purchases.

- Emissions up to the farmgate were assumed to be $53.7 \%$ of the total emissions. To get total, the emissions were divided by this.

○ This was used for ALL food items, as was done by the Food IAT.

- All emission calculations use $\mathrm{GWP}_{100}$ factors.

- If population growth is selected, the amount of food purchased is expected to increase (proportionally) with population.

- E.g. a $1 \%$ growth in population leads to $1 \%$ more food being purchased.

- Population growth is relative to 2019. It increases linearly.

- While reduction of food waste is an option on the waste module, the emissions saved are considered here (i.e., this is where the result will show up).

○ That negative "source reduction" value is added to this.

- All protein replacements were done using a protein equivalency.

$\circ$ In the protein replacement scenarios, it was assumed that if a protein source were being replaced, it would be replaced by an equal amount of protein from another source.

- If "Plant Protein" was selected, $60 \%$ of protein replaced came from legumes and pulses, $20 \%$ from soy, and $20 \%$ from nuts and seeds.

- Soymilk was used as a replacement for dairy on a mass basis.

- Red meat includes beef, lamb, and pork.

- All costs per kg of food are an (aggregated) price based on current purchases. 
○ E.g. the cost $/ \mathrm{kg}$ of soy is determined using the ratio of soy products (e.g. edamame, tempeh) purchased (weight-based average).

- There are three separate soy categories on the model. They represent:

- Soy: cumulative-This represents current purchases, which include both soy protein sources (e.g. edamame) and soymilk. This was marked as unchanging, and all changes occurred from the more specific sources.

○ Soy: protein replacement-This represents soy purchased to replace protein.

- Emission factor was the average of tofu, edamame, and tempeh

- This will begin as 0 because other purchases are included in the "soy: cumulative" category.

- Soymilk- represents replacement of dairy.

- This will begin as 0 because other purchases are included in the "soy: cumulative" category.

Strategies

Slow: 50\% Reduction of Beef and Milk 2025 - 2045 (Meat replaced with better meats and plants, milk with soymilk)

Medium: 50\% Reduction of Red Meat and Milk $\quad 2021$ - 2040 (Meat replaced with better meats and plants, milk with soymilk)

Fast: 50\% reduction of all meat and dairy $2021-2035$ (Meat and dairy (including yogurt and cheese) replaced by plants) 


\section{Waste}

- Business as usual case

- Assumed no population growth

- Baseline data on waste generation is all obtained from an updated version of the IAT report, based on 2019 .

- Total waste generation

\begin{tabular}{|c|c|c|c|c|c|c|}
\hline Location & $\begin{array}{l}2019 \\
\text { Recycling } \\
\text { tons }\end{array}$ & $\begin{array}{l}2019 \\
\text { Compost } \\
\text { tons }\end{array}$ & $\begin{array}{l}2019 \\
\text { Landfill } \\
\text { tons }\end{array}$ & $\begin{array}{l}\text { Food } \\
\text { recovered }\end{array}$ & $\begin{array}{l}2019 \\
\text { Mulch } \\
\text { tons }\end{array}$ & $\begin{array}{l}\text { TOTAL } \\
\text { WASTE }\end{array}$ \\
\hline Hospital System & 1,636 & 211 & 5,900 & - & - & 7,747 \\
\hline Buildings with major food operations & 1,487 & 211 & 5,558 & - & - & 7,256 \\
\hline Administrative and academic buildings & 149 & - & 342 & - & - & 491 \\
\hline Rest of Ann Arbor Campus & 3,943 & 1,118 & 6,901 & 2.4 & - & 11,964 \\
\hline Buildings with major food operations & 1,087 & 774 & 1,791 & 2.4 & - & 3,655 \\
\hline Administrative and academic buildings & 2,856 & 344 & 5,110 & - & - & 8,309 \\
\hline UM AA Landscaping mulch & & & & & 642 & \\
\hline UM Dearborn & 305 & - & 307 & 0.2 & - & 612 \\
\hline UM Flint* & 247 & - & 249 & 0.6 & - & 497 \\
\hline TOTAL & 6,131 & 1,329 & 13,357 & 3.3 & 642 & 21,462 \\
\hline
\end{tabular}

- In the Ann Arbor campus and Michigan Medicine, buildings were split into those with and without major food operations as there are assumed to be differences in the composition of the landfill waste.

$\circ$ By default, the model uses baseline 1 over baseline 2 to estimate the composition of the landfill waste.

\begin{tabular}{|l|r|l|l|r|r|r|}
\hline & \multicolumn{3}{|c|}{ Baseline 1 } & \multicolumn{3}{c|}{ Baseline 2 } \\
\hline & $\begin{array}{l}\text { Mixed } \\
\text { Waste }\end{array}$ & $\begin{array}{l}\text { Recyclable } \\
\text { Waste }\end{array}$ & $\begin{array}{l}\text { Food } \\
\text { Waste }\end{array}$ & $\begin{array}{l}\text { Mixed } \\
\text { Waste }\end{array}$ & $\begin{array}{l}\text { Recyclable } \\
\text { Waste }\end{array}$ & $\begin{array}{l}\text { Food } \\
\text { Waste }\end{array}$ \\
\hline $\begin{array}{l}\text { Ann Arbor, Food } \\
\text { Operations }\end{array}$ & $70 \%$ & $20 \%$ & $10 \%$ & $65 \%$ & $20 \%$ & $15 \%$ \\
\hline $\begin{array}{l}\text { Ann Arbor, Academic } \\
\text { and Admin Buildings }\end{array}$ & $60 \%$ & $20 \%$ & $20 \%$ & $55 \%$ & $20 \%$ & $25 \%$ \\
\hline Dearborn & $55 \%$ & $15 \%$ & $30 \%$ & $50 \%$ & $15 \%$ & $35 \%$ \\
\hline Flint & $55 \%$ & $15 \%$ & $30 \%$ & $50 \%$ & $15 \%$ & $35 \%$ \\
\hline
\end{tabular}


○ Compost

- Assumed that compost would increase by 100 tons per year for years 2021 and 2022 at the Ann Arbor campus.

- Due to a conversation with Anya Dale stating that there were more buildings that would be able to compost over the next few years, in addition to more education.

$\circ$ Recycling

- Medium confidence

- Recycling rate remains constant at the Ann Arbor campus. If there is population growth, it grows proportionally with population.

- Anya Dale didn't expect much change unless there was a change in purchasing.

- Low confidence. There had been increases in recycling for the past couple years.

- WARM emission factors.

- All emission factors were obtained from the EPA WARM model. They are in metric tons of $\mathrm{CO}_{2}$ e per short ton of waste.

- All of these were using default values.

- The landfill both uses and flares landfill gas. When better information on how much is flared and how much is used is obtained, the emission factors can be adjusted using this ratio to increase the accuracy.

- The user should also select offsetting electricity in Michigan.

- According to the EPA WARM model and many other sources, the end of life emissions for recycling and composting are often negative.

- This indicates that for recycling offsetting production of virgin materials prevents more greenhouse gas emissions than those associated with recycling the materials.

- Composting fixes more carbon in the soil than is emitted while handling and transporting carbon.

- The emission factor is only looking at the end of life. While the end of life value may be negative, it is smaller in magnitude than the emissions incurred during production of items such as food (which are considered) or recyclable materials (which are not considered).

○ (Food Waste)

- Used "Food Waste," includes average ratios of meat found in the US.

○ (Mulch)

- Used "Yard Trimmings" 
- Food spoilage

O As recommended by EPA, it was assumed that $3 \%$ of food sent to donation spoiled.

○ The $97 \%$ that did not spoil was given the credit of avoided food waste, while the $3 \%$ that spoiled was assumed to go to the landfill.

- Ratio of food waste

- Strategies that prevent food waste reduce the total amount of managed organic waste. This reduces the possible amount that could be handled by methods such as composting and may ultimately result in a lower diversion rate.

- Options for future iterations

o This model includes options for sending organic waste to livestock and for anaerobic digestion. These are included to allow future developers to build in the functionality for these options.

- For food sent to livestock, this may require simply adding a representative emission factor. Functionality for anaerobic digestion may require either an emission factor or may require estimations of usable heat and electricity produced.

- These options should be locked on this iteration.

- The EPA WARM model does have an emission factor for anaerobic digestion, and this was put into the model. This value should receive more scrutiny if this option is allowed to be selected because the emission factor shows less very little greenhouse gas avoidance. For a future iteration, the method that WARM uses to evaluate anaerobic digestion should be considered. Reports on anaerobic digestion in Ann Arbor or nearby areas should be evaluated. Using the electricity production to offset grid emissions should be considered.

○ "Reduce other waste" shows up as an option, but is not actually implemented. This refers to not having to dispose of waste generation from sources that are not food related. This may refer to paper, single-use items, or many other waste streams.

- This would only account for managing the wastes. Emissions from producing these wastes are not quantified.

- The waste module calculates avoided food waste and emissions reduced because this was considered a waste strategy. These results output on the food module because this waste prevention mostly affects the carbon footprint of food production.

- Selecting options

○ There is a drop-down option to select the location where the strategy will apply. If a location is selected, then the changes to waste management at that location will occur at the magnitude and rates selected.

- If the user would like different rates or starting dates by location (e.g. if one campus is more ready than others), the user should go to the advanced options tab to input this information. 
○ The default year on strategies is 2051 , which indicates that the strategy is not selected.

- The "Year Initiative Begins" should be the year that changes are made, and the "Year Initiative Reached" is the year that all progress on the goal is finished.

- It is assumed that the initiative begins in January for the year the initiative begins, and ends in December for the year the Initiative is reached. This means that the number of years that the initiative occurs is

- Year Initiative Reached - Year Initiative begins +1

- Progress is assumed to occur linearly for all strategies.

- This generates a percent change per year, which can be found on the calculations tab. The percent refers to percent of a total type of waste, and not a percent change from a baseline. For example, $-9 \%$ organic waste to a landfill indicates that each year $9 \%$ less of the total organic waste is sent to a landfill, and not that the portion of organic waste sent to landfills decreases by $9 \%$ each year.

- The model lets you not select a strategy, customize a strategy, or select preselected strategies created by the IAT.

- Both strategies assume that no food waste or recyclable waste go to the landfill.

- The first doubles donations, and then diverts all organic waste to compost, and all recyclable waste to recycling.

- The second triples food donations, and prevents half of organic waste from being generated. All remaining organic waste is sent to composting, and all recyclable waste is sent to recycling.

- This assumes that half of organic waste is food that is wasted and is not inedible scraps or other compostable material.

- There are small projected increases in composting and recycling at the Ann Arbor campus and Michigan Medicine. Because of these increases, the percent of waste handled with each method in the Business as Usual case is being shown after these changes have finished.

- The model allows composting in Flint and Dearborn, though these campuses do not have large-scale composting.

- It does output a warning.

- If the user selects population growth, then waste generated is assumed to scale linearly.

$\circ$ Future iterations should further evaluate this assumption. Landfill waste at the Ann Arbor campus has remained relatively constant.

- How the model itself works

- The calculations begin with the estimated weights of each waste type in the business as usual case.

- To estimate the weight of each waste type for the selected strategies, the first step is estimating the change in weight from business as usual. 
- This occurs for each of the following waste categories:

\begin{tabular}{|c|c|}
\hline Waste Category & Strategy that Affects It \\
\hline Landfill-Mixed Waste & N/A \\
\hline Landfill-Recyclable Waste & Increase Recycling \\
\hline Landfill-Food Waste & Divert or Prevent Organic Waste \\
\hline Recovery-Recycled & Increase Recycling \\
\hline Recovery-Composted & Divert or Prevent Organic Waste \\
\hline Recovery-Mulch & N/A \\
\hline Recovery-Donated & Divert or Prevent Organic Waste \\
\hline Recovery-Sent to Livestock & Divert or Prevent Organic Waste \\
\hline Recovery-Anaerobic Digestion & Divert or Prevent Organic Waste \\
\hline Avoided-Food Waste & Divert or Prevent Organic Waste \\
\hline
\end{tabular}

Grey font indicates that option is not currently implemented.

- If the location is not selected or the year is before the initiative is implemented, then the change equals 0 .

- If the initiative is ongoing, then the change is equal to:

$$
\Delta M_{y}=\text { Initiative Year } \cdot \Delta m_{W} \cdot W_{x} \cdot \frac{\text { Population }}{\text { Baseline Population }}
$$

Where: $\Delta M_{y}=$ Change in mass of weight managed using a certain method (y, e.g. recyclable waste recycled) in a year (short tons per year)

Initiative Year $=$ How many years the initiative has been ongoing

$\Delta m_{W}=\%$ change of total waste type managed using that method per year

$W_{x}=$ Total of waste type produced in a year (e.g. recyclable or organic waste)

When the initiative is complete, the change is equal to:

$$
\Delta M_{y}=\operatorname{sign}\left(\Delta m_{W}\right) \cdot\left|m_{W, i}-m_{W, f}\right| \cdot W_{x}
$$

Where: $\Delta M_{y}=$ Change in mass of weight managed using a certain method (y, e.g. recyclable waste recycled) in a year (short tons per year)

$$
\begin{aligned}
& m_{W, i}=\text { Original } \% \text { of waste managed using that method } \\
& m_{W, f}=\text { Final } \% \text { of waste managed using that method }
\end{aligned}
$$

The amount of waste generated using each method in the selected scenario is calculated by subtracting the change from the business as usual case for each year. 
The greenhouse gas emissions are then determined by multiplying the mass of waste by the emission factor for each waste type and method.

\section{Strategies}

Slow: IAT Scenario 1 (divert all, don't prevent) 2021 - 2045

Medium: IAT Scenario 1 (divert all, don't prevent) 2021 - 2040

Fast: IAT Scenario 2 (divert all, waste prevent) $2021-2035$ 


\section{Biosequestration}

- It was assumed that the biosequestration rate in the business as usual case was always equal to the current estimated biosequestration rate. This value was not assumed to change over time.

- The biosequestration rate in the selected scenario is the sum of the biosequestration rate in the business in usual case and any changes due to strategies selected.

- This model does not include the functionality of factoring new development on UM land.

- Any construction selected on another module will not reduce the biosequestration rate nor release carbon stored in the ground.

- Carbon sequestration of farmland that may be converted is assumed to be 0 tons/year.

- As much agricultural land emits carbon, this is likely a conservative estimate.

- Existing turf on campus is not assumed to sequester or emit carbon.

- Turfgrass originally sequesters carbon, but after approximately 30 years begins emitting carbon. Because the age of the many turf grass areas on campus is unknown, it was assumed that they do not sequester carbon.

- If a user elects to replace turf, the existing sequestration in each campus will not decrease because the turf is not assumed to sequester carbon, and will instead only increase by the capacity of the selected land type.

- Same thing with adding greenspace.

- Emissions from mowing and fertilizing turf grass are considered

- Carbon sequestered by canopy cover is considered, while carbon sequestered by new low-grow fescue or meadow is not as this was not considered in the IAT report.

- These are not included because it was assumed by the IAT that they would sequester carbon at a similar rate to the other turf grass. 
- Time series data were used for certain strategies to enhance accuracy when data were available.

- In cases where time series data were not available, ranges were used instead.

$\circ$ The following table shows which series used time series data.

\begin{tabular}{|l|l|l|}
\hline \multirow{4}{*}{ Strategy } & Substrategy & $\begin{array}{l}\text { Time } \\
\text { series? }\end{array}$ \\
\hline \multirow{4}{*}{$\begin{array}{l}\text { Convert existing landscape } \\
\text { types (off-campus) }\end{array}$} & $\begin{array}{l}\text { Agricultural land to } \\
\text { constructed wetlands }\end{array}$ & Yes \\
\cline { 2 - 3 } & $\begin{array}{l}\text { Reforest agricultural } \\
\text { land }\end{array}$ & Yes \\
\hline $\begin{array}{l}\text { Enhance existing } \\
\text { landscape types (off- } \\
\text { campus) }\end{array}$ & Wetlands & Yes \\
\cline { 2 - 3 } Convert Turfgrass & Forest & Yes \\
\cline { 2 - 3 } & Canopy & Yes \\
\cline { 2 - 3 } & No mow fescue & No \\
\cline { 2 - 3 } & Meadow & No \\
\hline \multirow{4}{*}{$\begin{array}{l}\text { Construct Green } \\
\text { Infrastructure }\end{array}$} & Green Roofs & Yes \\
\cline { 2 - 3 } & Bioswales & No \\
\cline { 2 - 3 } & Native Grassland & No \\
\hline
\end{tabular}

- The time series data often contained gaps, and sometimes used data from regions other than the Midwest United States.

- If there was a gap year and either the previous or next biosequestration rate was from the Midwest, that value was used.

- Time series data for green roofs only extended to 4.2 years after construction. It was assumed that after this point the biosequestration rate remained constant.

- All strategies that do not have time series data allow gradual implementation of a strategy over time. Strategies that have time series data do not allow gradual implementation.

- For the strategies of replacing turf or adding green infrastructure, the ratio of land converted by campus was equal to the ratio of total turf by campus.

$\circ$ E.g. The Ann Arbor campus contains 94\% of total turfgrass of the three campuses. If all locations are selected, $94 \%$ of the turfgrass replaced will be on the Ann Arbor campus.

○ The only assumed difference this assumption makes is which campus will be credited with the biosequestration.

- The calculation for enhancing forests converts trees to hectare equivalents, and then uses the carbon sequestration rate for the habitat (as recommended by IAT).

○ It is assumed that 1000 trees are equal to 5-hectare equivalents.

- Biosequestration rate data were provided in ranges due to the large uncertainty.

○ The user needs to select a value from 0 to 1 , with 0 being the low end of the range, and 1 being the high end of the range. 
- All base case scenarios use the middle of the range, or when provided, the mean. Each base case should also display the low and high ends of the range as well.

- We assume that the existing rate of biosequestration would not change over time.

- Factors excluded from our model include:

- Land acknowledgment

- Monetary value of ecosystems services

- Social cost of carbon

- Other important benefits (e.g. reduced stormwater due to green infrastructure).

- The strategy of purchasing wetlands were excluded because it was uncertain if additionality could be proven/demonstrated.

- The strategies used in each case:

- Case A: Follow all IAT recommendations

- construct 89 acres of wetlands, (2028)

- Because time factors were used, was unable to stagger the production over time, and had them "appear" in the middle of the time frame.

- enhance 127 acres of wetland, (2028)

- enhance forest/plant 1000 trees off campus, (2021-2031)

- convert 340 acres of campus turf grass to trees (2028)

- covert remaining (434 acres) turf grass to no mow fescue (2021-2035)

- Create 74 acres of green infrastructure, split evenly between green roofs, bioswales, and native grassland (IAT did not specify, and made little change). (2021-2035)

$\circ$ Case B: Only pursue actions listed as $<\$ 50 / \mathrm{MT} \mathrm{CO} 2 \mathrm{e}$

- Enhance 127 acres of Wetland (2030)

- Enhance forest /plant 1000 trees off campus (2030)

- Case C: None 


\section{Appendix C Methane leakage and other GHG emissions from natural gas fuel cycle}

1. Memo Re: Methane leakage and other greenhouse gas emissions from natural gas fuel cycle, Greg Keoleian to PCCN, November 20, 2019

2. Report: Methane Emissions and the University of Michigan, August 2019 
To: President's Commission on Carbon Neutrality

From: Greg Keoleian

PCCN Carbon Accounting Subcommittee, chair

Date: November 12, 2019

Re: Methane leakage and other greenhouse gas emissions from natural gas fuel cycle

Cc: Subcommittee members: Austin Glass, Catie Hausman, Ken Keeler, Eric Kort, Geoff Lewis, Daniel Raimi

This memo provide a summary of the Carbon Accounting subcommittee analysis of upstream (precombustion) greenhouse gas (GHG) emissions associated with the natural gas fuel cycle, including methane leakage.

Two separate analyses were conducted to characterize these GHG emissions based on FY2019 natural gas consumption at University of Michigan Ann Arbor campus:

1. DEA Analysis Analysis of methane leakage by Daniel Raimi, Eric Kort, and Austin Glass (DEA). This analysis used methane leakage rates (2.3\%) from Alvarez et al. (2018) for natural gas production.

2. CSS Analysis Analysis of precombustion GHG emissions (methane leakage and other sources from the natural gas fuel cycle) by Greg Keoleian and Geoff Lewis at the Center for Sustainable Systems (CSS). This analysis was based on the GREET (Greenhouse Gases, Regulated Emissions, and Energy Use in Transportation) model from Argonne National Laboratory, which has two options for methane leakage (one based on EPA estimates and the other based on adjusted Alvarez et al. (2018) data, called EDF in GREET).

Notes:

a. The DEA Analysis has a higher value for methane leakage rates than the GREET model used to characterize methane leakage in the CSS Analysis.

b. The DEA Analysis does not include precombustion GHG emissions other than methane leakage.

c. Global Warming Potentials (GWPs) indicate the relative effectiveness of GHGs in trapping the Earth's heat over a certain time horizon. $\mathrm{CO}_{2}$ is used as the reference gas and has a GWP of one. GWP values used in these analyses differ slightly. DEA used a GWP $100\left(\mathrm{CH}_{4}\right)=34 ; \mathrm{GWP}_{20}\left(\mathrm{CH}_{4}\right)=$ 86. GREET uses GWP $100\left(\mathrm{CH}_{4}\right)=30$ and $\mathrm{GWP}_{20}\left(\mathrm{CH}_{4}\right)=85$, which were used in the CSS analysis. These values are all cited by IPCC in AR5 and reflect different assumptions regarding inclusion of carbon cycle feedback effects and $\mathrm{CO}_{2}$ effects of oxidized $\mathrm{CH}_{4}$.

\section{Key Findings}

The results of these two studies show the significance of methane leakage and other upstream GHG emissions related to natural gas use and how they compare to natural gas combustion emissions.

Both analyses show that methane emissions and other upstream GHG emissions associated with the natural gas fuel cycle are significant. Note the combustion related GHG emissions (shown in blue) are the same for all analyses. 
The DEA analysis in Figure 1 indicates that methane leakage (shown in orange) increases GHG emissions above natural gas combustion emissions (shown in blue) by $27 \%$ for the $100 \mathrm{yr}$ horizon and $69 \%$ for the 20 yr horizon cases.

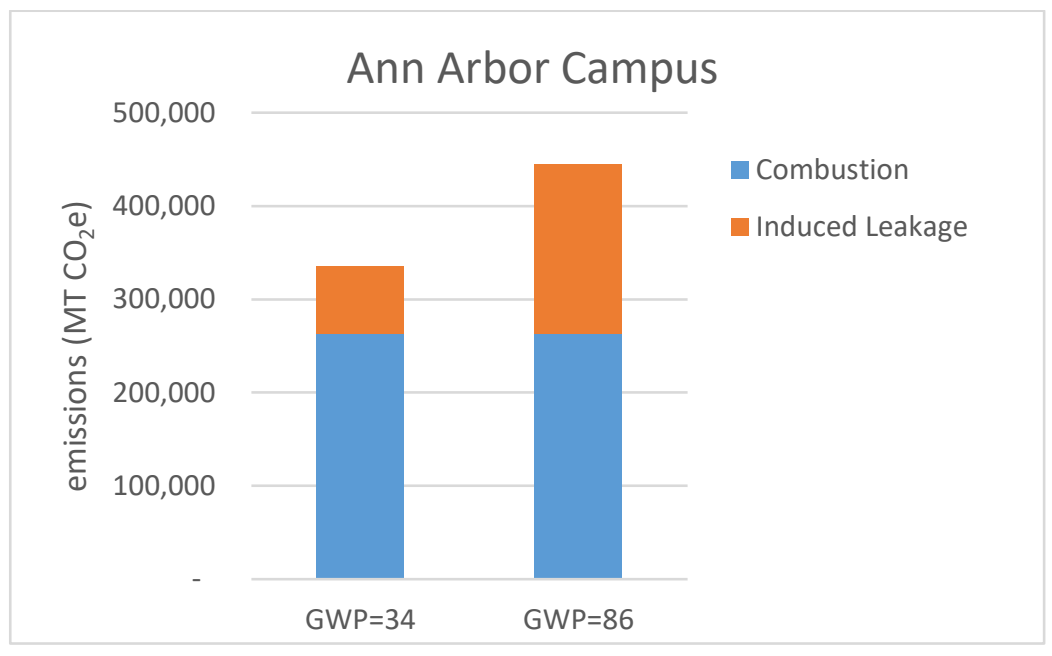

Figure $26-D E A$ GHG emissions results for Ann Arbor campus, including NG combustion and $\mathrm{CH}_{4}$ leakage, using $G W P_{100}\left(C \mathrm{CH}_{4}\right)=$ 34 and $G W P_{20}\left(\mathrm{CH}_{4}\right)=86$.

The CSS analysis in Figure 2 indicates methane leakage (shown in orange) and other GHG upstream emissions (shown in grey) relative to natural gas combustion emissions (shown in blue) for EPA and the GREET adjusted Alvarez methane leakage rates and based on $100 \mathrm{yr}$ horizon and $20 \mathrm{yr}$ horizon GWP values. Note in the GREET model that cites Alvarez the methane leakage from natural gas and oil production is allocated according to production of each fuel so this value is less than $2.3 \%$ reported by Alvarez and used by DEA. The orange bars for leakage are therefore lower in the CSS analysis compared to the DEA analysis.

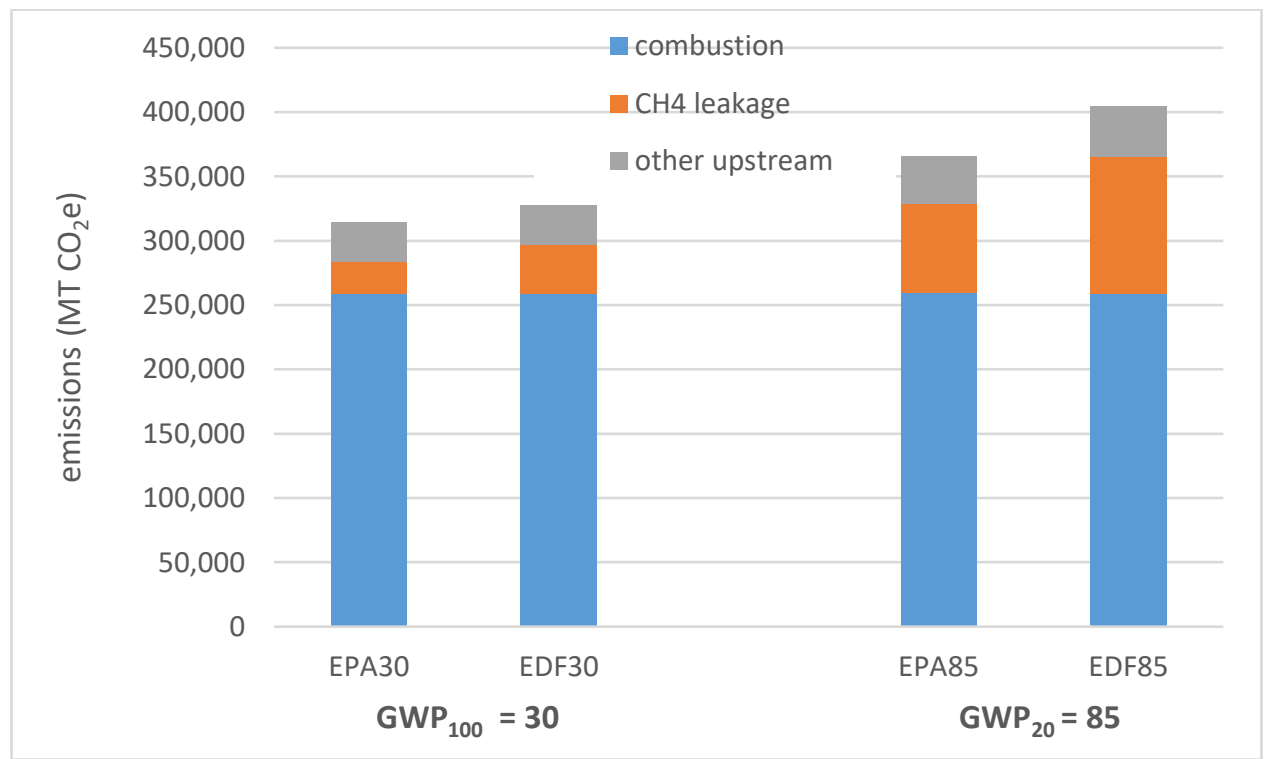

Figure 27-CSS GHG emissions results for Ann Arbor campus, including combustion, $\mathrm{CH}_{4}$ leakage, and other upstream emissions, using both EPA and EDF (Alvarez et al. 2018) estimates, $G W P_{100}\left(C_{4}\right)=30$ and $G W P_{20}\left(C_{4}\right)=85$. 
For the Alvarez (EDF) case, accounting for methane leakage (shown in orange) and other GHG upstream emissions (shown in grey) increases GHG emissions above natural gas combustion emissions (shown in blue) by $15 \%$ for the $\mathrm{GWP}_{100}$ and $41 \%$ for the $\mathrm{GWP}_{20}$ cases.

Accounting for methane leakage and other upstream GHG emissions when comparing electricity from coal and natural gas power plants does not make natural gas more carbon intensive than coal. Coal based electricity is still more carbon intensive than natural gas based electricity. Alvarez et al. (2012), referenced in the memo by DEA, and the GREET model both demonstrate this.

CSS compared natural gas and coal power plants using GREET using both the EDF and EPA methane leakage cases. Values of GHG intensity for electricity (combustion + all upstream) that span the range of GHG intensity for natural gas and coal plants in GREET (IGCC denotes integrated coal gasification combined cycle, which is an efficient coal plant) are:

$\begin{array}{llll}\text { GWP }_{100} \text { (EPA) } & \text { NG } & \text { combined cycle } 462 \mathrm{~g} / \mathrm{kWh} & \text { simple cycle } 747 \mathrm{~g} / \mathrm{kWh} \\ & \text { Coal } & \text { IGCC } 981 \mathrm{~g} / \mathrm{kWh} & \text { basic boiler } 1062 \mathrm{~g} / \mathrm{kWh} \\ \text { GWP }_{20} \text { (EDF) } & \text { NG } & \text { combined cycle } 584 \mathrm{~g} / \mathrm{kWh} & \text { simple cycle } 944 \mathrm{~g} / \mathrm{kWh} \\ & \text { Coal } & \text { IGCC } 1056 \mathrm{~g} / \mathrm{kWh} & \text { basic boiler } 1144 \mathrm{~g} / \mathrm{kWh}\end{array}$

Increasing the output of the UM Central Power Plant will displace DTE electricity but the benefits in terms of GHG savings are significantly reduced when accounting for methane leakage, and will decline over time as DTE's $\mathrm{CO}_{2}$ intensity shrinks. DTE supplied $\mathrm{CO}_{2}$ intensity projections for 2019-2040, which are plotted in Figure 3 below. They use both Fleet and Net Short (EPRI) annual accounting methods. The Fleet method divides total generating fleet $\mathrm{CO}_{2}$ emissions by the sum of dispatchable and nondispatchable generation, while the Net Short method divides net short emissions (the sum of nondispatchable and purchased emissions) by adjusted load. These methods are described more fully in an EPRI report commissioned by DTE (EPRI, 2019). DTE's 2018 fuel mix is $64 \%$ coal, 19\% nuclear, 9\% NG, and $8 \%$ renewables, and their estimated 2040 mix is $40 \%$ NG, $30 \%$ wind, $20 \%$ nuclear, and $10 \%$ solar.

Ken Keeler of the UM Office of Campus Sustainability recently completed a draft estimate of combustion only GHG savings resulting from installation of a new NG combustion turbine at the Central Power Plant. This estimate includes the increase in CPP GHG emissions due to the new turbine (both combustion and $\mathrm{CH}_{4}$ leakage based on the DEA analysis), boiler retirement, and the decrease in emissions due to reduced purchases of electricity from DTE, incorporating the changing mix of DTE's generating resources between 2018 and 2040 and including transmission and distribution losses. Ken found that the GHG emission reduction benefit of the NG turbine decreases over time due to DTE shifting to less carbonintensive electricity generation, but that the overall benefit is positive. His analysis, however, did not include methane leakage from the electricity imported from DTE or the other upstream GHG emissions associated with natural gas combustion. 


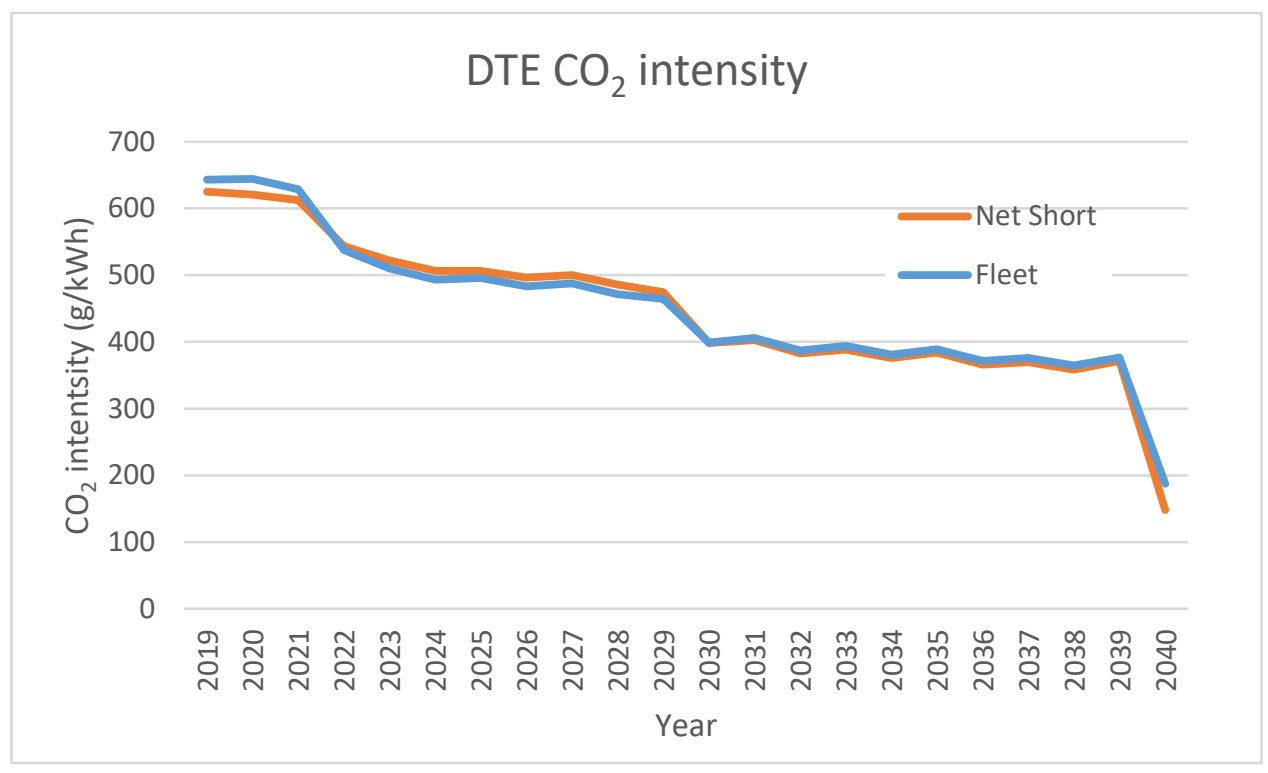

Figure 28 - DTE projected combustion-only $\mathrm{CO}_{2}$ intensity, 2019-2040, using both Fleet and Net Short methods. DTE's CO2 intensity path is based on information provided to the Michigan Public Service Commission as part of an ongoing regulatory proceeding. This path could change based on regulatory decisions expected in the 1st quarter of 2020

\section{Related Carbon Accounting Future Work}

1. Develop accounting methods and categories for Scope 3 emissions

a. in collaboration with internal analysis teams

b. e.g., make recommendations on inclusion of methane leakage and other precombustion emissions; accounting for offsets and RECs.

2. Resolve GWP values and time horizons to use

a. one option is to report GHG emissions based on both the $100 \mathrm{yr}$ and $20 \mathrm{yr}$ horizon GWP values

3. Explore level of effort by UM and Utilities (DTE and Consumers) to assess and reduce methane leakage in the local transmission and distribution system.

\section{References}

Alvarez, R. A., D. Zavala-Araiza, D. R. Lyon, D. T. Allen, Z. R. Barkley, A. R. Brandt, K. J. Davis, S. C. Herndon, D. J. Jacob, A. Karion, E. A. Kort, B. K. Lamb, T. Lauvaux, J. D. Maasakkers, A. J. Marchese, M. Omara, S. W. Pacala, J. Peischl, A. L. Robinson, P. B. Shepson, C. Sweeney, A. Townsend-Small, S. C. Wofsy, S. P. Hamburg, Assessment of methane emissions from the U.S. oil and gas supply chain. Science (2018), doi:10.1126/science.aar7204.

Alvarez, R. A., S. W. Pacala, J. J. Winebrake, W. L. Chameides, S. P. Hamburg, Greater focus needed on methane leakage from natural gas infrastructure. PNAS. 109, 6435-6440 (2012).

DTE 2040 estimated generation mix from: https://www.utilitydive.com/news/dte-clarifies-goal-to-cutcarbon-emissions-80-from-2005-levels-by-2050/442948/

Methods to Account for Greenhouse Gas Emissions Embedded in Wholesale Power Purchases. EPRI, Palo Alto, CA. Technical Update 3002015044, March 2019. 
Methane Emissions and the University of Michigan

Daniel Raimi, Eric Kort, Austin Glass

August 2019

Executive Summary: Natural gas is primarily composed of methane, and combustion of natural gas, like all fossil fuels, produces carbon dioxide. Because methane is itself a much more potent greenhouse gas than carbon dioxide, losses of methane along the natural gas supply chain can compromise the climate benefits of switching from coal-fired to natural gas-fired power plants. Although the latest data show methane emissions exceed U.S. EPA estimates, natural gas power generation, as is planned in the UM power plant upgrade, creates fewer emissions than coal-based power generation. In the long term, achieving carbon neutrality will require eliminating all emissions, including those from natural gas, but in the short term, this transition provides clear climate benefits, even when accounting for the latest science on methane emissions.

Oil and natural gas production have increased rapidly in the United States in recent years due to advances in technologies such as horizontal drilling and hydraulic fracturing ("fracking"). This growth has reduced domestic natural gas prices, and encouraged broader use of the fuel for power generation and other purposes. Because combustion of natural gas produces approximately half as much carbon dioxide $\left(\mathrm{CO}_{2}\right)$ as combustion of coal for the same amount of electricity generated, displacement of coal by gas in the power sector has reduced U.S. $\mathrm{CO}_{2}$ emissions.

\section{Methane's climate impact}

Methane - the primary component of natural gas - is itself a potent greenhouse gas, and a gram of methane $\left(\mathrm{CH}_{4}\right)$ traps more heat than a gram of $\mathrm{CO}_{2}$. However, methane is chemically active in the atmosphere, and as a consequence its lifetime is roughly a decade, much shorter than the effective lifetime of hundreds of years for the relatively chemically inert $\mathrm{CO}_{2}$. Because of these differing effects, the relative climate impacts of methane and $\mathrm{CO}_{2}$ vary with the chosen time horizon.

The heat-trapping effectiveness of methane relative to $\mathrm{CO}_{2}$ is conveyed through its "Global Warming Potential" (GWP). The most recent Assessment Report (AR5) from the IPCC applies what is currently considered the most representative GWP of methane: 34 over a 100-year time frame, and 86 over a 20-year time frame. These GWP values indicate that one ton of methane traps 34 times more heat than one ton of $\mathrm{CO}_{2}$ over a 100-year time frame, and 86 times more heat over a 20 -year time frame $(1)$.

The warming associated with methane contributes significantly to the overall climate impact of natural gas, as methane may be released into the atmosphere prior to combustion. If more than approximately $8 \%$ of natural gas escapes into the atmosphere before it is burned and converted into $\mathrm{CO}_{2}$, the climate benefits of switching from coal to natural gas for electric power vanish over a 100 -year time frame, and if approximately $4 \%$ escapes, those benefits disappear over a 20-year period (2). 


\section{Estimating methane emissions}

Methane emissions can occur at virtually every stage of the natural gas system (Fig. 1). Methane can escape from leaky valves or malfunctioning equipment at oil and gas well sites, natural gas pipelines, gas processing facilities, and elsewhere. Because there are over 1 million active oil and gas wells, thousands of natural gas processing facilities, and over 2 million miles of natural gas pipelines in the United States, it is difficult to precisely measure the scale of emissions from the whole system.

The U.S. EPA, which estimates oil- and gas-related methane emissions each year (3), had, until recently, relied on outdated emissions factors in its accounting protocols. In an effort to provide better data, dozens of studies have been carried out in recent years to measure emissions in a variety of locations and from a variety of sources. These studies have yielded a wide range of results, with estimates in some regions as low as 0.1 percent, and others as high as 10 percent or more (Fig. 2).

The best available summary of this work comes in a recent study from Alvarez et al. (4) (including UM co-authorship), which synthesizes the results of numerous studies (many involving UM researchers) carried out across the U.S. This study estimates that roughly 13 Teragrams of methane were emitted to the atmosphere by U.S. oil and gas systems in 2015, equivalent to roughly $\mathbf{2 . 3 \%}$ of domestic production in that year. This is roughly $60 \%$ higher than the EPA's estimate for that same year. This is the current best-estimate of the loss rate from the U.S. natural gas supply chain.

Some uncertainty remains in this estimate. Emissions estimates may continue to be revised upwards if new research shows that natural gas storage, local distribution systems, and other downstream infrastructure are 'leakier' than currently estimated. Recent work from UM has indeed shown that cities are 'leakier' than currently estimated (5), however these results do not change the overall assessment of using natural gas for power plants.

As summarized by Alvarez et al. (4), although many studies have shown that methane emissions are greater than previously estimated by the EPA, natural gas power plants have a lower climate impact than coal plants of the same power output. Further, these studies have highlighted opportunities for reducing loss of methane in the natural gas supply chain.

\section{Implications for the University of Michigan}

The above analysis suggests that for every 100 tons of $\mathrm{CO}_{2}$ emitted from the combustion of natural gas at the University of Michigan or elsewhere, methane emissions contribute an additional 27 tons of $\mathrm{CO}_{2}$-equivalent assuming a 100-year GWP, and an additional 68 tons of $\mathrm{CO}_{2}$-equivalent assuming a 20 -year GWP. Figure 4 illustrates the effect of adding both metrics to the existing $\mathrm{CO}_{2}$ footprint of the University's annual natural gas use. 


\section{Opportunities}

This analysis assumes the natural gas used at UM is lost at the average U.S. rate. Further work could be done to track the sources of the natural gas used at UM, and create a custom loss rate for UM's natural gas supply chain. This could involve tracking the natural gas chain for campus and using production-basin-specific loss rates, and could involve new measurements along the supply chain, from the production field to end-use in Ann Arbor, in order to directly observe loss rates.

\section{References}

1. G. Myhre, D. Shindell, F.-M. Breon, W. Collins, J. Fuglestvedt, J. Huang, D. Koch, J.-F. Lamarque, D. Lee, B. Mendoza, T. Nakajima, G. Stephens, T. Takemura, H. Zhang, Anthropogenic and Natural Radiative Forcing. In: Climate Change 2013: The Physical Science Basis. Contribution of Working Group I to the Fifth Assessment Report of the Intergovernmental Panel on Climate Change (Cambridge University Press, Cambridge ; New York, 2013).

2. R. A. Alvarez, S. W. Pacala, J. J. Winebrake, W. L. Chameides, S. P. Hamburg, Greater focus needed on methane leakage from natural gas infrastructure. PNAS. 109, 6435-6440 (2012).

3. EPA, "Inventory of U.S. Greenhouse Gas Emissions and Sinks: 1990-2016" (EPA 430P-18-001, U.S. Environmental Protection Agency (EPA), Washington, DC, 2018), p. various, (available at https://www.epa.gov/sites/production/files/2018-

01/documents/2018_complete_report.pdf).

4. R. A. Alvarez, D. Zavala-Araiza, D. R. Lyon, D. T. Allen, Z. R. Barkley, A. R. Brandt, K. J. Davis, S. C. Herndon, D. J. Jacob, A. Karion, E. A. Kort, B. K. Lamb, T. Lauvaux, J. D. Maasakkers, A. J. Marchese, M. Omara, S. W. Pacala, J. Peischl, A. L. Robinson, P. B. Shepson, C. Sweeney, A. Townsend-Small, S. C. Wofsy, S. P. Hamburg, Assessment of methane emissions from the U.S. oil and gas supply chain. Science (2018), doi:10.1126/science.aar7204. 5. G. Plant, E. A. Kort, C. Floerchinger, A. Gvakharia, I. Vimont, C. Sweeney, Large fugitive methane emissions from urban centers along the US East Coast. Geophysical Research Letters. 0, doi:10.1029/2019GL082635. 